Aus der Abteilung Kardiologie und Pneumologie

(Prof. Dr. med. G. Hasenfuß)

im Zentrum Innere Medizin

der Medizinischen Fakultät der Universität Göttingen

\title{
Der Einfluss von Tabakentwöhnung auf die funktionellen Eigenschaften von endothelialen Progenitorzellen
}

\author{
Inaugural-Dissertation \\ zur Erlangung des Doktorgrades \\ der Medizinischen Fakultät \\ der Georg-August-Universität zu Göttingen \\ vorgelegt von \\ Lena Immer, geb. Stijohann \\ aus \\ Münster
}

Göttingen 2011 
Dekan: Prof. Dr. med. C. Frömmel

1. Berichterstatterin: Prof. Dr. med. K. Schäfer

2. Berichterstatter/in: Priv.-Doz. Dr. med. D. Patschan

3. Berichterstatter/in: Prof. Dr. med., Dr. rer. nat. Th. Crozier

Tag der mündlichen Prüfung: 18.04.2012 


\section{Inhaltsverzeichnis}

Abbildungsverzeichnis $\quad$ VII

Tabellenverzeichnis $\quad$ VIII

$\begin{array}{ll}\text { Abkürzungsverzeichnis } & \text { IX }\end{array}$

1. Einleitung 1

1.1. Rauchen als globale Epidemie 1

1.1.1. Kardiovaskuläre Erkrankungen als Folge des Rauchens $\quad 1$

1.1.2. Der Nutzen von Tabakentwöhnung 2

1.1.3. Entwöhnungsprogramm 3

1.2. Pathogenese der Atherosklerose 3

1.2.1. Endotheliale Dysfunktion 4

1.3. Endotheliale Progenitozellen (EPC) 5

1.3.1. Charakterisierung endothelialer Progenitorzellen 5

1.3.2. EPC in klinischen Studien $\quad 6$

1.4. ADMA als Auslöser und Biomarker endothelialer Dysfunktion 7

1.5. Reaktive Sauerstoffspezies (ROS) und oxidativer Stress 7

1.5.1. Rauchen und endotheliale Dysfunktion 8

1.5.2. Tabakkonsum führt zu oxidativem Stress 9

1.6. Endotheliale Progenitorzellen bei Rauchern 10

1.6.1. Bisherige Untersuchungen unserer Arbeitsgruppe zum Verhalten von EPC bei Raucherentwöhnung 11

1.7. Zielsetzung der Arbeit $\quad 12$

2. Material und Methoden 13

2.1. Studiendesign und Probandenkollektiv 13

2.2. Bestimmung von Lipidstatus, Entzündungsparametern und $\begin{array}{ll}\text { hämatologischen Parametern } & 14\end{array}$

2.2.1. Bestimmung des Asymmetrischen Dimethyl-Arginin (ADMA) 15 
2.3. Isolierung und Kultivierung der humanen endothelialen

Progenitorzellen (EPC)

2.4. Proliferationsverhalten von HUVEC und EPC unter Einfluss von $\begin{array}{ll}\text { Cigarette Smoke Extract (CSE) } & 18\end{array}$

2.4.1. Inkubation von HUVEC mit Cigarette Smoke Extract (CSE) 18

2.4.2. Stimulierung von EPC mit CSE 19

2.4.3. Untersuchung des Proliferationsvermögens mittels

Anti-BrdU- Färbung 19

2.4.4. Auswertung der Poliferationsversuche 20

2.5. Untersuchungen zur Adhäsion von EPC an Fibronektin und an humanen Endothelzellen aus der Vena umbilicalis (HUVEC) 21

2.5.1. Markierung der EPC mit acLDL 21

2.5.2. Lösen der EPC von der fibronektinbeschichteten Platte 21

2.5.3. Adhäsion an Fibronektin 22

2.5.4. Adhäsion an HUVEC 23

2.5.5. Auswertung der Adhäsionsversuche 24

2.5.6. Matrigel Tubul Assay $\quad 24$

2.6. Durchflusszytometrische Untersuchung der Expression bestimmter $\begin{array}{ll}\text { Integrin-Untereinheiten } & 26\end{array}$

2.7. Durchflusszytometrischer Nachweis reaktiver Sauerstoffspezies $\begin{array}{ll}\text { (ROS) in EPC } & 27\end{array}$

$\begin{array}{lll}2.8 . & \text { Statistik } & 27\end{array}$

3. Ergebnisse 28

3.1. Klinische Charakteristika des Probandenkollektivs 28

3.1.1. Klinische Charakteristika der Subgruppen der funktionellen

Untersuchungen 30

3.1.2. Klinische Charakteristika der Untergruppen „gesunde Probanden“ und „Probanden mit weiteren kardiovaskulären Risikofaktoren oder Erkrankungen“

3.2. Proliferationsverhalten von HUVEC und EPC unter Einfluss von Cigarette Smoke Extract (CSE) 33

3.2.1. Einfluss von CSE auf das Proliferationsverhalten von HUVEC 33

3.2.2. Einfluss von CSE auf das Proliferationsvermögen von EPC 36 
3.3. Der Einfluss von Tabakentwöhnung auf das Adhäsionsverhalten von EPC

3.3.1. Tabakentwöhnung reduziert die Adhäsion von EPC an Fibronektin sowie an reifen Endothelzellen (HUVEC)

3.3.2. Tabakentwöhnung reduziert die Anzahl inkorporierter EPC in kapillarähnliche Strukturen

3.3.3. Tabakentwöhnung reduziert die Expression von $\beta 1$ - und $\beta 2$-Integrinuntereinheiten auf EPC

3.4. Tabakentwöhnung reduziert reaktive Sauerstoffspezies (ROS) in EPC 45

3.5. Einfluss von Tabakentwöhnung auf verschiedene Plasmaparameter 46

3.5.1. Einfluss von Tabakentwöhnung auf ADMA-Konzentrationen

\section{Diskussion}

4.1. Der Einfluss von Tabakentwöhnung auf die Anzahl zirkulierender EPC

4.2. Ist die endotheliale Physiologie eines Rauchers direkt nach

Tabakentwöhnung derjenigen eines Nichtrauchers gleichzusetzen?

4.3. Der Einfluss von Tabakentwöhnung auf die Anzahl kultivierbarer acLDL+Lectin+ Zellen (,early outgrowth EPC“) und deren

Adhäsionseigenschaften

4.4. Untersuchungen zum Verhalten von Monozyten bei Rauchern 52

4.5. Adhäsion an das Endothel wird über Integrine vermittelt

4.6. Einfluss von tabakbedingtem oxidativen Stress auf die

Adhäsionsfähigkeit von EPC sowie auf Expression

und Funktion der Integrine

4.7. Oxidativer Stress und EPC 54

4.8. Tabakentwöhnung reduziert oxidativen Stress 56

5. Ausblick

5.1. Erhöhter „EPC-Bedarf“ in der Peripherie als möglicher Erklärungsansatz der höheren EPC-Zahlen vor Tabakentwöhnung?

5.2. Limitationen der Studie 
6. Zusammenfassung $\quad 61$

$\begin{array}{ll}\text { 7. Literaturverzeichnis } & 63\end{array}$

\section{Abbildungsverzeichnis}

Abbildung 1. Endotheliale Progenitorzellen nach 7-tägiger Kultivierung, ungefärbt

Abbildung 2. Nachweis proliferierender HUVEC mit DAPI-Kernfärbung (blau) und Anti-BrdU-Färbung (rot)

Abbildung 3A) Adhäsion der acLDL-markierten EPC an Fibronektin

Abbildung 3B) Adhäsion der acLDL-markierten EPC an HUVEC

Abbildung 4. Anlagerung acLDL-markierter EPC in kapillarähnliche Netzwerke

Abbildung 5. Einfluss von CSE auf die Zellproliferation von HUVEC

Abbildung 6. Proliferation von HUVEC nach 24h Inkubation mit CSE

Abbildung 7. Einfluss von Tabakentwöhnung auf das Adhäsionsverhalten von EPC

7A) Adhäsion von EPC an Fibronektin 38

7B) Quantitative Analyse der Adhäsion an Fibronektin

7C) Adhäsion an Fibronektin bei gesunden Probanden und Probanden mit kardiovaskulären Risikofaktoren/ Erkrankungen

7D) Adhäsion von EPC an mit TNF- $\alpha$ stimulierten HUVEC

7E) Quantitative Analyse der Adhäsion von EPC an TNF- $\alpha$ stimulierten HUVEC 
Abbildung 8A) Einfluss von Tabakentwöhnung auf die Inkorporation

von EPC im Matrigel ${ }^{\mathrm{TM}}$-Assay

Abbildung 8B) Quantitative Analyse der EPC-Inkorporation in kapilläre

Netzwerke im Matrigel ${ }^{\mathrm{TM}}$-Assay

Abbildung 9. Einfluss von Tabakentwöhnung auf die Expression von $\beta 1$ - und $\beta 2$-Integrinen auf EPC

9A) Quantitative Analyse von $\beta 1$

9B) Quantitative Analyse von $\beta 2$

Abbildung 10. Einfluss von Tabakentwöhnung auf die Produktion von intrazellulärem ROS

10A) Repräsentative Dot Plots zeigen die Produktion von intrazellulärem ROS (Kopplung an den Fluoreszenzfarbstoff DCF)

10B) Quantitative Analyse der ROS-Level in EPC

\section{Tabellenverzeichnis}

Tabelle 1. Klinische Charakteristika der 144 Probanden

Tabelle 2. Klinische Charakteristika der Subgruppen der funktionellen Untersuchungen

Tabelle 3. Klinische Charakteristika der Untergruppen ,gesunde Probanden“ und „Probanden mit weiteren kardiovaskulären Risikofaktoren oder Erkrankungen“

Tabelle 4. Einfluss von Tabakentwöhnung auf verschiedene Plasmaparameter 


\section{Abkürzungsverzeichnis}

acLDL

ADMA

BrdU

BSA

CD

$\mathrm{CO}$

$\mathrm{CO}_{2}$

CSE

DCF

DMSO

ECM

EDTA

ELISA

EPC

FCS

FITC

HDL

hsCRP

HUVEC

IgCAM

LDL

NO

PBS

PC

ROS

RT

TNF- $\alpha$ acetyliertes Low Density Lipoprotein

Asymmetrisches Dimethylarginin

Bromodesoxyuridin

Bovines Serum-Albumin

Cluster of Differentiation

Kohlenmonoxid

Kohlendioxid

Cigarette smoke extract

Dichlorofluorescin

Dimethylsulfoxid

Endothelzellmedium

Ethylendiamintetraessigsäure

enzyme-linked immuno-sorbent assay

Endothelial Progenitor Cell(s)

Fetal Calf Serum

Fluoresceinisothiocyanat

High-Density-Lipoprotein

high-sensitivity-C-reaktives Protein

Human Umbilical Vein Endothelial Cells

Immunoglobulin superfamily cell adhesion molecule

Low-Density-Lipoprotein

Stickstoffmonoxid

Phosphate Buffered Saline

Progenitor Cells

Reactive Oxygen Species

Raumtemperatur

Tumornekrosefaktor $\alpha$ 


\section{Einleitung}

\subsection{Rauchen als globale Epidemie}

Tabakkonsum ist die führende Ursache vermeidbarer Todesfälle in der westlichen Welt (BARTECCHI et al. 1994) und verantwortlich für mehr als 5 Millionen Todesfälle pro Jahr weltweit (MATHERS und LONCAR 2006). Berechnungen von Mathers und Loncar zufolge wird die Anzahl der tabakbedingten Todesfälle auf 6,4 Millionen im Jahre 2015 und 8,3 Millionen im Jahre 2030 ansteigen. Rauchen wird demnach 2015 für 10\% aller Todesfälle verantwortlich sein - 50\% mehr als HIV/Aids (MATHERS und LONCAR 2006). Auch der wirtschaftliche Schaden ist immens: Im Jahr 1996 beliefen sich die Kosten für die sieben häufigsten durch Rauchen bedingten Erkrankungen in Deutschland auf 16,6 Milliarden Euro (RUFF et al. 2000).

Die WHO spricht von einer globalen Tabakepidemie, der man jetzt mit aller Kraft entgegentreten müsse. „, Reversing this entirely preventable epidemic must now rank as a top priority for public health and for political leaders in every country of the world. " (Dr. Margaret Chan, Generaldirektorin der WHO, WHO REPORT ON THE GROBAL TOBACCO EPIDEMIC, 2008, S.7). Im MPOWER, einem Konzept zur Eindämmung des weltweit stark anwachsenden Konsums von Tabak und der damit verbundenen gesundheitlichen Folgen, veröffentlichte sie eine Zusammenstellung der sechs wichtigsten und effektivsten Richtlinien. Dieses beinhaltet u.a. Aufklärung, Nichtraucherschutz, ein Verbot von Werbung, die Erhöhung der Tabaksteuer sowie professionelle Hilfe zur Tabakentwöhnung.

\subsubsection{Kardiovaskuläre Erkrankungen als Folge des Rauchens}

Mit 35\% sind kardiovaskuläre Erkrankungen die führende Ursache der tabakbedingten Todesfälle, gefolgt von chronischen Lungenerkrankungen und Lungenkrebs (EZZATI und LOPEZ 2003). Raucher haben gegenüber Nichtrauchern ein zweifach erhöhtes Risiko, an koronarer Herzkrankheit zu sterben (OCKENE und MILLER 1997). Ebenso verdoppelt sich bei Rauchern das Risiko eines Schlaganfalls (SHINTON und BEEVERS 1989). Langjähriger Zigarettenkonsum bereits in jungen Jahren verdreifacht die altersspezifische Mortalität und verringert die Lebenserwartung um zehn Jahre (DOLL et al. 2006). Dabei gerät zunehmend 
auch die Bedeutung des Passivrauchens als Risikofaktor für Herzkreislauferkrankungen in den Fokus (RAUPACH et al. 2006).

Untersuchungen bezüglich des Voranschreitens einer Atherosklerose infolge des Rauchens, gemessen als Intima-Media Dicke der Arteria Carotis im Ultraschall, konnten die Bedeutung sowohl des Aktiv- wie auch des Passivrauchens zeigen (HOWARD et al. 1998).

\subsubsection{Der Nutzen von Tabakentwöhnung}

Zahlreiche prospektive Untersuchungen konnten eine beachtliche Senkung der KHKbedingten Mortalität bei ehemaligen Rauchern gegenüber solchen Patienten, die weiter rauchten, nachweisen (GORDON et al. 1974). Dabei zeigt sich der Nutzen der Tabakentwöhnung bereits nach relativ kurzer Zeit. Rea et al. konnten belegen, dass das Risiko eines Zweitereignisses bei Patienten mit Myokardinfarkt, die daraufhin mit dem Rauchen aufhören, bereits nach drei Jahren dem von Nichtrauchern entspricht (REA et al. 2002). Ähnliche Ergebnisse bezüglich des schnell sinkenden Risikos nach Tabakentwöhnung wurden auch für den Schlaganfall publiziert (WOLF et al. 1988).

VAN BERKEL et al. veröffentlichten 1999 eine Metaanalyse der bis dato publizierten Studien über den Einfluss von Tabakentwöhnung auf die Prognose von Patienten mit koronarer Herzkrankheit sowie über Raucherentwöhnungsprogramme. Demnach lag das relative Risiko für Tod durch Herzinfarkt bei ehemaligen Rauchern im Vergleich zu Patienten mit fortgesetztem Tabakkonsum bei 0,13 bis 0,72 (VAN BERKEL et al. 1999). Auch Crichley und Capewell unterstrichen die Bedeutung von Tabakentwöhnung zur Senkung der Mortalität bei Patienten mit koronarer Herzkrankheit (CRITCHLEY und CAPEWELL 2003). Yusuf et al. stellten nach multivariater Analyse fest, dass erhöhte Lipidwerte und Rauchen die stärksten Risikofaktoren für Myokardinfarkt waren. Zudem bestand eine starke Korrelation zwischen der Anzahl gerauchter Zigaretten und dem Infarktrisiko, ohne dass ein Schwellenoder ein Höchstwert benannt werden konnte, da selbst das Rauchen von fünf Zigaretten pro Tag das Risiko erhöhte (YUSUF et al. 2004). 


\subsubsection{Entwöhnungsprogramme}

In Deutschland rauchen 33,4\% der männlichen und 20,4\% der weiblichen Bevölkerung (RUFF et al. 2000). Ein Drittel der Raucher würde gerne aufhören, jedoch gelingt dies ohne Hilfe nur etwa 2,5 \% von ihnen. Die Teilnahme an einem professionellen Raucherentwöhnungsprogramm mit pharmakologischer Unterstützung kann die Erfolgsquote auf über 30\% nach sechs Monaten erhöhen. Dabei spielt insbesondere eine konsequente und ausreichend lange Nikotinersatztherapie eine entscheidende Rolle (RAUPACH et al. 2008; FELTEN et al. 2006).

Die vorausgegangenen Abschnitte verdeutlichen den gut belegten hohen Nutzen einer Tabakentwöhnung, dieser die Problematik einer relativ geringen Erfolgsaussicht, was nochmals die Notwendigkeit zur Etablierung weit verbreiteter professioneller Hilfsangebote unterstreicht.

\subsection{Pathogenese der Atherosklerose}

Der Entstehung einer Atherosklerose liegt ein komplexer multifaktorieller Prozess zugrunde, dessen Ätiologie noch nicht in allen Einzelheiten bekannt ist.

Nach der „Response-to-injury-Hypothese“ von ROSS et al. (1977) steht eine Endothelläsion am Beginn der Entwicklung einer atherosklerotischen Läsion. Später zeigte ROSS, dass bereits eine endotheliale Dysfunktion als Auslöser ausreichend ist (ROSS 1999). Es kommt zu einer erhöhten Permeabilität des Endothels mit Einstrom von Lipoproteinen, welche z.B. durch reaktive Sauerstoffspezies oxidiert und in der Intima abgelagert werden können. Eine verminderte Expression der NO-Synthase führt zu einer eingeschränkten Fähigkeit zur Vasodilatation. Die Endothelzellen bilden eine Reihe von Chemokinen, welche zusammen mit der Expression verschiedener Zelladhäsionsmoleküle zur Adhäsion von Monozyten ans Endothel führt. Diese durchwandern das Endothel und werden in der Intima durch verschiedene Wachstumsfaktoren zur Proliferation und Ausdifferenzierung zu Makrophagen angeregt, welche oxidiertes LDL aufnehmen. Die entstehenden Schaumzellen bilden als sog. fatty streaks das erste morphologische Erscheinungsbild der atherosklerotischen Erkrankung. Die Einwanderung und Proliferation von glatten Muskelzellen führt durch Bildung von extrazellulärer Matrix zur Entstehung einer fibrösen Kappe und damit letztlich zu einer Verdickung der arteriellen Wand. In einem komplexen Prozess gegenseitiger Stimulation 
durch Proteasen, Chemokine, Radikale und andere Entzündungsmediatoren kommt es zu einer Entzündungsreaktion, an deren Ende die sog. complicated lesion mit der Gefahr einer Plaqueruptur steht (HANSSON 2005). Die anhaltende Entzündungsreaktion führt zur Einwanderung weiterer Lymphozyten und Makrophagen in die artherosklerotische Läsion, welche ihrerseits hydrolytische Enzyme und Zytokine sezernieren und damit fokale Nekrosen hervorrufen. Eine Ulzeration der fibrösen Kappe infolge überwiegender Proteolyse führt schließlich zur Plaqueruptur mit nachfolgender Thrombozytenaggregation und damit zum Verschluss des arteriellen Lumens (ROSS 1999).

\subsubsection{Endotheliale Dysfunktion}

Das Endothel gilt als Hauptregulator der vaskulären Homöostase. Es behauptet die Balance zwischen Vasodilatation und Vasokonstriktion, Inhibition und Stimulation der Proliferation und Migration glatter Muskelzellen sowie Thrombogenese und Fibrinolyse. Der Begriff der endothelialen Dysfunktion wird zur Beschreibung einer Vielzahl pathologischer Situationen verwendet, in denen Störungen essentieller Endothelfunktionen auftreten. Schon 1980 konnten FURCHGOTT und ZAWADSKI in ihrer Arbeit mit isolierten Blutgefäßen von Kaninchen zeigen, dass eine Relaxation des Endothels nach Inkubation mit Acetylcholin von der Präsenz intakter Endothelzellen abhängig ist. Später wurde der vasoaktive Mediator Stickstoffmonoxid (NO) als wichtigster Auslöser der endothelabhängigen Gefäßerweiterung identifiziert (PALMER et al. 1988; MONCADA und HIGGS 1993). NO wird in Endothelzellen durch die NO-Synthase (eNOS) aus L-Arginin gebildet und führt über eine Relaxation der glatten Muskelzellen der Media zu einer Dilatation der Gefäße. Ferner hat NO einen antithrombotischen Einfluss auf Blutplättchen, inhibiert die Monozyten/Leukozytenadhäsion am Endothel sowie die Proliferation glatter Muskelzellen (BÖGER 2003). In verschiedenen Studien konnte gezeigt werden, dass kardiovaskuläre Erkrankungen mit einer Schädigung des Endothels resultierend in einer endothelialen Dysfunktion als Frühstadium der Atherosklerose assoziiert sind (KINLAY und GANZ 1997; ROSS 1999; VERMA und ANDERSON 2002). 


\subsection{Endotheliale Progenitorzellen (EPC)}

\subsubsection{Charakterisierung endothelialer Progenitorzellen}

Die lange bestehende Ansicht, dass die endotheliale Regeneration ausschließlich durch Teilung ortsständiger Endothelzellen erfolgt (FOLKMAN und SHING 1992), ist in dieser Form nicht mehr gültig. Inzwischen konnte eine Beteiligung zirkulierender Zellen aus Blut und Knochenmark an der Reendothelialisierung nachgewiesen werden (WU MH et al. 1995; GREISLER et al. 1988). Dieser Befund wird weiterhin unterstützt durch die Tatsache, dass sich Endothel- und Blutzellen von einer gemeinsamen Ursprungszelle in der Embryonalzeit ableiten, dem CD34-positiven Hämangioblasten aus Blutinseln im Dottersack (FLAMME und RISAU1992). Neuere Erkenntnisse geben auch Anhalt für eine gemeinsame Vorläuferzelle innerhalb der embryonalen Aorta (DURAND und DZIERZAK 2005; BOLLEROT et al. 2005).

Diesen Erkenntnissen folgend konnte Asahara seine Theorie von im Blut zirkulierenden endothelialen Vorläuferzellen, welche die Fähigkeit zur weiteren Ausdifferenzierung haben, bestätigen. Diese als endotheliale Progenitorzellen (EPC) beschriebenen CD34-positiven Zellen können aus der mononukleären Zellfraktion isoliert und unter speziellen Kulturbedingungen in Zellen mit endothelialem Charakter transdifferenziert werden. Dazu gehört, dass sie nach siebentägiger Kultivierung auf Fibronektin eine spindelförmige Morphologie ausbilden und die Fähigkeit zur Koloniebildung sowie zur Ausbildung kapillarähnlicher Netzwerke besitzen. Weitere endotheliale Eigenschaften sind die Aufnahme von fluoreszenzmarkiertem acLDL, die Anfärbbarkeit mit endothelspezifischem Lectin sowie die Expression der NO-Synthase III (eNOS) und des Von-Willebrand-Faktors. Asahara konnte zudem im in-vivo-Modell zeigen, dass die EPC bei künstlich induzierter Gewebeischämie in die Neovaskularisationszone wandern, was auf eine Beteiligung der EPC an postnatalen Vaskularisationsprozessen schließen lässt (ASAHARA et al.1997).

Zahlreiche Arbeiten zur Charakterisierung der phänotypischen und funktionellen Eigenschaften der EPC folgten der Publikation von Asahara. Später gelang die Kultivierung von Zellen mit endothelialem Charakter aus der mononukleären Zellfraktion des peripheren Blutes auch ohne vorherige Anreicherung von CD34-positiven Zellen. Die Expression zahlreicher verschiedener Oberflächenmarker der hämatopoetischen, endothelialen und Monozyten-Makrophagen-Zellinie wurde beschrieben. So handelt es sich bei den in der Literatur beschriebenen EPC offenbar um eine nicht klar definierte, heterogene Gruppe von 
Zellen, die möglicherweise verschiedenen Ursprungs sind und unterschiedliche Reifegrade besitzen (SCHATTEMAN et al. 2007; HIRSCHI et al.2008). Weitgehende Einigkeit besteht darüber, dass Zellen, die die Oberflächenmarker CD34, CD133 und VEGFR2 tragen, eine Population mit Fähigkeit zur Ausbildung von endothelialen Charakteristika darstellen und an Neovaskularisationsprozessen beteiligt sind.

In einem als Homing und Recruitment bezeichneten Prozess werden die EPC aus dem Knochenmark in die Zirkulation freigesetzt und reichern sich in ischämischem Gewebe an, wo es dann letztendlich zur Ausdifferenzierung kommt. Als Stimulus zur Mobilisation können neben einer Gewebehypoxie auch (exogen zugefügte) Zytokine wirken (TAKAHASHI et al. 1999).

\subsubsection{EPC in klinischen Studien}

Zahlreiche Studien konnten den Zusammenhang zwischen klinischen Endpunkten und Anzahl bzw. funktionellen Eigenschaften der EPC belegen. So zeigten endotheliale Vorläuferzellen, die aus dem Knochenmark von Patienten mit chronisch-ischämischer Kardiomyopathie isoliert worden waren, eine reduzierte funktionelle Kapazität (HEESCHEN et al. 2004). Ferner wurde eine Beziehung zwischen EPC und dem Vorhandensein kardiovaskulärer Risikofaktoren gefunden. So beschrieben TEPPER et al. 2002 eine geringere Proliferation, Adhäsion und geringeres angiogenetisches Potential endothelialer Progenitorzellen bei Typ IIDiabetikern. Vasa et al. zeigten eine inverse Korrelation zwischen der Anzahl bestehender kardiovaskulärer Risikofaktoren entsprechend dem Framingham Risk Score und der Anzahl bzw. dem Migrationsvermögen zirkulierender EPC (VASA et al. 2001 a). Hill et al. belegten zudem eine inverse Korrelation zwischen der Anzahl von zirkulierenden EPC und der Funktion des Endothels (HILL et al. 2003). Klinische Relevanz könnten EPC als Biomarker erreichen, da gezeigt werden konnte, dass eine erniedrigte Anzahl zirkulierender EPC einen unabhängigen Prädiktor kardiovaskulärer Ereignisse darstellt (WERNER et al. 2005; SCHMIDT-LUCKE et al. 2005). Jedoch ist bisher nicht eindeutig geklärt, ob der erniedrigten Anzahl zirkulierender EPC bei Patienten mit kardiovaskulären Erkrankungen ein erhöhter Verbrauch oder eine reduzierte Mobilisation zugrunde liegt.

Es wurde weiter gezeigt, dass die Anzahl zirkulierender EPC auch erhöht sein kann, so z.B. bei regelmäßiger körperlicher Aktivität (LAUFS et al. 2004), Statintherapie (VASA et al. 2001 b) oder durch Östrogene (STREHLOW et al. 2003). 


\subsection{ADMA als Auslöser und Biomarker endothelialer Dysfunktion}

VALLANCE et al. (1992) beschrieben erstmals das asymmetrische Dimethylarginin (ADMA) als einen im Plasma zirkulierenden kompetitiven Inhibitor der NO-Synthase. ADMA entsteht aus dem Abbau methylierter Proteine und wird renal ausgeschieden. Erhöhte ADMA-Spiegel führen über die Hemmung der NO-Synthase zu niedrigeren NO-Konzentrationen und so letztlich zur Hemmung der endothelabhängigen Vasodilatation. Wird ADMA intraarteriell infundiert, kommt es daher zur Vasokonstriktion (BÖGER 2003).

Erhöhte ADMA-Werte konnten nicht nur bei verschiedenen kardiovaskulären Erkrankungen gemessen werden, sondern es bestand bereits eine positive Korrelation zwischen dem ADMA-Spiegel und dem Vorliegen kardiovaskulärer Risikofaktoren. Weiterhin zeigte sich diese positive Korrelation auch für die Intima-Media-Dicke der Arteria carotis, sodass ADMA als ein früher Marker der Atherosklerose angesehen werden kann (MIYAZAKI et al. 1999).

\subsection{Reaktive Sauerstoffspezies (ROS) und oxidativer Stress}

Reaktive Sauerstoffspezies (reactive oxygen species, ROS) sind reaktionsfreudige Sauerstoffabkömmlinge wie z.B. das Hyperoxid-Anion (alte Bezeichnung: Superoxid-Anion) $\mathrm{O}_{2} \cdot{ }^{-}$, das hochreaktive Hydroxyl-Radikal $\mathrm{OH}$ oder stabile molekulare Oxidanzien wie Wasserstoffperoxid $\mathrm{H}_{2} \mathrm{O}_{2}$. ROS entstehen zum einen bei der Atmungskette in jeder aeroben Zelle, zum anderen können sie auch exogen zum Beispiel durch das Rauchen aufgenommen werden. Auch im Rahmen von Entzündungsprozessen oder anderen „Stresssituationen“ kommt es zur vermehrten Bildung von ROS.

Normalerweise liegt im Organismus ein Gleichgewicht zwischen oxidierenden (ROS) und reduzierenden Substanzen vor, das durch antioxidative Schutzsysteme aufrecht gehalten wird. Dazu gehören eine Reihe von enzymatischen und nicht-enzymatischen Abfangreaktionen sowie exogen zugeführte Antioxidanzien wie z.B. Vitamin E und C. Übersteigt jedoch die Anzahl der ROS das physiologische Ausmaß, so dass verschiedene biologische Strukturen oxidiert und dadurch geschädigt werden, spricht man von oxidativem Stress. Die Folgen sind Lipidperoxidation, Proteinoxidation sowie Schädigung der DNA. Die Auswirkungen von ROS und oxidativem Stress rücken zunehmend in den Fokus der Wissenschaft, so z.B. bei 
Alterungsprozessen, bei der Entstehung von neurodegenerativen Erkrankungen und bei kardiovaskulären Erkrankungen.

So wird oxidativem Stress auch eine Schlüsselrolle bei der Entstehung und Progression der Atherosklerose zugeschrieben: Dazu gehören die Oxidierung von LDL und dessen anschließende Aufnahme durch Makrophagen, die Rekrutierung von Entzündungszellen zur Gefäßwand und die Inaktivierung von endothelialem NO (MÜGGE 1998).

In zahlreichen Studien wurde der Einfluss von zugeführten Antioxidanzien auf das atherosklerotische Geschehen untersucht. So konnte in tierexperimentellen Studien die abnorme endotheliale Dysfunktion verhindert werden. In klinischen Studien zeigte sich, dass die oxidative Modifizierbarkeit durch Antioxidanzien erschwert wurde. Auch der Nutzen von Antioxidanzien als Sekundärprophylaxe, z.B. nach Myokardinfarkten, wurde beschrieben (MÜGGE 1998).

\subsubsection{Rauchen und endotheliale Dysfunktion}

Zigarettenrauchen führt $\mathrm{zu}$ einer dosisabhängigen Dysfunktion des Endothels, welche potentiell reversibel ist (CELERMAJER et al. 1993). Offenbar ist eine Reihe von Reaktionen an dieser endothelialen Dysfunktion und letztlichen Schädigung der Gefäße beteiligt, wobei oxidativer Stress eine wichtige Rolle zu spielen scheint.

MULLICK et al. (2002) konnten zeigen, dass reaktive oxidierende Substanzen im Zigarettenrauch zu einer direkten Schädigung des Endothels führen, indem es zur Permeabilitätserhöhung und Anreicherung von oxidiertem LDL in der Gefäßwand kommt. BARUA et al. (2001) untersuchten den Zusammenhang zwischen einer reduzierten endothelabhängigen Vasodilatation und einer reduzierten NO-Produktion bei Rauchern. Dabei fand sich eine erhöhte Expression der eNOS-Proteine bei gleichzeitig reduzierter Aktivität der eNOS- und NO-Produktion. Weiter konnten BARUA et al. zeigen, dass ROS offenbar eine entscheidende Ursache für die gestörte Biosynthese von NO ist (BARUA et al. 2003). Dies beschrieben auch RAIJ et al. (2001), die eine erhöhte Anzahl Superoxid-Anionen als Ursache für die reduzierte Menge an NO sahen. 


\subsubsection{Tabakkonsum führt zu oxidativem Stress}

Zigarettenrauch enthält neben den Stoffen Kohlenstoffmonoxid und Nicotin mehr als 4000 bekannte und ca.100 000 noch nicht identifizierte Substanzen.

Üblicherweise wird Zigarettenrauch in zwei Phasen eingeteilt: Die Gasphase und die Partikeloder Teerphase. Die Gasphase enthält neben dem CO unter anderem Formaldehyd, Acetaldehyd und Acrolein. Die festen Bestandteile der Teerphase sind definiert als Partikel, die zwischen 0,1 und $1 \mu \mathrm{m}$ groß sind und zu 99,9\% von einem Cambridge Glas-Filter abgefangen werden (PRYOR und STONE 1993). Zu ihnen zählen Nikotin, Phenole und die als Teer zusammengefassten Substanzen (SMITH und FISCHER 2001).

Raucher sind einer Vielzahl verschiedener Radikale und somit schädlichem oxidativem Stress ausgesetzt. Sowohl die Gasphase als auch die Teerphase enthalten große Mengen an reaktionsfreudigen oxidierenden Substanzen, welche sich jedoch in ihren biologischen Halbwertzeiten und damit in ihrer Wirkung auf den gesamten Organismus stark unterscheiden. Während die Radikale der Gasphase bereits nach Zehntel-Sekunden zerfallen, sind die Radikale der Teerphase zum Teil mehrere Monate stabil. Die löslichen Substanzen können in der Lunge aufgenommen und über das Gefäßsystem im Organismus verteilt werden. Dort können sie dann durch ihre Fähigkeit zur Oxidierung von Sauerstoff zur Generierung von ROS und somit zur Schädigung von verschiedenen biologischen Strukturen führen (PRYOR und STONE 1993). Die negativen Folgen der langlebigen Radikale der Teerphase konnten PRYOR et al. (1998) am Beispiel der DNA-Schädigung bestätigen.

SMITH und FISCHER (2001) sahen weitere Ursachen für den erhöhten oxidativen Stress bei Rauchern zum einen in der endogenen Generierung von ROS in den Makrophagen der Lunge und Leukozyten im peripheren Blut sowie in der Ernährung von Rauchern, die durchschnittlich weniger antioxidative Substanzen als die von Nichtrauchern enthält.

Die Untersuchungen von Mc CUSKER und HOIDAL (1990) deuten weiter darauf hin, dass der Organismus auch selbst versucht, dem oxidativen Stress entgegenzuwirken. So fanden sie einen selektiven Anstieg der Aktivität von verschiedenen antioxidativ wirkenden Enzymen in den Alveolarmakrophagen von Rauchern. 


\subsection{Endotheliale Progenitorzellen bei Rauchern}

Wenngleich Rauchen als ein wichtiger Auslöser für endotheliale Dysfunktion und die Progression von Atherosklerose bekannt ist, sind die zugrunde liegenden Mechanismen sowie die mögliche Rolle endothelialer Progenitorzellen nicht hinreichend geklärt.

Der Einfluss des Rauchens auf die Anzahl und die funktionellen Eigenschaften von EPC wird in der Literatur kontrovers diskutiert.

VASA et al. beschrieben bei Patienten mit koronarer Herzkrankheit und einer Reihe kardiovaskulärer Risikofaktoren das Rauchen als stärksten unabhängigen Prädiktor für erniedrigte EPC-Level und reduziertes Migrationsvermögen. Das Zigarettenrauchen allein zeigte jedoch keinen signifikanten Einfluss (VASA et al. 2001 a). Im Gegensatz dazu konnte eine weitere Untersuchung an einem Kollektiv mit und ohne kardiovaskuläre Risikofaktoren Rauchen nicht als unabhängigen Prädiktor für die Anzahl von EPC ausmachen (HILL et al. 2003).

MICHAUD et al. (2006) verglichen die Anzahl und die funktionellen Eigenschaften der EPC von 15 gesunden Rauchern mit denen von 11 Nichtrauchern. Nach 4-tägiger Kultivierung zeigten sich signifikant weniger acLDL ${ }^{+}-$lectin $^{+}$-Zellen in der Gruppe der Raucher. Zudem wiesen die EPC von Rauchern eine geringere Adhäsion an HUVEC sowie eine geringere Integration in kapillare Netzwerke im Matrigel ${ }^{\mathrm{TM}}$-Assay auf.

KONDO et al. veröffentlichten 2004 die bisher einzige Studie zum Verhalten von EPC bei Tabakentwöhnung. Studienobjekte waren darin ausschließlich gesunde Männer mittleren Alters, die keine Medikamente einnahmen, und zwar 14 Nichtraucher und 15 Raucher, die weiter in die Subgruppen leichte und starke Raucher ( $\geq 20$ Zigaretten pro Tag) unterteilt wurden. Untersucht wurde der Einfluss von Tabakkonsum und Tabakentwöhnung auf die Anzahl der im Blut zirkulierenden Zellen mittels FACS-Analyse. Dabei wurden die zirkulierenden Zellen durch die Expression folgender Oberflächenmarker definiert: CD45 $5^{\text {low }}$ $\mathrm{CD}^{+} 4^{+} \mathrm{CD}_{133^{+}}$als Progenitorzellen (PC), und $\mathrm{CD}^{\text {low }} \mathrm{CD}^{+} 4^{+} \mathrm{CD}_{133^{+}}$VEGFR2 $^{+}$als endotheliale Progenitorzellen (EPC). Der Versuch, die Zellen zu kultivieren, scheiterte, da die Zellen der starken Raucher nach kurzer Kulturzeit nicht mehr nachweisbar waren. Als Ergebnis zeigten Kondo et al., dass die Anzahl der im Blut zirkulierenden PC und EPC bei Rauchern gegenüber den Nichtrauchern geringer war, und zwar umso geringer, je mehr Zigaretten geraucht wurden. Als Folge einer 4-wöchigen Tabakabstinenz stieg die Anzahl der PC signifikant an und fiel schließlich bei erneutem regelmäßigem Tabakkonsum wieder ab. Der Einfluss von Tabakentwöhnung auf die Anzahl der EPC war hingegen nicht signifikant. 
Untersuchungen bezüglich der funktionellen Eigenschaften der EPC wurden nicht durchgeführt.

\subsubsection{Bisherige Untersuchungen unserer Arbeitsgruppe zum Verhalten von EPC bei Raucherentwöhnung}

Vorangegangene Untersuchungen an Probanden unseres Kollektivs (PULS et al. 2011) beschäftigten sich mit dem Einfluss von Tabakentwöhnung auf die Anzahl von zirkulierenden EPC im peripheren Blut sowie nach siebentägiger Kultur auf Fibronektin.

Die Anzahl zirkulierender doppelt positiver CD34+-VEGF-R2 ${ }^{+}$-Zellen wurde mittels FACSAnalyse aus frischem Venenblut bestimmt. Die Ergebnisse zeigten keine signifikante Erniedrigung in der Anzahl der CD34+-VEGF-R2 ${ }^{+}$-Zellen am Ende des fünfwöchigen Tabakentwöhnungsprogramms ( $n=24$ Probanden; $\mathrm{p}=0,14)$; nach sechs Monaten war der Effekt jedoch signifikant ( $\mathrm{n}=7$ Probanden; $\mathrm{p}=0,047$ vs. Ausgangswert).

Ferner wurde der Einfluss von Tabakentwöhnung auf die Anzahl acLDL ${ }^{+}$-lectin ${ }^{+}-Z e l l e n$ nach siebentägiger Kultur auf einer mit Fibronektin beschichteten Platte untersucht. Dabei zeigte sich, dass am Ende des fünfwöchigen Kurses die Anzahl der kultivierbaren acLDL ${ }^{+}$-lectin ${ }^{+}-$ Zellen gegenüber dem Ausgangswert signifikant erniedrigt war ( $n=67$ Probanden; $p<0.001$ ). Sechs Monate nach Kursende blieb die Anzahl kultivierbarer Zellen bei den weiterhin abstinenten Probanden ( $\mathrm{n}=15)$ auf konstantem Niveau ( $\mathrm{P}=0.8$ vs. Kursende).

In einer Subgruppenanalyse zeigte sich, dass die Reduktion von acLDL ${ }^{+}$-lectin ${ }^{+}$-Zellen sowohl bei gesunden Probanden $(n=33 ; p=0,01)$ als auch besonders ausgeprägt bei Personen mit zusätzlichen kardiovaskulären Risikofaktoren $(n=34 ; p=0.0003)$ zu finden war. 


\subsection{Zielsetzung der Arbeit}

Die vorliegende Arbeit untersucht den Einfluss von Tabakentwöhnung auf die funktionellen Eigenschaften von EPC und baut damit auf den unter 1.6.1. beschriebenen Ergebnissen auf. Der Schwerpunkt wurde dabei auf die Analyse der Adhäsionseigenschaften der EPC gelegt. Dabei wurde der Hypothese nachgegangen, dass die unter 1.6.1. beschriebene reduzierte Anzahl der kultivierbaren acLDL ${ }^{+}$-lectin ${ }^{+}$-Zellen nach Tabakentwöhnung auf ein verändertes Adhäsionsverhalten der EPC zurückzuführen ist. Dazu wurde die Expression von Integrinen sowie das Vorliegen von oxidativem Stress als mögliche zugrunde liegende Mechanismen analysiert. Das Probandenkollektiv bestand dabei aus einer größeren Zahl unselektierter Probanden verschiedenen Alters, von denen etwa die Hälfte neben dem Rauchen weitere kardiovaskuläre Risikofaktoren aufwies oder bereits an manifesten Herzkreislauferkrankungen litt. 


\section{Material und Methoden}

\subsection{Studiendesign und Probandenkollektiv}

Im Rahmen unserer prospektiven Studie wurden von August 2004 bis November 2007 unselektierte Teilnehmer des Tabakentwöhnungsprogramms der Universitätsklinik Göttingen untersucht. Dieses kognitiv-verhaltenstherapeutisch orientierte Raucherentwöhnungsprogramm wurde im März 2003 im Rahmen des Konzeptes „Nichtraucherschutz“ unter der Leitung einer Diplom-Psychologin (Dorothea Felten) im Herzzentrum an dem Universitätsklinikum Göttingen etabliert. Das Angebot richtete sich sowohl an Patienten und Klinikumsmitarbeiter als auch an alle interessierten Raucher. Einem persönlichen Vorgespräch folgten sechs Gruppensitzungen in jeweils einwöchigem Abstand (Dauer 90 120 min) mit max. 14 Teilnehmern, in denen Informationen zu Suchtentstehung und aufrechterhaltung gegeben wurden. Die Aufhörwilligen wurden mit verschiedenen verhaltenstherapeutischen Techniken dazu angeleitet, ihr Rauchverhalten zu analysieren und zu ändern. Ein wichtiger Bestandteil war zudem die individuelle Beratung über mögliche pharmakologische Unterstützung durch Nikotinersatzprodukte oder Bupropion. Jeder Teilnehmer wählte dann ein festes Aufhördatum zwischen der ersten und dritten Sitzung, an welchem der Tabakkonsum komplett eingestellt wurde (FELTEN et al. 2006; RAUPACH et al. 2008). Nach einer eigenen Studie der Mitarbeiter des Raucherentwöhnungsprogramms waren am Ende des so konzipierten Kurses 72,0 \%, nach 6 Monaten 37,6 \% und nach 12 Monaten 27,1 \% der Probanden rauchfrei (FELTEN et al. 2006).

Am ersten Kurstag stellten wir unser Projekt vor und schlossen zunächst alle interessierten Raucher in unsere Untersuchungen ein. Es wurde eine Anamnese mit den Schwerpunkten Rauchverhalten, kardiovaskuläre Risikofaktoren, Begleiterkrankungen und aktuelle Medikation mit Hilfe eines standardisierten Fragebogens erhoben. Hypercholesterinämie wurde definiert als ein LDL-Cholesterin $\geq 160 \mathrm{mg} / \mathrm{dL}$ oder eine bestehende Behandlung mit lipidsenkenden Medikamenten (nach den Empfehlungen des Third Report on the National Cholesterol Education Program 2002). Das Vorliegen einer arteriellen Hypertonie oder eines Diabetes mellitus wurde gezählt, wenn die Probanden entsprechende Medikation einnahmen, jedoch nicht durch Messung überprüft.

Die Angaben der Probanden über ihr Rauchverhalten wurden mittels CO-Messung in der endexspiratorischen Atemluft verifiziert (Geräte: Vitalograph, Hamburg und Micro Medical, Hamburg) (MIDDLETON und MORICE 2000). Der Kohlenmonoxidgehalt der ausgeatmeten 
Luft steht nachgewiesenermaßen in Relation zum Rauchverhalten des Probanden und ist abhängig von der Anzahl der gerauchten Zigaretten pro Zeit, der Inhalationstiefe sowie der Inhalationsdauer (WALD et al. 1981). Die CO-Messung erfolgte immer zu Beginn der Kurssitzung. Außerdem wurden venöse Blutproben entnommen, wobei am ersten Kurstag ein Zeitraum von ca. 120 Minuten zwischen dem letzten Tabakkonsum und der Probengewinnung lag. Am letzten Kurstag wurden die Untersuchungen wiederholt. Zudem kontaktierten wir alle Probanden nach sechs Monaten erneut, um mögliche Langzeiteffekte untersuchen zu können.

Die Teilnehmer, die den fünfwöchigen Kurs nicht beendeten oder bei Kursende weiterhin rauchten (CO-Konzentration in der Ausatemluft $>6 \mathrm{ppm}$ und/oder zugegebener Nikotinkonsum von mehr als 5 Zigaretten seit Kursende; (MIDDLETON und MORICE 2000; WEST et al. 2005)), wurden von weiteren Analysen ausgeschlossen. Bezüglich Alter, Begleiterkrankungen und Vormedikation bestanden keine Auswahlkriterien.

Das Studienprotokoll wurde von der Ethikkommission der Universitätsmedizin Göttingen genehmigt. Von allen Studienteilnehmern wurde nach Aufklärung eine schriftliche Einwilligung eingeholt.

\subsection{Bestimmung von Lipidstatus, Entzündungsparametern und hämatologischen Parametern}

Zur Bestimmung des Lipoproteinstatus wurden Serum-Monovetten verwendet, zur Bestimmung des hs-CRP und des Fibrinogen dienten Citrat-Monovetten und zur Erhebung des Blutbildes EDTA-Monovetten (jeweils Monovetten der Firma Sarstedt, Nümbrecht).

Das Serum und das Citrat-Plasma wurden direkt nach Blutentnahme durch 10-minütiges Zentrifugieren der Monovetten bei 3000 U/min (Rotat/S, Hettich, Tuttlingen) vom Blutkuchen getrennt und die Monovetten dann mit einem Phasentrenner versehen. Bis zur Probenmessung (im Falle des Lipidstatus, des Fibrinogens und des hsCRP spätestens 12 Stunden nach Blutentnahme) wurden die Proben bei $+5 \mathrm{C}^{\circ}$ gelagert.

Die Bestimmung des Lipidstatus (Gesamtcholesterin, LDL, HDL und Triglyceride) erfolgte enzymatisch (Roche/Hitachi MODULAR P/D, Roche Diagnostics, Mannheim). Das hsCRP wurde turbidimetrisch nach Agglutination mit Antikörper-beschichteten Latexpartikeln bei einer Wellenlänge von $552 \mathrm{~nm}$ gemessen (COBAS INTEGRA 800, Roche Diagnostics, Mannheim). Für die Fibrinogen-Bestimmung wurde die Methode nach Clauss verwendet, 
wobei Citrat-Plasma mit einem Thrombinüberschuss zum Gerinnen gebracht wird (CLAUSS, BCS analyses, Dade Behring, Marburg).

Weiterhin wurde aus frischem EDTA-Blut durch automatische Zählung mittels eines Blutbildautomaten (Cell-Dynn 4000, Abbott, Wiesbaden / ADVIA ${ }^{\circledR} 120$, Bayer Health Care, Fernwald) ein rotes Blutbild mit Thrombozytenzahl sowie ein Differentialblutbild erstellt.

\subsubsection{Bestimmung des Asymmetrischen Dimethyl-Arginin (ADMA)}

Für die Bestimmung der ADMA-Konzentrationen wurden jeweils $800 \mu \mathrm{l}$ des frisch gewonnenen Serums (s.o.) in Eppendorf-Tubes (Firma Eppendorf, Hamburg) überführt und diese unmittelbar nach Aliquotierung der Proben bei $-79^{\circ} \mathrm{C}$ eingefroren. Die Messung erfolgte zu einem späteren Zeitpunkt nach einmaligem Auftauen der Proben.

Zur Bestimmung der ADMA-Level wurde ein kompetitiver ELISA (Enzyme-linked Immunosorbent Assay) im Mikrotiterplatten-Format (ADMA ${ }^{\circledR}$-ELISA, DLD Diagnostica, Hamburg) verwendet.

Zunächst erfolgte eine Acylierung des ADMA in der zu untersuchenden Probe, ehe diese auf die mit ADMA beschichtete Mikrotiterplatte gegeben wurde. Dann wurde ein Antiserum mit hochspezifischen Antikörpern gegen ADMA zugefügt, so dass das freie acylierte ADMA der Proben und das gebundene ADMA der Mikrotiterplatte um eine definierte Zahl von Antikörper-Bindungsstellen konkurrierten. Nach Einstellung des Reaktionsgleichgewichts wurden die nicht am Plattenboden gebundenen Antigen-Antikörperkomplexe durch Waschen entfernt. Die Menge der gebundenen Antikörper wurde mittels eines an „horseradish peroxidase" gekoppelten spezifisch gegen den Anti-ADMA-Antikörper gerichteten Enzymkonjugates bestimmt, wobei die Peroxidase einen hinzugefügten Farbstoff (TMB) umsetzt und letztlich über ein Photometer die Absorption bei $450 \mathrm{~nm}$ an einem Mikrotiterplatten-Lesegerät (sog. ELISA-Reader, BIO-TEK Instruments GmbH, Bad Friedrichshall) bestimmt werden kann. Die Farbintensität verhält sich dabei umgekehrt proportional zur Höhe der ADMA-Level in der Ausgangsprobe.

Die Kreuzreaktivität mit anderen im Serum enthaltenen Stoffen ist laut Hersteller bei diesem Enzymimmunoassay vernachlässigbar gering (L-Arginin <0,02\%, Monomethylarginin 1,0\% und symmetrisches Dimethylarginin (SDMA) 1,2\%). Der Standardmessbereich liegt zwischen $0,1 \mu \mathrm{mol} / \mathrm{l}$ und $5,0 \mu \mathrm{mol} / 1$. 


\subsection{Isolierung und Kultivierung der humanen endothelialen Progenitorzellen (EPC)}

Die Isolierung der mononukleären Zellen erfolgte durch Dichtegradientenzentrifugation aus peripherem Venenblut. Dafür wurden den Probanden 18 - $27 \mathrm{ml}$ Blut entnommen (9-mlHeparin-Monovetten der Firma Sarstedt, Nümbrecht), die vor Durchführung der Zellisolierung maximal $2 \mathrm{~h}$ bei RT gelagert wurden. Alle Schritte der Isolierung, Kultivierung sowie der nachfolgend beschriebenen Versuche wurden unter sterilen Bedingungen unter einer Reinraumwerkbank durchgeführt (ESCO $^{\circledR}$ Airstream $^{\circledR}$ Klasse II Biohazard Sicherheitswerkbank, Esco biotechnology, Singapur).

Das Blut wurde zunächst zu gleichem Anteil mit Phosphate Buffered Saline (PBS, GIBCO, Karlsruhe) gemischt und vorsichtig in einem 50-ml-Falconröhrchen (Sarstedt, Nümbrecht) über Histopaque ${ }^{\mathrm{TM}}$ (Histopaque-1077, Sigma, Taufkirchen) geschichtet. Danach erfolgte eine 30-minütige Zentrifugation bei $1800 \mathrm{U} / \mathrm{min}$ bei Raumtemperatur ohne Bremsfunktion (Megafuge $2.0 \mathrm{R}$, Heraeus Instruments, Hanau), was $\mathrm{zu}$ einer Auftrennung der Blutbestandteile gemäß dem Dichtegradienten führte. Die mit der Polysaccharose aggregierten Erythrozyten und Granulozyten sedimentierten, während die mononukleären Zellen in der Grenzschicht, dem sog. „,buffy coat“, zwischen Serum und Histopaque zu liegen kamen. Diese Interphase wurde vorsichtig mit einer Pasteurpipette (WU, Mainz) abgenommen und in ein 50-ml-Falconröhrchen mit $10 \mathrm{ml}$ Endothelzellmedium (ECM) (Endothelial Cell Growth Medium MV Kit, Promo Cell ${ }^{\mathrm{TM}}$, Heidelberg), versetzt mit 20\% fetalem Rinderserum (FCS, Gibco, Karlsruhe), Penicillin (100 U/ml) und Streptomycin (100 $\mathrm{g} / \mathrm{ml})$ (beides Gibco, Karlsruhe), überführt. Zur Aufreinigung der Zielzellen wurde die Zellsuspension zunächst bei $1600 \mathrm{U} / \mathrm{min}$ für $10 \mathrm{~min}$ bei Raumtemperatur zentrifugiert, der Überstand verworfen und das Zellpellet dann erneut in $10 \mathrm{ml}$ ECM resuspendiert. Dieser Vorgang wurde bei $900 \mathrm{U} / \mathrm{min}$ wiederholt und das Zellpellet in $6 \mathrm{ml}$ ECM aufgenommen. Im Anschluss an eine automatische Bestimmung der Zellkonzentration durch einen Blutbildautomaten (Cell-Dyn 4000, Abbott, Wiesbaden / ADVIA ${ }^{\circledR} 120$, Bayer, Leverkusen) wurde die Zellsuspension so verdünnt, dass letztlich 4 x $10^{7}$ Zellen in $12 \mathrm{ml} \mathrm{ECM} \mathrm{auf} \mathrm{eine} \mathrm{Kulturplatte} \mathrm{von} 10 \mathrm{~cm}$ Durchmesser (Sarstedt, Nümbrecht) ausgesät wurden. Diese war zuvor mit einer Lösung von $10 \mu \mathrm{g} / \mathrm{ml}$ Fibronektin (Tebu-Bio, Offenbach) in PBS für 2 h bei Raumtemperatur beschichtet und das überschüssige Fibronektin dann durch Waschen mit PBS entfernt worden. An Tag 4 wurden die nicht adhärenten Zellen durch gründliches Abspülen mit PBS entfernt und anschließend frisches ECM zugegeben. 
Für alle Versuche wurden Zellen nach siebentägiger Kultivierung bei $37{ }^{\circ} \mathrm{C}$ und $5 \% \mathrm{CO}_{2}$ im Brutschrank (SANYO $\mathrm{CO}_{2}$ Inkubator, Sanyo Fischer, München) verwendet.

\section{Abbildung 1. Endotheliale Progenitorzellen nach 7-tägiger Kultivierung, ungefärbt}

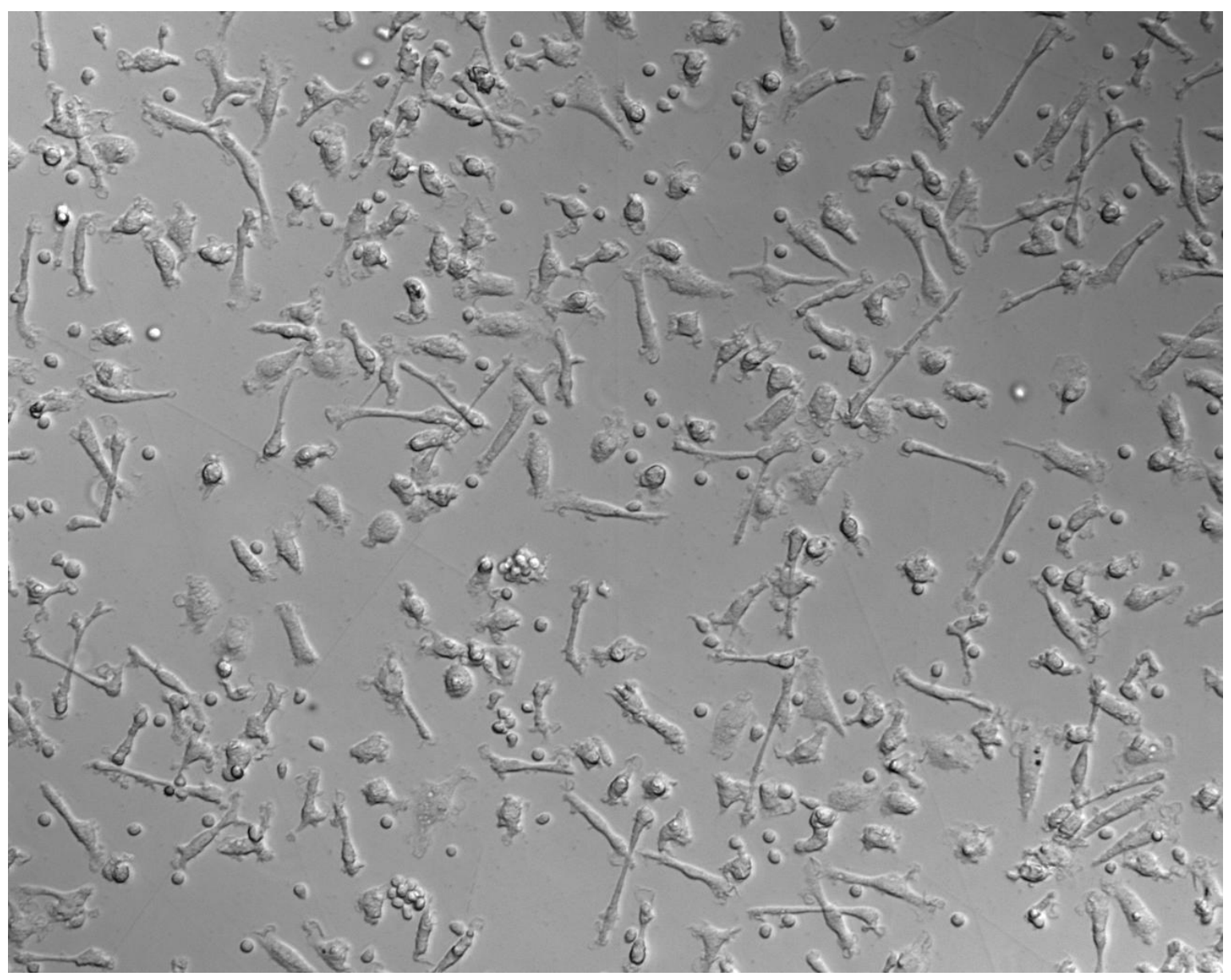




\subsection{Proliferationsverhalten von HUVEC und EPC unter Einfluss von Cigarette Smoke Extract (CSE)}

Ein möglicher Einfluss von CSE auf die Proliferationsaktivität von HUVEC und EPC wurde unter Verwendung des Thymidin-Analogon Bromodesoxyuridin (BrdU) analysiert, welches während der Proliferation von der Zelle aufgenommen und anstelle von Thymidin in die neu synthetisierte DNA eingebaut wird. Dafür wurden HUVEC und EPC mit CSE in verschiedenen Konzentrationen inkubiert und die Proliferationsrate im Vergleich zu unstimulierten Kontrollzellen analysiert.

\subsubsection{Inkubation von HUVEC mit Cigarette Smoke Extract (CSE)}

Cigarette Smoke Extract (CSE) ist eine Art „flüssiger Zigarettenrauch“, der von den Phillip Morris Research Laboratories selbst hergestellt wird und dessen genaue Zusammensetzung nicht veröffentlicht wird. CSE ist in 100\% Dimethylsulfoxid (DMSO) gelöst und unter einer Lagerung bei $-80^{\circ} \mathrm{C}$ stabil.

Zunächst wurden Proliferationsversuche an mit CSE stimulierten HUVEC durchgeführt. Dafür wurden einen Tag vor dem Versuch 3 mit Gelatine (1\% Gelatine aus Schweinehaut, Sigma-Aldrich, Steinheim in 0,1N HCl-Lösung, Merck, Darmstadt) beschichtete 24-wellPlatten vorbereitet, indem je 6000 HUVEC (Zellreihe Huvec, Promocell, Heidelberg) pro well ausgesät wurden. Der bei $-80^{\circ} \mathrm{C}$ gelagerte CSE wurde erst kurz vor dem Versuch aufgetaut und bei $4^{\circ} \mathrm{C}$ auf Eis gehalten. Die Verdünnung des CSE erfolgte entsprechend den Zielkonzentrationen $50 \mu \mathrm{g} / \mathrm{ml}, 25 \mu \mathrm{g} / \mathrm{ml}$ und $5 \mu \mathrm{g} / \mathrm{ml}$ in HUVEC-Medium. Zusätzlich wurde dem Medium BrdU (Serva, Heidelberg) als Proliferationsmarker in einer Konzentration von 0,02 mM zugesetzt. Nach 2-maligem Waschen der vorbereiteten 24-well Platten mit PBS wurden in jeweils zwei wells 500 $\mu$ d des CSE/BrdU-Mediums einer Konzentration gefüllt. Zur Kontrolle verwendeten wir DMSO (Sigma-Aldrich, Steinheim) ebenfalls in den Konzentrationen $50 \mu \mathrm{g} / \mathrm{ml}, 25 \mu \mathrm{g} / \mathrm{ml}$ und $5 \mu \mathrm{g} / \mathrm{ml}$ in BrdU-Medium. Je eine Platte wurde für $6 \mathrm{~h}, 24 \mathrm{~h}$ und $48 \mathrm{~h}$ bei $37^{\circ} \mathrm{C}$ inkubiert. 


\subsubsection{Stimulierung von EPC mit CSE}

Analog zu den Untersuchungen an HUVEC wurden ebenfalls Versuche an EPC durchgeführt. Dafür wurden EPC aus dem Blut freiwilliger Spender nach oben beschriebenem Protokoll isoliert und je 2 x $10^{6}$ Zellen pro well auf einer Fibronektin-beschichteten Platte kultiviert. Die Untersuchungen wurden an 4 und 7 Tage alten EPC durchgeführt. Stimuliert wurde wieder mit CSE in den Konzentrationen $50 \mu \mathrm{g} / \mathrm{ml}, 25 \mu \mathrm{g} / \mathrm{ml}$ und $5 \mu \mathrm{g} / \mathrm{ml}$ in BrdU-Medium (BrdU der Konzentration 0,02 mM). DMSO der gleichen Konzentrationen wurde wiederum als Kontrolle verwendet. Zusätzlich wurde die Proliferation nicht stimulierter EPC untersucht. Inkubiert wurde für 1, 2, 4, 6 und 10 Tage.

\subsubsection{Untersuchung des Proliferationsvermögens mittels Anti-BrdU- Färbung}

BrdU wird während der Proliferation von der Zelle aufgenommen und anstelle von Thymidin in die neu synthetisierte DNA eingebaut. Mit Hilfe spezifischer Antikörper gegen BrdU kann eine stattgefundene DNA-Synthese immunhistochemisch nachgewiesen und quantifiziert werden. Für die Bindung des Antikörpers an das BrdU ist eine Denaturierung der DNA, z. B durch Hitze, notwendig.

Nach der jeweiligen o.g. Inkubationszeit erfolgten ein zweimaliges Spülen der Platten mit PBS und anschließend die Fixierung der mit CSE stimulierten und durch BrdU markierten Zellen durch Methanol (Merck, Darmstadt) für 10 min bei $-20^{\circ} \mathrm{C}$. Danach wurden die wells halbvoll mit der Pufferlösung 1x Na-Citrat (Sigma-Aldrich, Steinheim) gefüllt und zur Steigerung der Permeabilität eine Denaturierung der Zellen durch Erhitzen in der Mikrowelle für 5 min bei 800 Watt herbeigeführt. Nach dem Abkühlen erfolgte die Blockierung unspezifischer Bindungsstellen mit $250 \mu \mathrm{l}$ 10\% Normal Goat Serum (Dako, Hamburg) in PBS für $10 \mathrm{~min}$ bei $37^{\circ} \mathrm{C}$. Der BrdU-Antikörper (monoklonaler Maus-Anti-BrdU, code M0744, Dako, Hamburg) wurde 1:100 in der Pufferlösung PBS mit 0,5\% Tween 80 (SigmaAldrich, Steinheim) verdünnt. Nach einer 40-minütigen Inkubation mit $250 \mu$ d dieser Lösung pro well bei $37^{\circ} \mathrm{C}$ wurde dreimal mit PBS gespült. Als sekundärer Antikörper wurde fluoreszenzmarkierter Anti-Maus Antikörper (Alexa Fluor 555., Invitrogen, Carlsbad, USA) in einer Verdünnung von 1:200 in PBS/0,5\% Tween 80 verwendet. Die Inkubation erfolgte diesmal mit $250 \mu \mathrm{l}$ der vorbereiteten Lösung pro well für 30 min bei Raumtemperatur im Dunkeln. Nach erneutem dreimaligen Spülen mit PBS erfolgte eine Kernfärbung durch 
Inkubation mit $250 \mu \mathrm{l}$ 4',6'-Diamidino-2-phenylinhydrochlorid (DAPI, $1 \mathrm{mg} / \mathrm{ml}$, SigmaAldrich, Steinheim) in einer Verdünnung von 1:100 in PBS für 15 min bei Raumtemperatur im Dunkeln. Wiederum wurde zweimal mit PBS gespült und im letzten Schritt die fixierten und gefärbten Zellen mit einem Tropfen Eindeckmedium (Immu-Mount; Shandon, Frankfurt) und einem Deckglas eingebettet.

\subsubsection{Auswertung der Poliferationsversuche}

Abschließend wurden alle wells mit dem Fluoreszensmikroskop (Axiovert 200, Carl Zeiss, Jena; Software Axio Vision 3.1) in 100-facher Vergrößerung fotografiert und dann auf 6 repräsentativen Bildern der prozentuale Anteil der proliferierenden Zellen (BrdU positive Zellen, rot) durch manuelle Auszählung bestimmt.

Abbildung 2. Nachweis proliferierender HUVEC mit DAPI-Kernfärbung (blau) und Anti-BrdU-Färbung (rot)

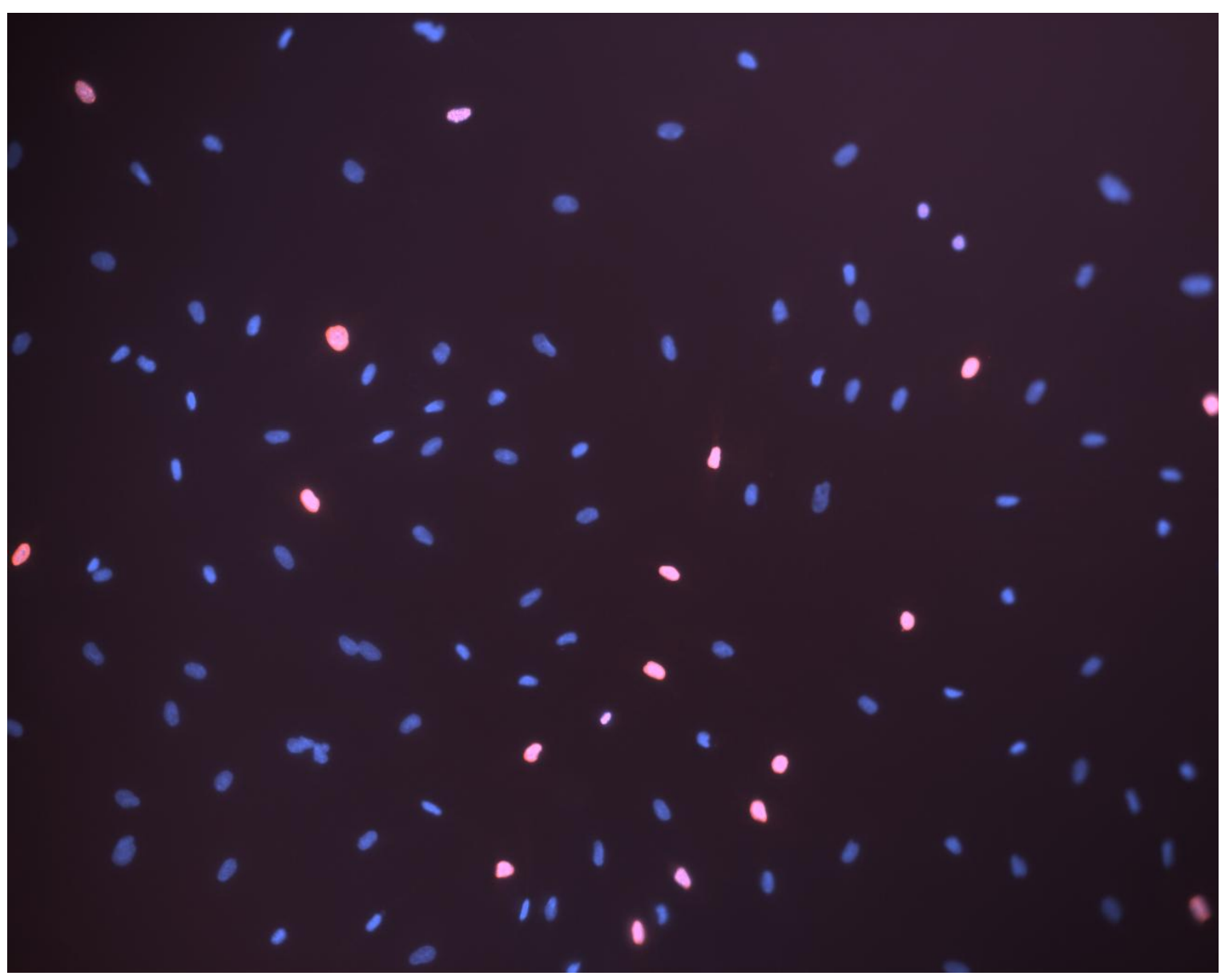




\subsection{Untersuchungen zur Adhäsion von EPC an Fibronektin und an humanen Endothelzellen aus der Vena umbilicalis (HUVEC)}

Zur Untersuchung ihrer Adhäsionsfähigkeit wurden gelöste EPC auf

a) eine mit Fibronektin beschichtete Platte und

b) eine mit HUVEC dicht bewachsene Platte

gegeben. Nach einer definierten Inkubationszeit von $\mathrm{x}$ Minuten wurden die noch nicht adhärenten Zellen durch kräftiges Waschen entfernt und die adhärenten Zellen fixiert und ausgezählt.

\subsubsection{Markierung der EPC mit acLDL}

Im ersten Schritt wurden dazu die wie oben beschrieben isolierten und für sieben Tage kultivierten EPC mit an das Fluorochrom 1,1'-Dioctadecyl-3,3,3',3'-TetramethylIndocarbocyanine gekoppeltem acLDL (Dil acLDL, L 3484, MoBiTec, Göttingen) markiert. Dafür wurde zunächst das Medium in den Kulturschalen durch Absaugen entfernt und dann neues Endothelzellmedium, versetzt mit 2,4 $\mu \mathrm{g} / \mathrm{ml}$ Dil acLDL (Verdünnung 1:400), zugegeben. Nach einstündiger Inkubation bei $37^{\circ} \mathrm{C}$ wurden die Platten zweimal mit PBS gewaschen.

\subsubsection{Lösen der EPC von der fibronektinbeschichteten Platte}

Zur Entfernung der EPC von der Kulturschale für die Adhäsions- bzw. Angiogeneseversuche erfolgte eine 10-minütige Inkubation mit PBS/EDTA $2 \mathrm{mM}$ (Merck, Darmstadt) im Brutschrank. Danach wurde das Lösen der Zellen durch Beklopfen der Kulturschale und mehrmaliges Spülen unterstützt. Anschließend wurde die Zellsuspension in ein 50-mlFalconröhrchen überführt und 10 min lang bei $1200 \mathrm{U} / \mathrm{min}$ zentrifugiert. Der Überstand wurde verworfen und das Zellpellet in Adhäsionsmedium (Endothelial Cell Growth Medium $M V$, Promo Cell ${ }^{\mathrm{TM}}$, Heidelberg, versetzt mit $1 \mathrm{mM} \mathrm{MgCl}_{2}, 1 \mathrm{mMCaCl}$ und $1 \mathrm{mM} \mathrm{Mn} \mathrm{Cl}_{2}$ (alle Merck, Darmstadt) und 0,05\% BSA) resuspendiert. Zuletzt wurde nach automatischer Zellzählung durch einen Blutbildautomaten bzw. nach manuellem Auszählen in der Neubauerzählkammer eine Konzentration von 2 x $10^{5}$ Zellen/ml eingestellt. 


\subsubsection{Adhäsion an Fibronektin}

Wir verwendeten dazu eine mit Fibronektin vorbeschichtete 24-well Platte ( $R \& D$ Systems, Minneapolis, USA). Zunächst wurden die unspezifischen Bindungsstellen durch 30-minütige Inkubation der wells mit 5\% BSA (Bovines Serum-Albumin, Sigma, Taufkirchen) in PBS blockiert. Nach Absaugen des PBS wurden dann je $500 \mu$ der wie oben beschrieben gewonnenen Zellsuspension ( 1 x $10^{5}$ Zellen) pro well zugegeben. Im Anschluss erfolgte eine erneute Inkubation für 30 min bei $37^{\circ} \mathrm{C}$. Nach Ablauf der Inkubationszeit wurden die noch nicht adhärenten Zellen durch zweimaliges Waschen mit PBS entfernt. Danach erfolgte eine Fixierung der fest adhärenten Zellen durch 10-minütige, lichtgeschützte Inkubation mit 2\% Paraformaldehyd (Sigma-Aldrich, Steinheim) in PBS.

\section{Abbildung 3A) Adhäsion der acLDL-markierten EPC an Fibronektin}

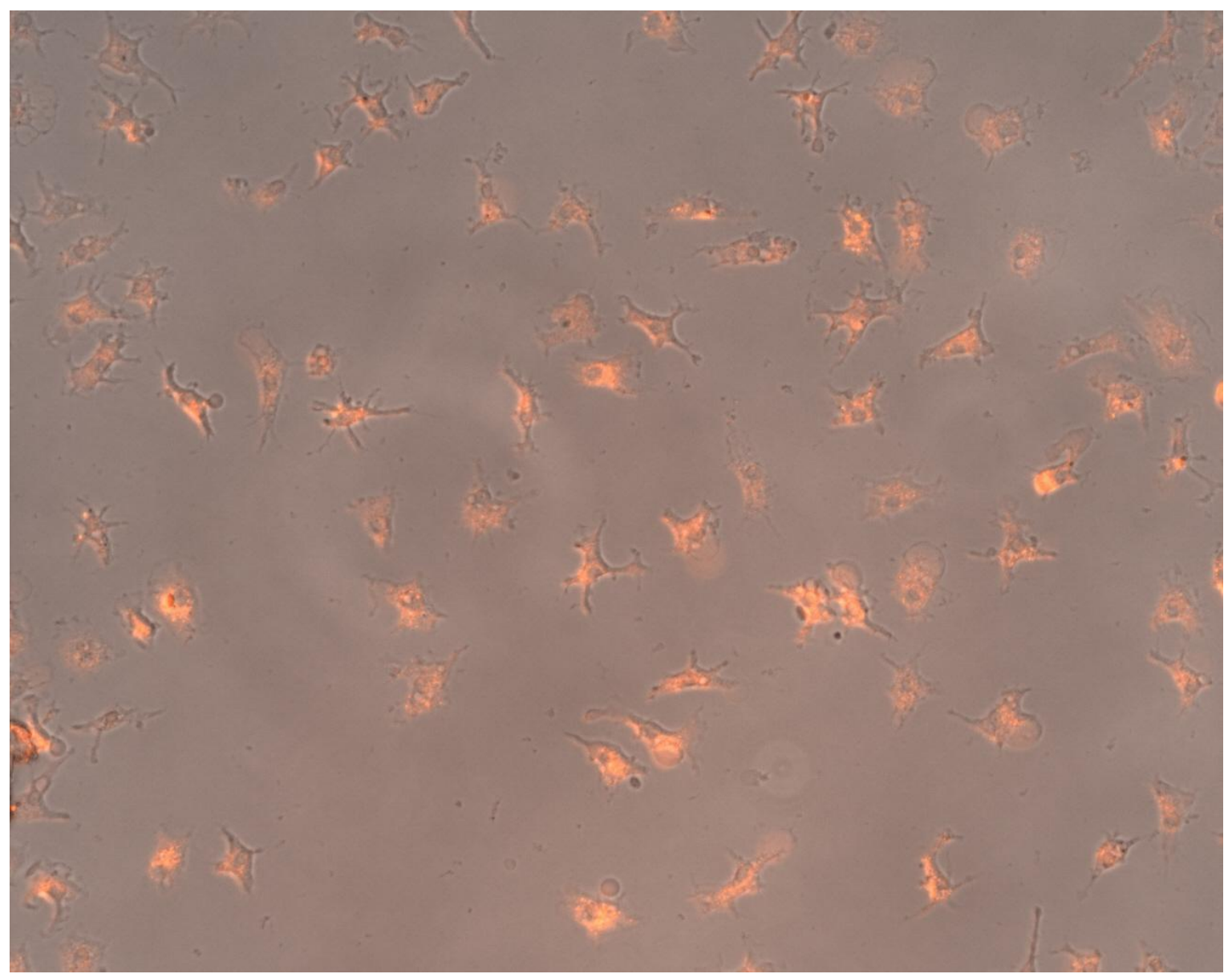




\subsubsection{Adhäsion an HUVEC}

Bereits zwei Tage vor dem Versuch wurden je 30000 HUVEC (Zellreihe Huvec, Promocell, Heidelberg) auf einer mit Gelatine (1\% Gelatine aus Schweinehaut, Sigma-Aldrich, Steinheim in 0,1N HCl-Lösung, Merck, Darmstadt) beschichteten 24-well Platte ausgesät, sodass am Versuchstag der Boden dicht bewachsen war. Zwölf Stunden vor Versuchsbeginn wurde dann die Hälfte der HUVEC mit $1 \mathrm{ng} / \mathrm{ml}$ TNF- $\alpha$ (R\&D Systems, Wiesbaden) in HUVEC-Medium (Endothelial Cell Growth Medium Kit, Promocell ${ }^{\mathrm{TM}}$, Heidelberg) stimuliert. Nachdem die HUVEC noch einmal mit PBS gewaschen worden waren, wurden auch hier 1 x $10^{5}$ der zuvor gelösten EPC in $500 \mu \mathrm{l}$ Versuchsmedium zugegeben und diesmal für $3 \mathrm{~h}$ bei $37^{\circ} \mathrm{C}$ inkubiert. Nach Ablauf der Inkubationszeit wurden auch für diesen Versuch die nicht-adhärenten Zellen durch zweimaliges Waschen mit PBS entfernt und dann die adhärenten Zellen durch 10minütige lichtgeschützte Inkubation mit 2\% Paraformaldehyd in PBS fixiert.

\section{Abbildung 3B) Adhäsion der acLDL-markierten EPC an HUVEC}

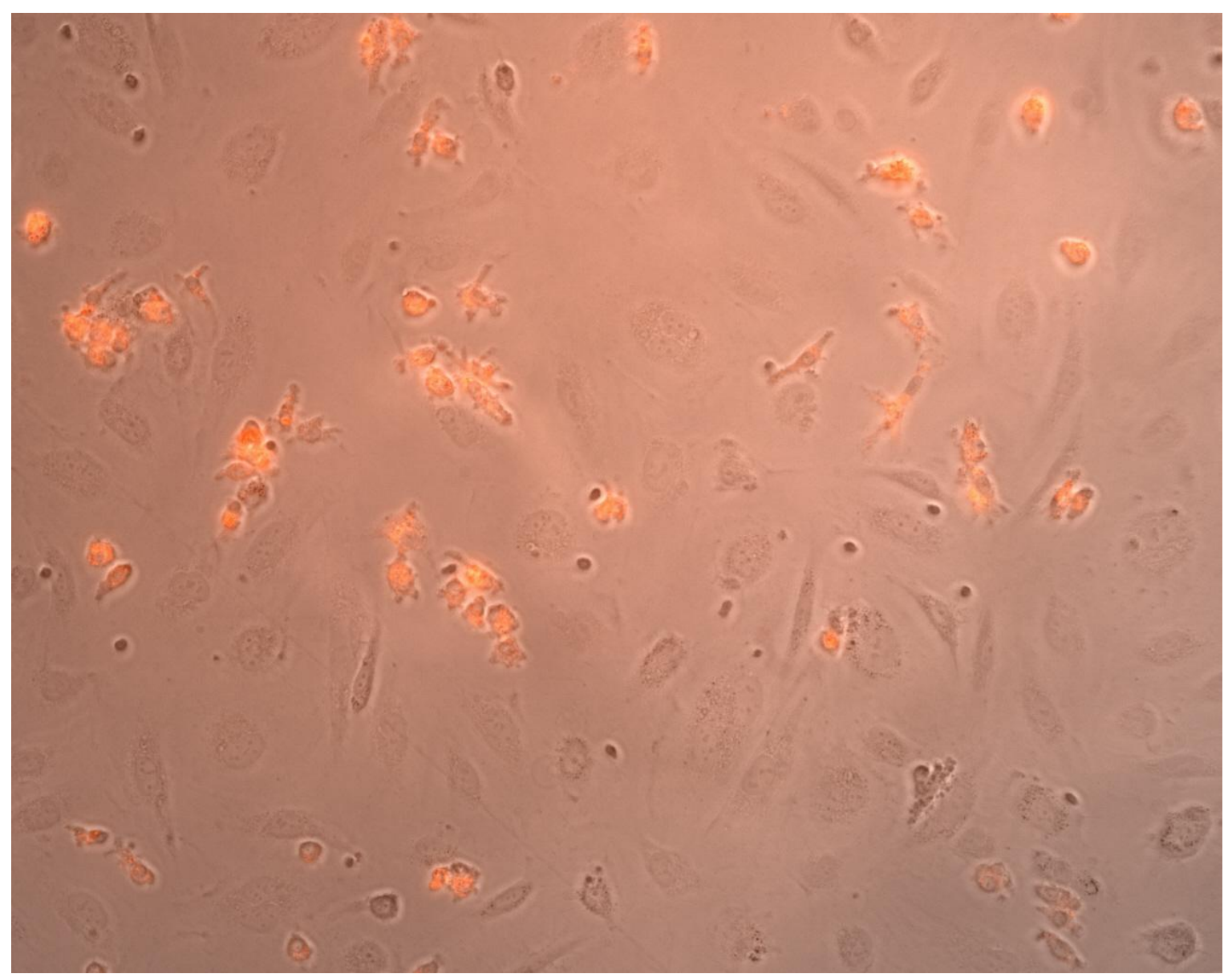




\subsubsection{Auswertung der Adhäsionsversuche}

Zuletzt wurden mit Hilfe des Fluoreszenzmikroskops (Axiovert 200, Carl Zeiss, Jena; Software Axio Vision 3.1) in 200-facher Vergrößerung 9 repräsentative Fotos aus 3 wells pro Proband angefertigt und die Anzahl der acLDL-positiven Zellen manuell gezählt. Als Ergebnis ist die durchschnittliche Zellzahl pro Gesichtsfeld angegeben.

\subsubsection{Matrigel Tubul Assay}

Das Adhäsionsverhalten von EPC an vaskulären Strukturen wurde mit dem Matrigel $^{\mathrm{TM}}$ Angiogeneseassay untersucht. Dabei bilden HUVEC kapillar-ähnliche Strukturen, denen die EPC anhaften. Matrigel stellt ein Modell für die extrazelluläre Matrix dar und wird aus dem Engelbreth-Holm-Swarm-Tumor der Maus gewonnen. Die Hauptbestandteile sind Laminin, Kollagen IV, Entactin, Heparansulfate, Proteoglycan, Kollagenase, Plasminogenaktivator und verschiedene Wachstumsfaktoren. Die Matrix liegt bei $4^{\circ} \mathrm{C}$ im flüssigen Zustand vor und verfestigt sich bei $37^{\circ} \mathrm{C}$.

Es wurde Wachstumsfaktor-reduziertes Matrigel $^{\mathrm{TM}}$ (BD Biosciences, Bedfort, USA) über Nacht bei $4^{\circ} \mathrm{C}$ aufgetaut. Puffer und Gellösung wurden auf Eis gelagert und vorsichtig unter Vermeidung von Luftblasen im Verhältnis 1:10 gemischt. Dann wurde in die Vertiefungen der vorgekühlten 96-Mikrowellplatte (Nunc ${ }^{\mathrm{TM}}$, Wiesbaden) mit Hilfe ebenfalls vorgekühlter Pipettenspitzen je $50 \mu \mathrm{l}$ der noch flüssigen Matrix gefüllt. Die vorbereitete Platte wurde dann für $1 \mathrm{~h}$ bei $37^{\circ} \mathrm{C}$ zur Aushärtung gebracht.

Derweil wurden die 7 Tage alten EPC wie oben beschrieben für $1 \mathrm{~h}$ bei $37^{\circ} \mathrm{C}$ mit Dil acLDL markiert und anschließend mit $2 \mathrm{mM}$ EDTA in PBS von der Platte gelöst. Nach Zentrifugation wurden die Zellen in Endothelzellmedium aufgenommen, maschinell gezählt und eine Konzentration von $3 \times 10^{4}$ Zellen/mL eingestellt.

Die benötigten HUVEC wurden mit Trypsin (Trypsin/EDTA (1x), Gibco, Karlsruhe) von der gelatinebeschichteten Platte gelöst und in der Neubauerzählkammer gezählt. Dafür wurde die Platte zunächst einmal mit HUVEC-Medium gewaschen, dann Trypsin zugegeben und nach 20 sec. abgesaugt. Die sich dann lösenden Zellen wurden schließlich mit HUVEC-Medium von der Platte gespült und aufgenommen. Es wurde eine Konzentration von 12 x $10^{4}$ Zellen/ml in HUVEC-Medium eingestellt. 
Schließlich wurden je $100 \mu \mathrm{l}$ der Zellsuspensionen $\left(3 \times 10^{3}\right.$ EPC und $12 \times 10^{3}$ HUVEC) zusammen auf das Matrigel gegeben. Nach achtstündiger Inkubation im Brutschrank bei $37^{\circ} \mathrm{C}$ wurden mit Hilfe des Fluoreszenzmikroskops pro Proband jeweils 8 repräsentative Fotos bei 100-facher Vergrößerung angefertigt. Die Länge des von den HUVEC gebildeten Kapillarähnlichen Netzwerkes wurde ausgemessen (Software: Image-Pro Plus) und die daran haftenden acLDL-positiven Zellen manuell ausgezählt. Das Ergebnis ist dargestellt als Anzahl der inkorporierten acLDL-positiven Zellen pro Netzwerklänge in mm.

\section{Abbildung 4. Anlagerung acLDL-markierter EPC in kapillar-ähnliche Netzwerke}

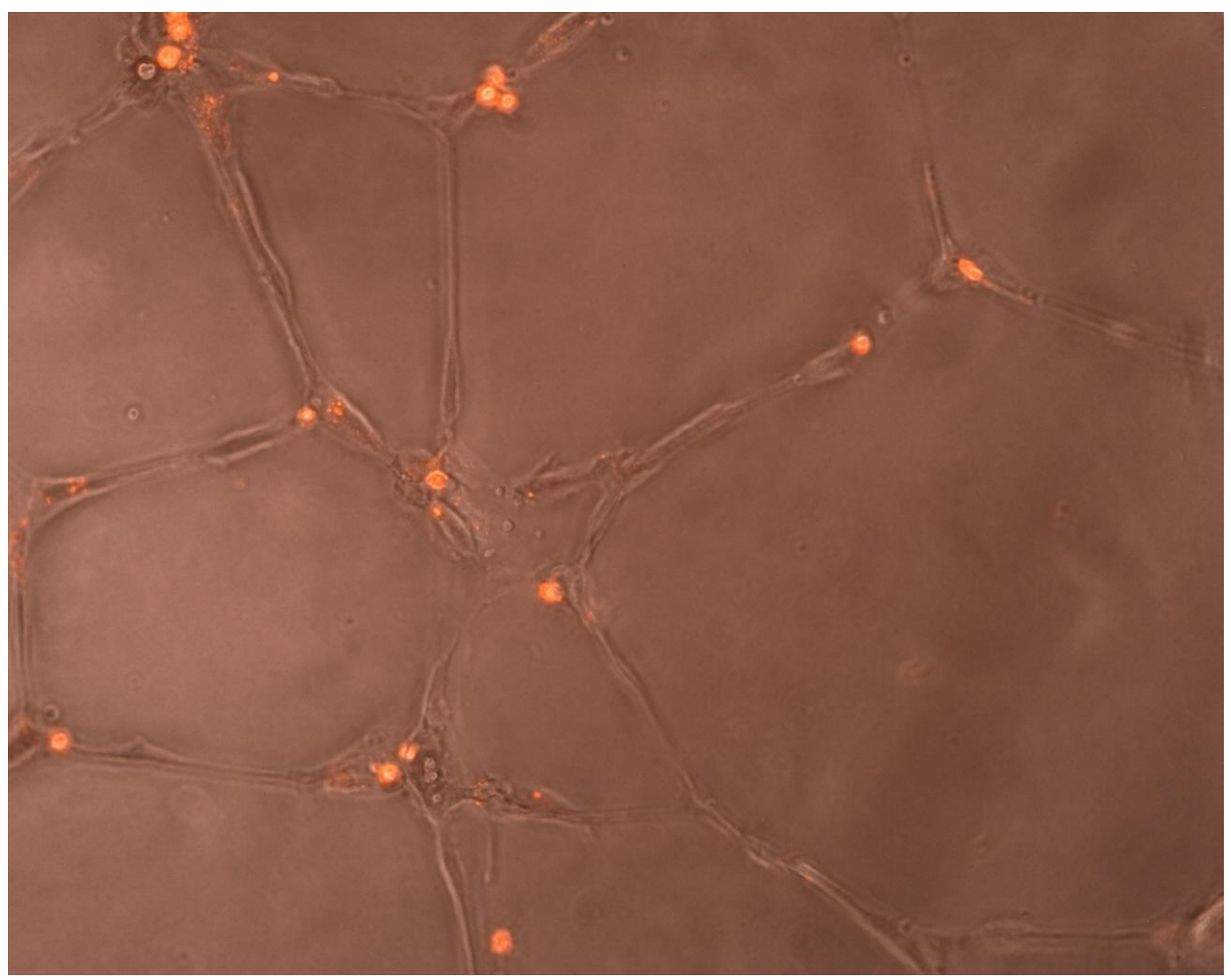




\subsection{Durchflusszytometrische Untersuchung der Expression bestimmter Integrin- Untereinheiten}

Integrine sind wichtige Rezeptoren zur Bindung von Zellen an extrazellulärer Matrix und spielen zudem eine wichtige Rolle bei der Zell-Zell-Verbindung. Sie bestehen aus zwei nicht kovalent verbundenen Transmembran-Glykoproteinen, die als $\alpha$ - und $\beta$ - Untereinheit bezeichnet werden. Derzeit sind etwa 24 verschiedene Integrin-Heterodimere identifiziert, welche sich aus den $18 \alpha$ - und $8 \beta$-Untereinheiten zusammensetzen.

Wir untersuchten die Expression bestimmter Integrin-Untereinheiten auf EPC mittels FACSAnalyse. Dazu wurden die Untereinheiten $\beta 1$ (CD29) und $\beta 2$ (CD18) ausgewählt, da deren Expression auf EPC bekannt ist (DEB et al.2004; CHAVAKIS et al. 2005). Sie vermitteln die Adhäsion an Fibronektin (vor allem über $\alpha 5 \beta 1$ und $\alpha 4 \beta 1$ ) und Endothelzellen (mittels Interaktion mit IgCAMs) (SCHROETER et al. 2008; PLOW et al. 2000).

Nach Isolierung und siebentägiger Kultivierung wie oben beschrieben wurden die Zellen mit PBS/EDTA 2mM von der Platte gelöst und das Zellpellett in PBS mit 0,5\% BSA resuspendiert. Die gelösten Zellen wurden in der Neubauerzählkammer ausgezählt und eine Konzentration von 1 x $10^{6}$ Zellen/ml eingestellt. Ein Volumen von $100 \mu \mathrm{l}$ der Zellsuspension wurde mit $10 \mu \mathrm{l}$ der FITC-gekoppelten Antikörper gegen humanes $\beta 1$ - oder $\beta 2$-Integrin (beides Chemicon, Temecula, USA) für $45 \mathrm{~min}$ bei $4^{\circ} \mathrm{C}$ inkubiert. FITC-gekoppelte IgG1sowie IgG2a-Antikörper der Maus (ebenfalls Chemicon, Temecula, USA) dienten als entsprechende Isotypenkontrollen.

Anschließend wurde erneut mit PBS/BSA gewaschen, zentrifugiert und das Pellet in $200 \mu 1$ PBS/BSA resuspendiert. Im FACScan ${ }^{\mathrm{TM}}$-Zytometer (Becton Dickinson, Franklin Lakes, USA; Software: Mac OS 9) wurden pro Ansatz mindestens 10000 Signale von mononukleären Zellen analysiert. Zur Auswertung wurde die Software winMDI 2.8 verwendet. 


\subsection{Durchflusszytometrischer Nachweis reaktiver Sauerstoffspezies (ROS) in EPC}

Zur Detektierung von intrazellulären ROS wurde $\mathrm{CM}-\mathrm{H}_{2}$ DCFDA verwendet, welches durch ROS zu einem fluoreszierenden Farbstoff oxidiert wird und dann mittels Durchflusszytometrie quantitativ untersucht werden kann.

Zunächst wurden die nichtadhärenten Zellen durch Waschen mit PBS aus der Kulturschale entfernt. Die sieben Tage-alten EPC wurden dann mit $10 \mu \mathrm{M}$ CM-H ${ }_{2}$ DCFDA (MoBiTec, Göttingen) in Endothelzellmedium für 60 min. bei Dunkelheit im Brutschrank inkubiert. Anschließend wurde das Reagenz durch zweimaliges Waschen mit PBS entfernt, die Zellen mit Trypsin gelöst und in Phenolrot-freiem Endothelzellmedium resuspendiert.

Die Analyse im FACScan ${ }^{\mathrm{TM}}$-Zytometer wurde wie unter Abschnitt 2.5. beschrieben durchgeführt. Dabei dienten mit $0,01 \% \mathrm{H}_{2} \mathrm{O}_{2}$ behandelte EPC als Positivkontrolle.

\subsection{Statistik}

Der modifizierte Kolmogorov-Smirnov-Test wurde zur Untersuchung auf Normalverteilung der Werte verwendet. Bei nicht gegebener Normalverteilung sind die kontinuierlichen Variablen als Median mit den entsprechenden 25. und 75. Perzentilen angegeben, bei Normalverteilung als Mittelwert mit Standardabweichung. Zum Vergleich von kontinuierlichen Variablen am Kursanfang, nach fünf Wochen und nach sechs Monaten (gepaarte Werte) wurde der Wilcoxon-Signed-Rank-Test verwendet. Der Vergleich von Kursteilnehmern mit und ohne kardiovaskuläre Risikofaktoren oder Erkrankungen wurde mit dem Mann-Whitney-Test durchgeführt. Die Anzahl der Probanden, die jeweils in einem Experiment untersucht wurden, ist entsprechend im Text angegeben. 


\section{Ergebnisse}

\subsection{Klinische Charakteristika des Probandenkollektivs}

In der Zeit von Juli 2004 bis November 2007 konnten 218 Raucher, die an einem fünfwöchigen Raucherentwöhnungsprogramm des Universitätsklinikums Göttingen teilnahmen, prospektiv in die Studie eingeschlossen werden. 74 Teilnehmer beendeten den fünfwöchigen Kurs nicht oder waren am Kursende nach der im Methodenteil genannten Definition weiterhin Raucher. Diese Probanden wurden von weiteren Analysen ausgeschlossen.

Die klinischen Charakteristika der letztendlich in die Studie eingeschlossenen 144 Probanden zeigt Tabelle 1. Dabei handelte es sich um 82 Frauen und 62 Männer im mittleren Alter (47,8 \pm 12,0 Jahre), die im Durchschnitt bereits mit 16,8 \pm 4,4 Jahren mit dem Rauchen angefangen hatten. Zum Zeitpunkt der ersten Untersuchung rauchten die Probanden 20,3 \pm 8,2 Zigaretten pro Tag (CO-Konzentration in der Ausatemluft 17,5 \pm 11,2 ppm).

Ungefähr die Hälfte des Kollektivs (49,3 \%) bestand aus gesunden Probanden, bei denen neben dem Rauchen keine weiteren Risikofaktoren für Herzkreislauferkrankungen bekannt waren. 73 Personen (50,7\%) wiesen dagegen einen oder mehrere zusätzliche Risikofaktoren auf, wobei eine positive Familienanamnese auf Grund von oft ungenauen Angaben nicht als Risikofaktor gezählt wurde. 15 Probanden (10,4\%) litten bereits an manifesten Herzkreislauferkrankungen. Eine regelmäßige Medikamenteneinnahme lag bei 38 Kursteilnehmern $(26,4 \%)$ vor.

Am Ende des fünfwöchigen Kurses hatten die Probanden durchschnittlich 24,2 \pm 9,2 Tage nicht geraucht, und die CO-Konzentration in der Ausatemluft war auf 0,5 $\pm 1,1 \mathrm{ppm}$ gefallen. 99 Personen $(68,8 \%)$ benutzten zum Zeitpunkt der zweiten Untersuchung Nikotinersatzprodukte. Im Vergleich zum Kursbeginn hatte es sonst keine Veränderungen in der Medikation gegeben. Das Körpergewicht der Probanden war allerdings bei Kursende gegenüber dem Ausgangswert um durchschnittlich zwei Kilogramm angestiegen $(p<0,001)$.

Nach sechs Monaten waren 56 der 144 erneut kontaktierten Teilnehmer zu einer dritten Untersuchung bereit. Allerdings hatten 23 Personen (41\%) wieder angefangen zu rauchen, so dass schließlich noch 33 Probanden in der Gruppe der „ehemaligen Raucher nach sechs Monaten“ untersucht werden konnten. Zu diesem Zeitpunkt wurden von keiner Person noch Nikotinersatzprodukte benutzt. Die verbleibenden 33 Probanden (14 Frauen / 19 Männer) 
waren im Durchschnitt 49,2 \pm 12,0 Jahre alt und etwa zur Hälfte (16 Probanden) gesunde Individuen ohne weitere Risikofaktoren für Herzkreislauferkrankungen.

Tabelle 1. Klinische Charakteristika der 144 Probanden

\begin{tabular}{|c|c|}
\hline Geschlecht, weiblich / männlich & $82 / 62$ \\
\hline Alter, in Jahren & $47,8 \pm 12,0$ \\
\hline Zigaretten pro Tag, $n$ & $20,3 \pm 8,2$ \\
\hline CO-Konzentration in der Ausatemluft, ppm & $17,5 \pm 11,2$ \\
\hline Alter zu Beginn des Tabakkonsums, in Jahren & $16,8 \pm 4,4$ \\
\hline Zusätzliche kardiovaskuläre Risikofaktoren, $n(\%)$ & $73(50,7)$ \\
\hline - $\quad$ Alter $>60$ Jahre & $24(16,7)$ \\
\hline - Body-Mass-Index $>30 \mathrm{~kg} / \mathrm{m}^{2}$ & $14(9,7)$ \\
\hline - $\quad$ arterieller Hypertonus & $36(25,0)$ \\
\hline - Diabetes mellitus & $9(6,3)$ \\
\hline - Hypercholesterinämie & $57(39,6)$ \\
\hline Vorbestehende kardiovaskuläre Erkrankungen, $n(\%)$ & $15(10,4)$ \\
\hline - Koronare Herzkrankheit & $6(4,2)$ \\
\hline - $\quad$ Schlaganfall & $5(3,5)$ \\
\hline - Periphere arterielle Verschlusskrankheit & $9(6,3)$ \\
\hline Medikation, $n(\%)$ & $38(26,4)$ \\
\hline - Aspirin & $12(8,3)$ \\
\hline - Statine & $16(11,1)$ \\
\hline - ACE-Hemmer / AT1-Blocker & $18(12,5)$ \\
\hline - Betablocker & $18(12,5)$ \\
\hline - Insulin und/oder orale Antidiabetika & $7(4,9)$ \\
\hline - Östrogenersatztherapie & $7(4,9)$ \\
\hline
\end{tabular}


Angaben für kontinuierliche Variablen (z.B. Alter, Zigaretten pro Tag) als Mittelwerte $\pm S D$, für kategorische Variablen (z.B. Geschlecht, Erkrankungen) als Anzahl sowie prozentualer Anteil

\subsubsection{Klinische Charakteristika der Subgruppen der funktionellen Untersuchungen}

Es konnten nicht alle Analysen zu funktionellen Eigenschaften der EPC mit den Zellen aller 144 Probanden durchgeführt werden. Der Hauptgrund dafür lag in der begrenzten Anzahl von EPC, die aus $27 \mathrm{ml}$ Blut der Probanden gewonnen werden konnten, und der Anzahl der für die entsprechenden Versuche benötigten Zellen. Des Weiteren war es auf Grund der begrenzten personellen und technischen Möglichkeiten schwierig, mehrere Versuche zeitgleich durchzuführen. So wurden die Probanden randomisiert und ohne vorherige Selektion auf die verschiedenen Versuche aufgeteilt. Dass die klinischen Charakteristika der einzelnen Subgruppen dennoch denen des Gesamtkollektivs entsprechen, zeigt Tabelle 2. Hinsichtlich Geschlechtsverteilung, Alter, Rauchverhalten oder der Verteilung kardiovaskulärer Risikofaktoren resp. Erkrankungen bestanden keine signifikanten Unterschiede. 
Tabelle 2. Klinische Charakteristika der Subgruppen der funktionellen Untersuchungen

\begin{tabular}{|c|c|c|c|c|c|c|c|}
\hline & $\begin{array}{l}\text { Gesamt- } \\
\text { kollektiv }\end{array}$ & $\begin{array}{c}\text { CD34 }^{+} \\
\text {CD133 }^{+} \\
\text {VEGFR2 }^{+} \\
\text {Zellen \# }\end{array}$ & $\begin{array}{c}\text { acLDL }^{+} \\
\text {Lectin }^{+} \\
\text {Zellen } \\
\text { an Tag 7\# }\end{array}$ & $\begin{array}{c}\text { Adhäsion } \\
\text { an FN }\end{array}$ & $\begin{array}{c}\text { Adhäsion } \\
\text { an } \\
\text { HUVEC }\end{array}$ & $\begin{array}{c}\text { Adhäsion an } \\
\text { kapillar- } \\
\text { ähnliche } \\
\text { Strukturen }\end{array}$ & $p$ \\
\hline Anzahl & 144 & 24 & 68 & 28 & 38 & 15 & \\
\hline $\begin{array}{l}\text { Geschlecht, \% } \\
\text { Männer }\end{array}$ & 43,1 & 50,0 & 36,8 & 60,1 & 55,2 & 40,0 & 0,33 \\
\hline Alter, Jahre & $47,8 \pm 12,0$ & $46,9 \pm 12,3$ & $46,8 \pm 11,0$ & $45,4 \pm 12,2$ & $47,0 \pm 13,5$ & $47,8 \pm 8,3$ & 0,98 \\
\hline $\begin{array}{l}\text { Weitere } \\
\text { kardiovaskuläre } \\
\text { Risikofaktoren, \% }\end{array}$ & 50,7 & 41,7 & 52,9 & 42,9 & 42,2 & 60,0 & 0,89 \\
\hline $\begin{array}{l}\text { Kardiovaskuläre } \\
\text { Erkrankungen, \% }\end{array}$ & 10,4 & 12,5 & 10,3 & 3,6 & 5,3 & 20,0 & 0,43 \\
\hline $\begin{array}{l}\text { Kardiovaskuläre } \\
\text { Medikation, \% }\end{array}$ & 26,4 & 33,3 & 22,1 & 32,1 & 31,6 & 46,7 & 0,51 \\
\hline $\begin{array}{l}\text { Nikotinersatz- } \\
\text { therapie, } \%\end{array}$ & 68,8 & 70,8 & 67,6 & 71,4 & 81,6 & 93,3 & 0,76 \\
\hline $\begin{array}{l}\text { Alter zu Beginn des } \\
\text { Tabakkonsums, Jahre }\end{array}$ & $16,8 \pm 4,4$ & $16,6 \pm 5,4$ & $17,0 \pm 4,9$ & $15,8 \pm 2,8$ & $16,2 \pm 3,5$ & $15,3 \pm 1,6$ & 0,78 \\
\hline Zigaretten pro Tag, $n$ & $20,3 \pm 8,2$ & $19,4 \pm 7,9$ & $19,9 \pm 7,3$ & $20,3 \pm 8,7$ & $19,8 \pm 8,2$ & $24,3 \pm 11,6$ & 0,75 \\
\hline $\begin{array}{l}\text { CO Konzentration in } \\
\text { der Ausatemluft, } p p m\end{array}$ & $17,5 \pm 11,2$ & $14,6 \pm 5,7$ & $17,2 \pm 10 ., 9$ & $16,1 \pm 14,3$ & $16,5 \pm 13,7$ & $17,5 \pm 10,1$ & 0,77 \\
\hline
\end{tabular}

\# Teil der vorangegangenen Untersuchungen (PULS et al. 2011)

Angaben bei kategorischen Parametern (z.B. Geschlecht, Erkrankungen) als prozentualer Anteil, bei kontinuierlichen Variablen (z.B. Alter, Zigaretten pro Tag) als Mittelwert \pm SEM. Statistischer Vergleich der Subgruppen mithilfe des Kruskal-Wallis-Tests 
3.1.2. Klinische Charakteristika der Untergruppen ,gesunde Probanden“ und „Probanden mit weiteren kardiovaskulären Risikofaktoren oder Erkrankungen“

Teilt man das Gesamtkollektiv nach Abwesenheit oder Vorliegen weiterer kardiovaskulärer Risikofaktoren oder Erkrankungen, erhält man zwei etwa gleich große Untergruppen, deren klinische Charakteristika Tabelle 3 zeigt. Zwischen den beiden Untergruppen liegen keine Unterschiede bezüglich der Geschlechterverteilung, des Rauchverhaltens oder der Verwendung von Nikotinersatzprodukten vor. Jedoch waren die Probanden der Gruppe mit weiteren kardiovaskulären Risikofaktoren oder Erkrankungen im Durchschnitt zehn Jahre älter $(\mathrm{p}<0,0001)$ und sieben Kilogramm $(\mathrm{p}=0,0074)$ schwerer.

Tabelle 3. Klinische Charakteristika der Untergruppen ,gesunde Probanden“" und „Probanden mit weiteren kardiovaskulären Risikofaktoren oder Erkrankungen““

\begin{tabular}{|c|c|c|c|}
\hline & $\begin{array}{l}\text { Gesunde Probanden } \\
\qquad(\mathbf{n}=\mathbf{7 3})\end{array}$ & $\begin{array}{c}\text { Probanden mit weiteren } \\
\text { kardiovaskulären } \\
\text { Risikofaktoren/ } \\
\text { Erkrankungen (n=71) }\end{array}$ & $\boldsymbol{P}$ \\
\hline Geschlecht, Frauen/Männer & $43 / 30$ & $39 / 32$ & 0,68 \\
\hline Alter, Jahre & $43 \pm 12$ & $53 \pm 10$ & $<0,0001$ \\
\hline Körpergewicht, $\mathrm{kg}$ & $70 \pm 13$ & $77 \pm 17$ & 0,0074 \\
\hline $\begin{array}{l}\text { Nikotinersatztherapie, } \\
n(\%)\end{array}$ & $46(63.0)$ & $53(74.6)$ & 0,17 \\
\hline $\begin{array}{l}\text { Alter zu Beginn des } \\
\text { Tabakkonsums, Jahre }\end{array}$ & $17 \pm 5,5$ & $17 \pm 2,9$ & 0,18 \\
\hline Zigaretten pro Tag, $n$ & $19 \pm 7,7$ & $21 \pm 8,7$ & 0,095 \\
\hline $\begin{array}{l}\text { CO Konzentration in der } \\
\text { Ausatemlusft, } p p m\end{array}$ & $18 \pm 11$ & $17 \pm 11$ & 0,95 \\
\hline
\end{tabular}

Angaben bei kategorischen Parametern (z.B. Geschlecht) als Anzahl sowie prozentualer Anteil, bei kontinuierlichen Variablen (z.B. Alter, Zigaretten pro Tag) als Mittelwert \pm SEM, statistische Analyse mittels Mann-Whitney-Test. 


\subsection{Proliferationsverhalten von HUVEC und EPC unter Einfluss von Cigarette Smoke Extract (CSE)}

Zur Klärung des Befundes einer signifikant verminderten Zahl kultivierbarer acLDL ${ }^{+}-$lectin $^{+}-$ Zellen nach Tabakentwöhnung folgten wir zunächst der Hypothese einer möglicherweise veränderten Proliferationskapazität der Zellen. Dazu untersuchten wir die Proliferation der EPC unter Verwendung des Thymidin-Analogon Bromodesoxyuridin (BrdU), wobei die Zellen mit Cigarette Smoke Extract (CSE) in verschiedenen Konzentrationen inkubiert und die Proliferationsrate im Vergleich zu unstimulierten Kontrollzellen analysiert wurden. HUVEC wurden als positive Kontrolle parallel analysiert.

\subsubsection{Einfluss von CSE auf das Proliferationsverhalten von HUVEC}

HUVEC besitzen bekanntermaßen eine hohe Proliferationsrate. Diese wurde durch CSE konzentrationsabhängig gehemmt (vgl. Abb. 5 und 6).

\section{Abbildung 5. Einfluss von CSE auf die Zellproliferation von HUVEC}

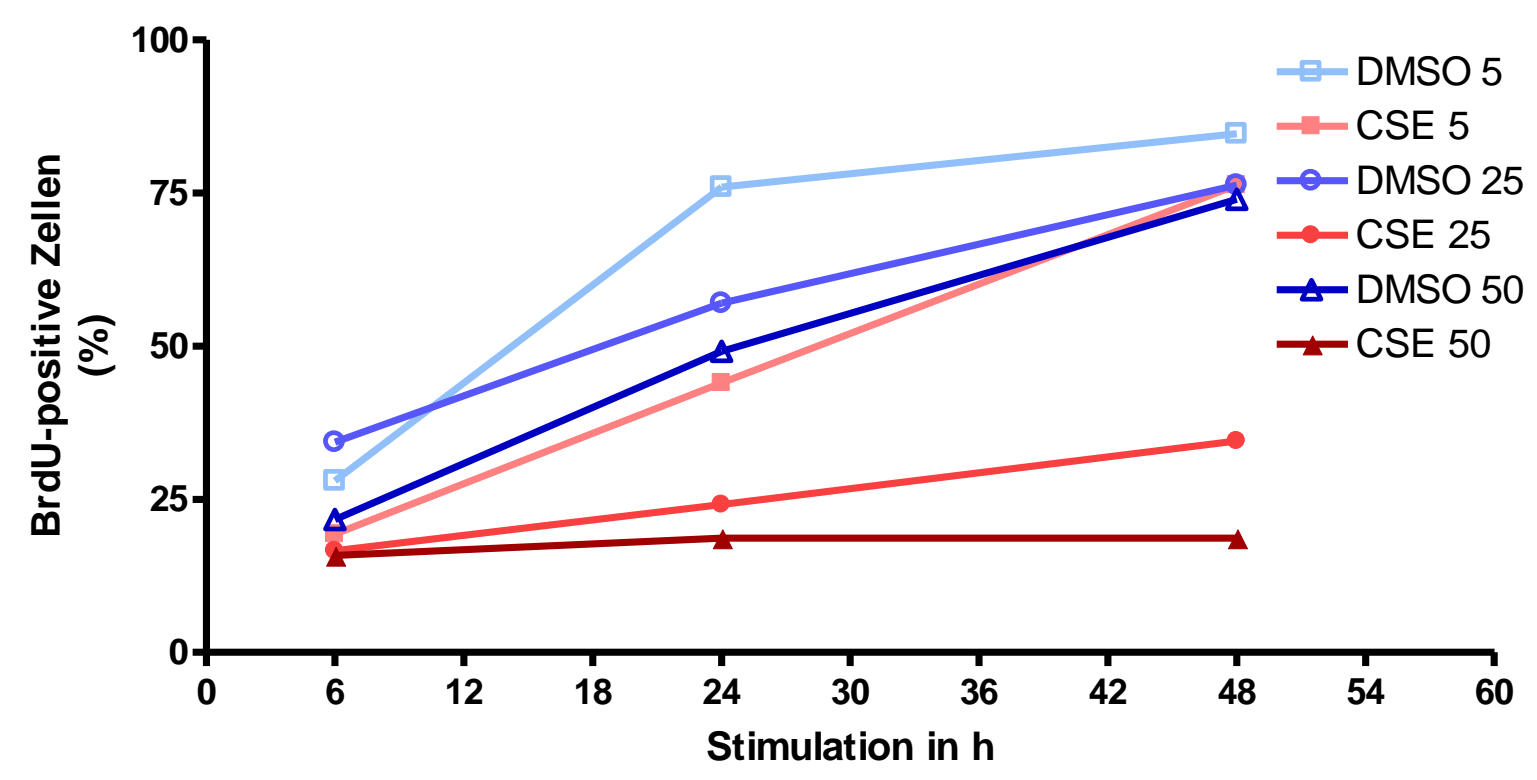


$6 \mathrm{~h}$

$24 \mathrm{~h}$

CSE $50 \mu \mathrm{g} / \mathrm{ml}$

DMSO $50 \mu \mathrm{g} / \mathrm{ml}$

$$
p=0,352
$$$$
p=0,009
$$$$
p=0,188
$$

CSE $25 \mu \mathrm{g} / \mathrm{ml}$

DMSO $25 \mu \mathrm{g} / \mathrm{ml}$

$$
p=0,014
$$$$
p=0,02
$$$$
p=0,003
$$

CSE $5 \mu \mathrm{g} / \mathrm{ml}$

DMSO $5 \mu \mathrm{g} / \mathrm{ml}$

$$
p=0,154
$$

$$
p=0,001
$$

$48 \mathrm{~h}$ 
Abbildung 6. Proliferation von HUVEC nach 24h Inkubation mit CSE

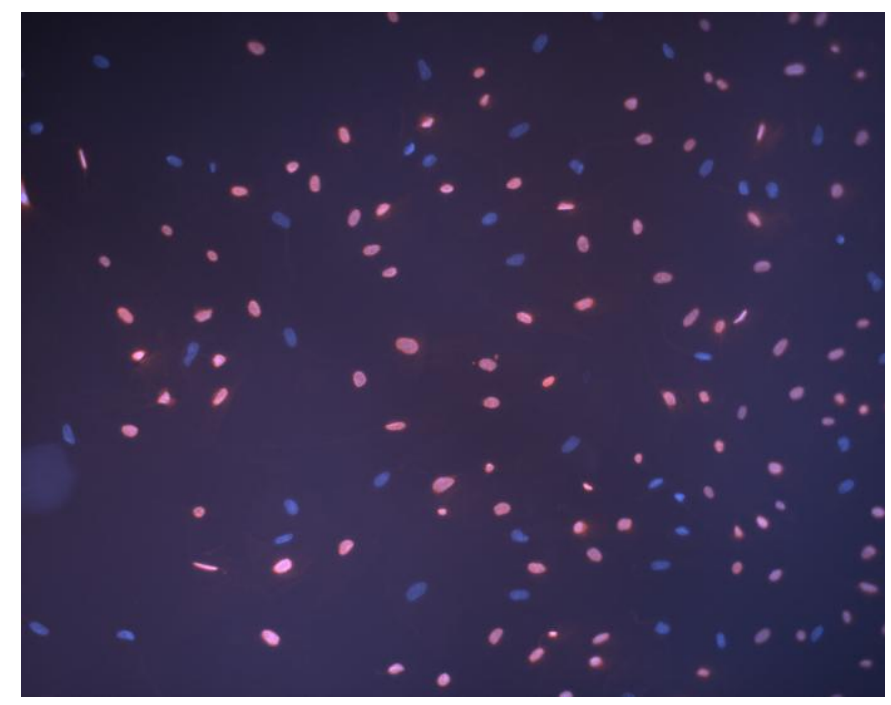

CSE $5 \mu \mathrm{g} / \mathrm{ml}$

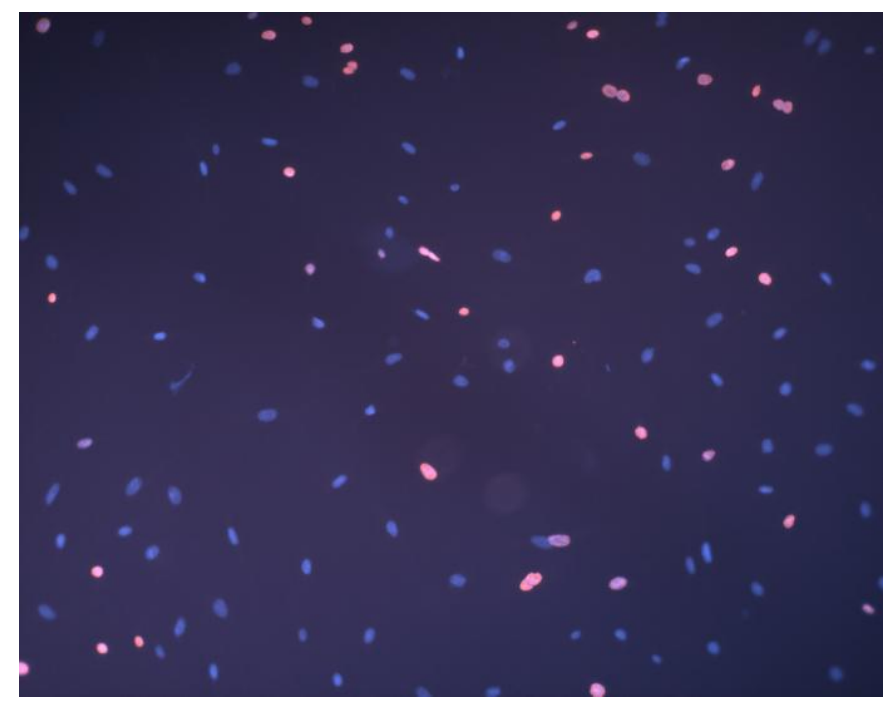

CSE $25 \mu \mathrm{g} / \mathrm{ml}$

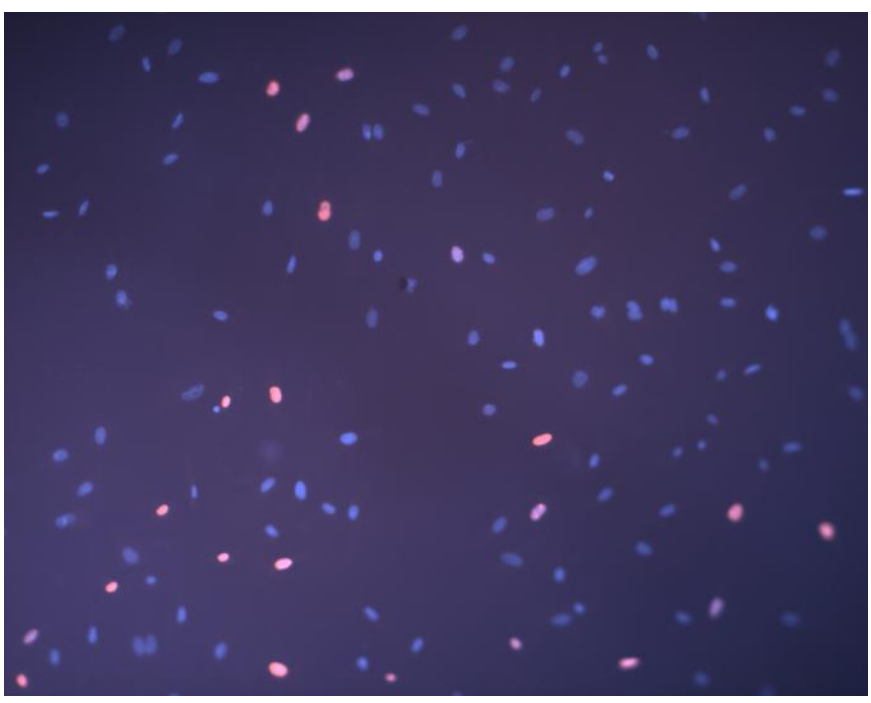

CSE $50 \mu \mathrm{g} / \mathrm{ml}$ 


\subsubsection{Einfluss von CSE auf das Proliferationsvermögen von EPC}

Analog zu den Versuchen mit HUVEC wurde der Einfluss von CSE auf die Proliferationskapazität 4 und 7 Tage alter EPC untersucht. In allen Versuchsansätzen, bei Inkubationszeiten zwischen 1 und 10 Tagen, wurden keine BrdU-positiven Zellen gefunden. Ebenso verhielten sich auch die unbehandelten Kontrollzellen, so dass wir davon ausgehen, dass unsere zuvor charakterisierten EPC nicht proliferieren. 


\subsection{Der Einfluss von Tabakentwöhnung auf das Adhäsionsverhalten von EPC}

Da der Befund einer signifikant verminderten Zahl kultivierbarer acLDL ${ }^{+}$-lectin ${ }^{+}$-Zellen nach Tabakentwöhnung nicht durch ein verändertes Proliferationsverhalten $\mathrm{zu}$ erklären war, untersuchten wir im Weiteren den Einfluss einer Tabakentwöhnung auf das Adhäsionsverhalten der EPC gegenüber Fibronektin sowie reifen Endothelzellen.

\subsubsection{Tabakentwöhnung reduziert die Adhäsion von EPC an Fibronektin sowie an reifen Endothelzellen (HUVEC)}

Es zeigte sich, dass die Adhäsionsfähigkeit der EPC auf dem Extrazellulärprotein Fibronektin am Ende des fünfwöchigen Kurses signifikant reduziert war $(64,0 \pm 26,1$ vs. $34,3 \pm 15,9$ Zellen; $\mathrm{p}<0,001$ vs. Kursbeginn; n=28). Die Wiederholung des Experiments nach 6 Monaten bestätigte diesen Effekt (26,9 \pm 15,2; p=0,002 vs. Kursbeginn; $n=10)$ (vgl. Abb.7A und B).

Ferner wurde das Adhäsionsverhalten der EPC an Fibronektin in den Subgruppen der gesunden Probanden und der Probanden mit weiteren kardiovaskulären Risikofaktoren oder Erkrankungen analysiert. Der Vergleich der Ausgangswerte zeigte eine signifikant geringere Adhäsion der Zellen der Probanden mit kardiovaskulären Risikofaktoren oder Erkrankungen gegenüber der Gruppe der gesunden Probanden $(p=0,028)$. Interessanterweise führte Tabakentwöhnung nur in der Gruppe der gesunden Probanden zu einer signifikant reduzierten Adhäsion ( $\mathrm{p}=0,0012$ vs. Ausgangswert), wohingegen in der Gruppe der Probanden mit kardiovaskulären Risikofaktoren oder Erkrankungen Tabakentwöhnung zu keiner signifikanten Änderung des Adhäsionsverhaltens führte ( $\mathrm{p}=0,23$ vs. Ausgangswert) (vgl. Abb. 7C).

Die Anzahl adhärenter Zellen an einem mit TNF- $\alpha$-stimulierten HUVEC-Monolayer war am Ende des fünfwöchigen Kurses ebenfalls signifikant vermindert (31,7 $\pm 14,3$ vs. $20,7 \pm 12,5$; p=0,003; n=38) (vgl. Abb.7D und 7E). Das Adhäsionsverhalten der EPC gegenüber HUVEC, die zuvor nicht mit TNF- $\alpha$ stimuliert worden waren, wurde durch Tabakentwöhnung nicht beeinflusst. 
Abbildung 7. Einfluss von Tabakentwöhnung auf das Adhäsionsverhalten von EPC 7A) Adhäsion von EPC an Fibronektin

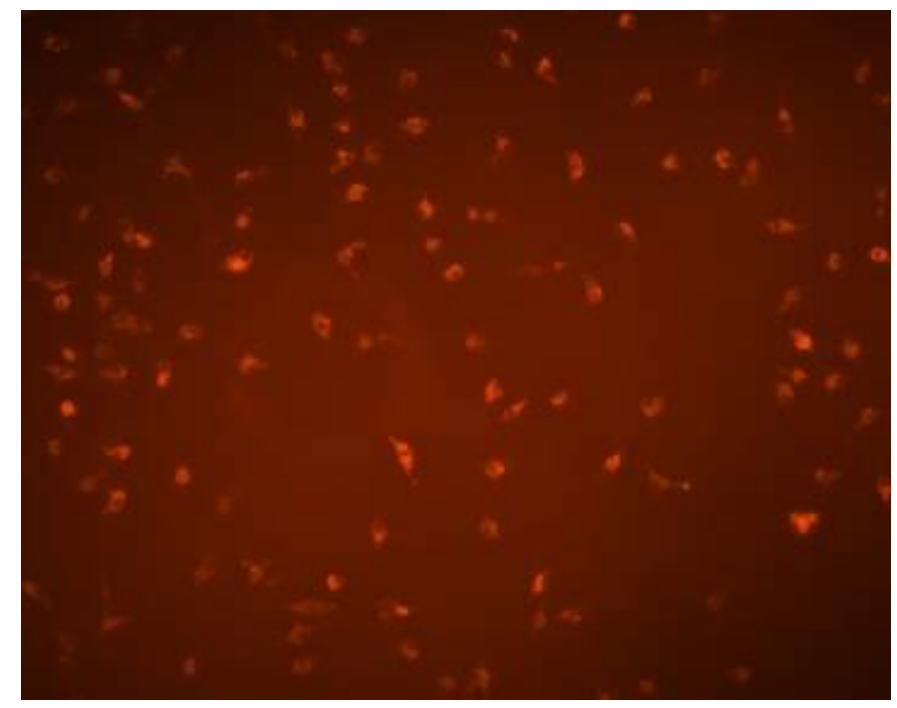

\section{Ausgangswert}

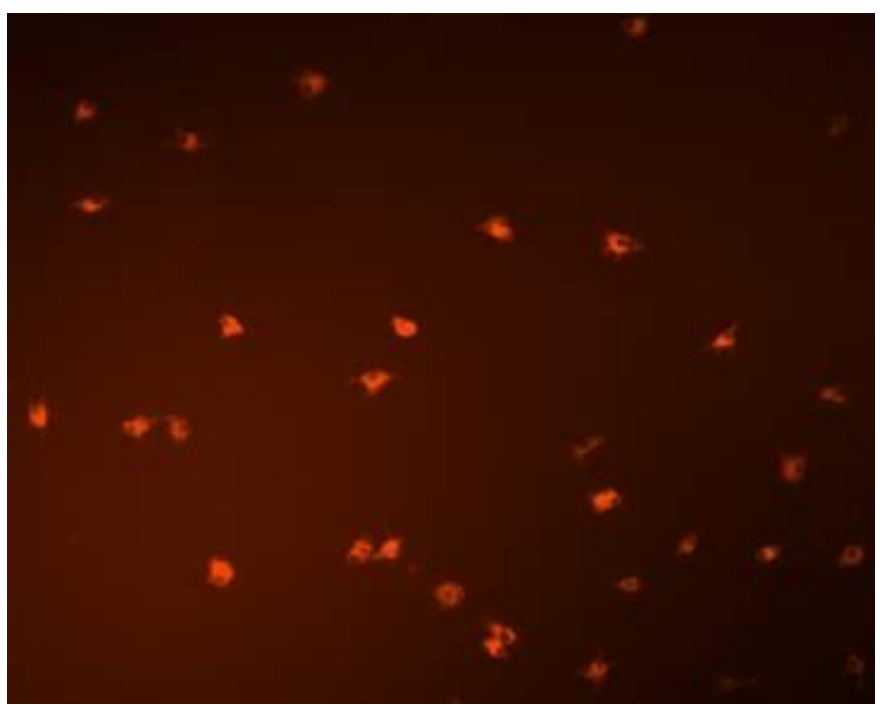

5 Wochen

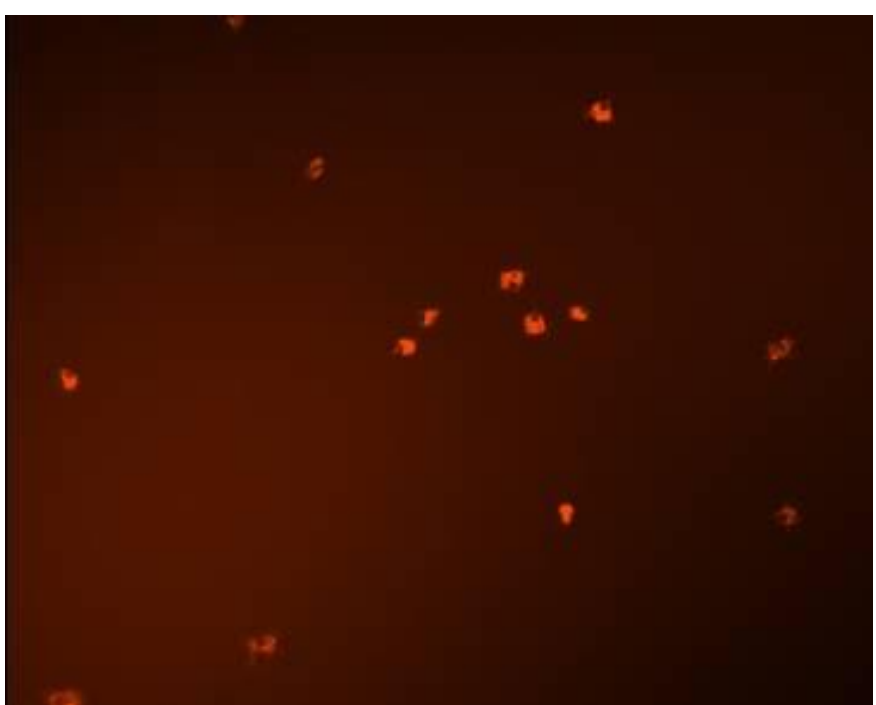

\section{Monate}

Repräsentative Fotos zeigen den Effekt von Tabakentwöhnung auf die Adhäsion fluoreszenzmarkierter EPC (rot) an Fibronektin. Vergrößerung 200x. 
7B) Quantitative Analyse der Adhäsion an Fibronektin

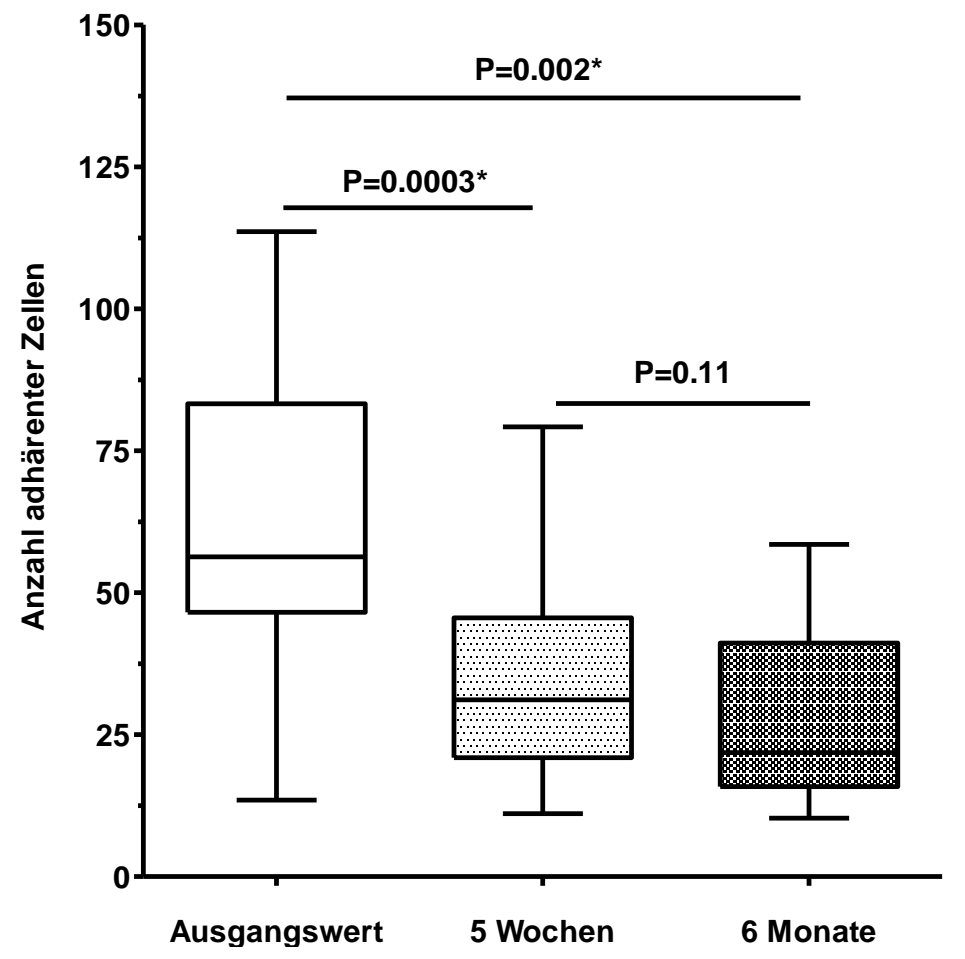

7C) Adhäsion an Fibronektin bei gesunden Probanden und Probanden mit kardiovaskulären Risikofaktoren/ Erkrankungen

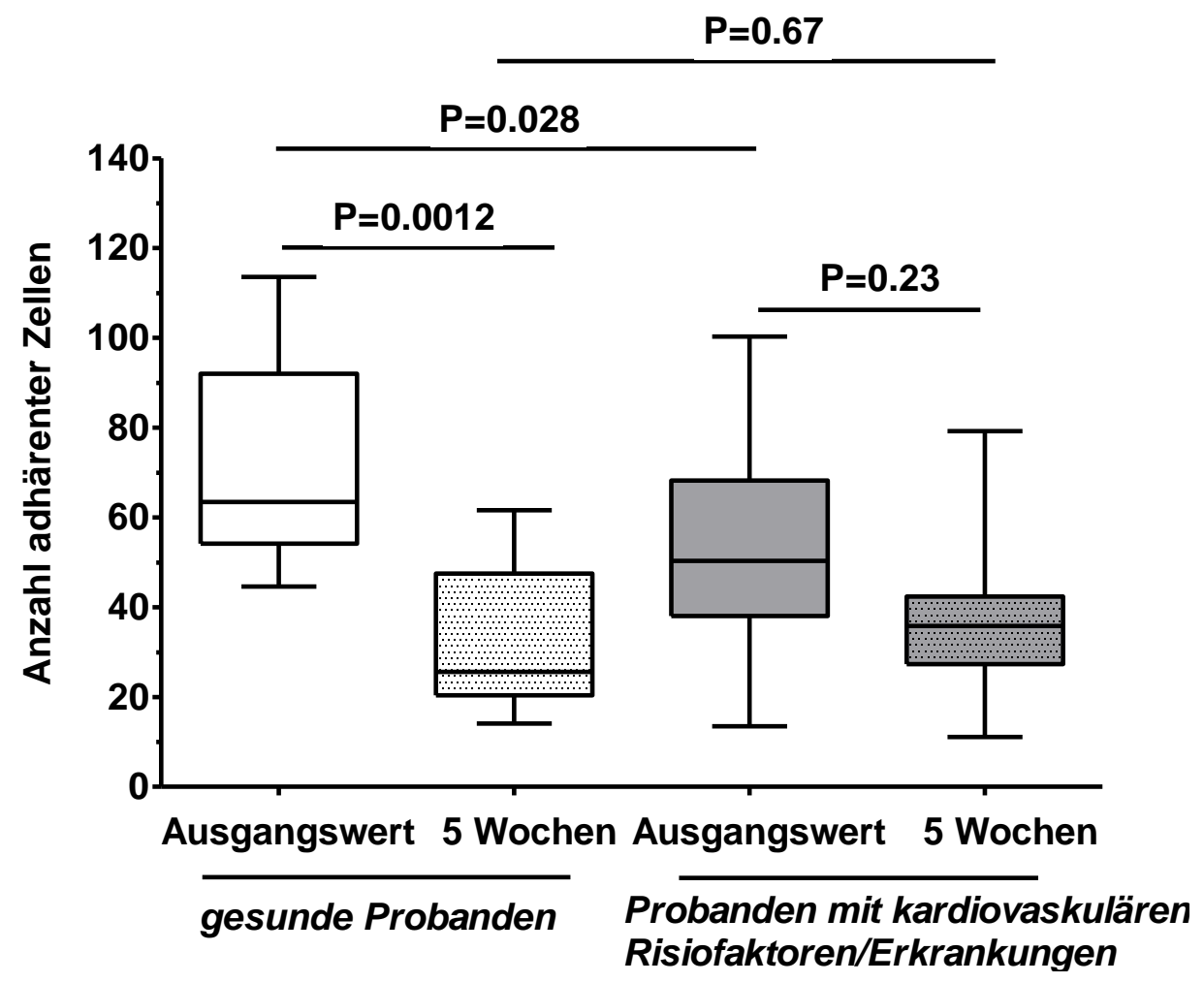


7D) Adhäsion von EPC an mit TNF- $\alpha$-stimulierten HUVEC

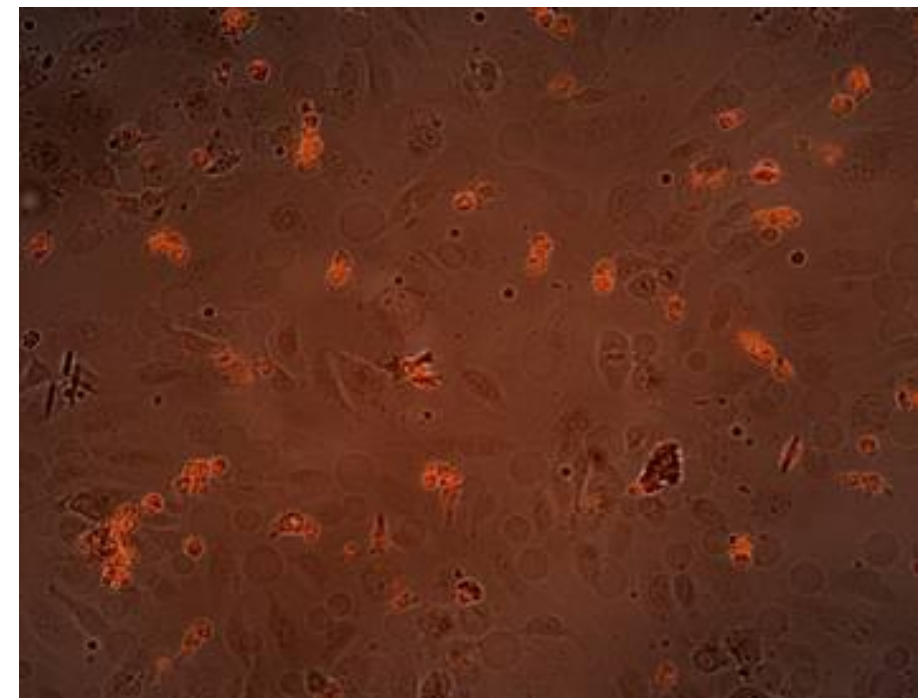

\section{Ausgangswert}

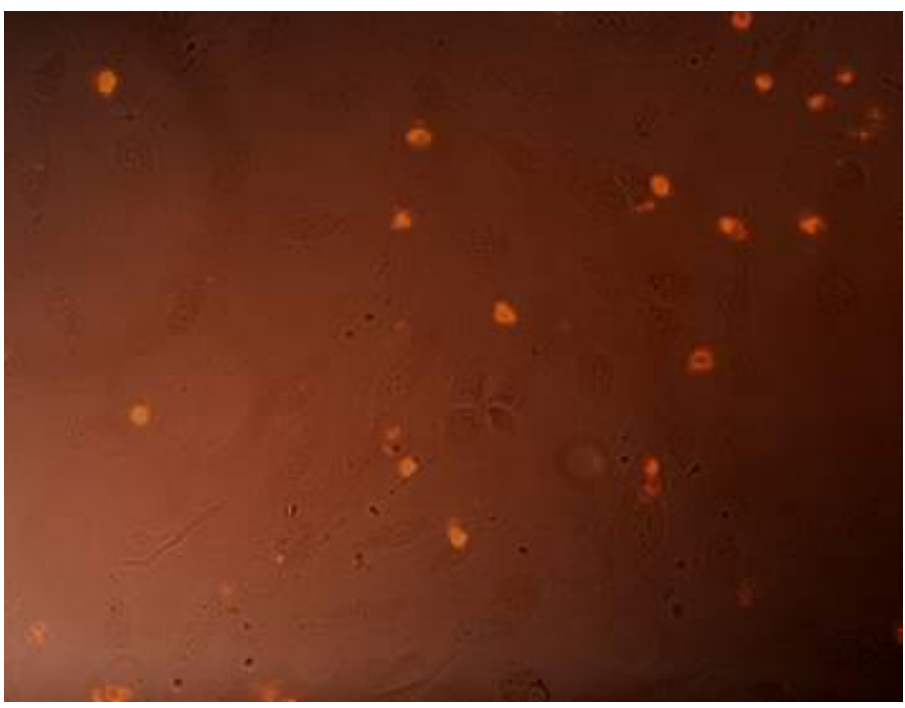

\section{Wochen}

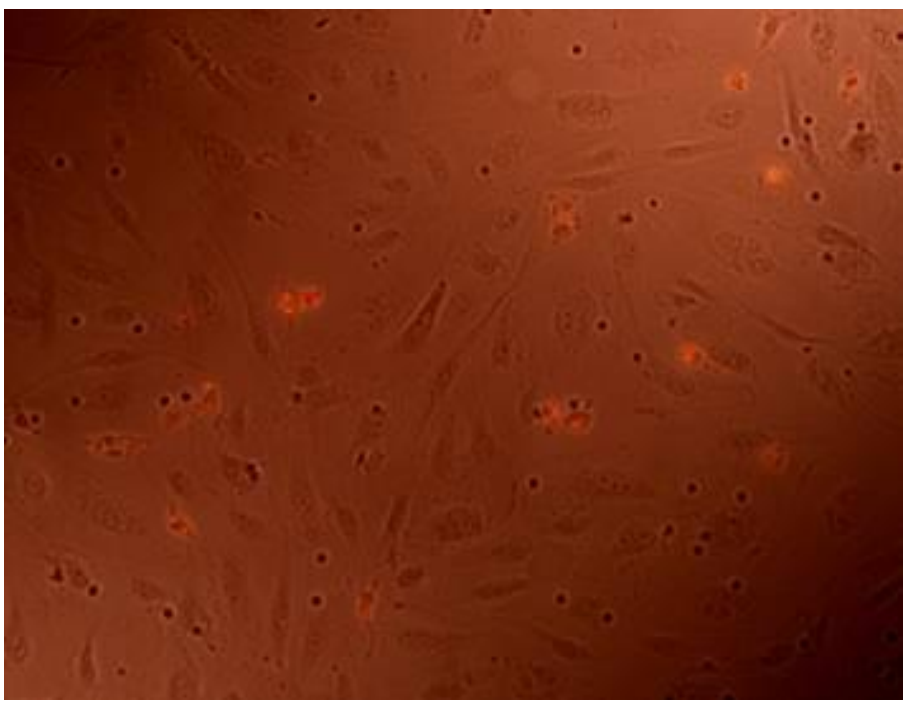

\section{Monate}

Repräsentative Fotos zeigen den Effekt von Tabakentwöhnung auf die Adhäsion fluoreszenzmarkierter EPC (rot) am TNF- $\alpha$-stimulierten HUVEC- Monolayer. Vergrößerung 200x. 
7E) Quantitative Analyse der Adhäsion von EPC an TNF- $\alpha$-stimulierten HUVEC

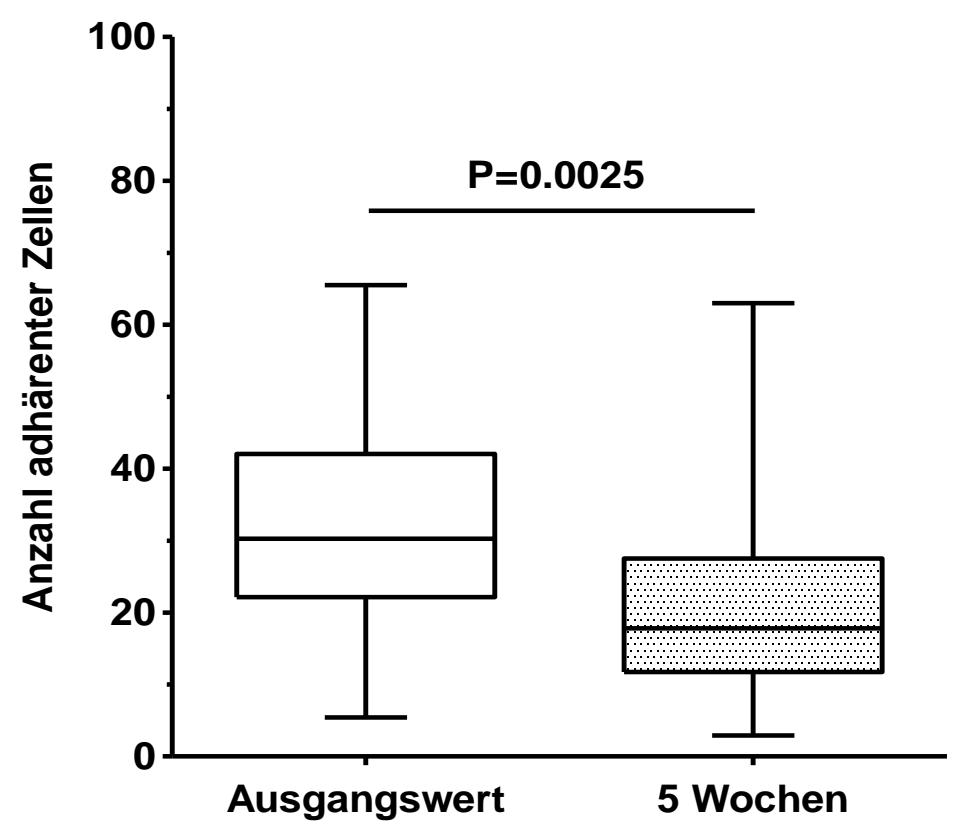




\subsubsection{Tabakentwöhnung reduziert die Anzahl inkorporierter EPC in kapillarähnliche Strukturen}

Ferner untersuchten wir das Adhäsionsverhalten von EPC an vaskulären Strukturen im Matrigel $^{\text {TM}}$-Angiogenese-Assay. Dabei bilden HUVEC kapillarähnliche Strukturen, denen die EPC anhaften, wobei das Matrigel ein Modell für die extrazelluläre Matrix darstellt.

Es zeigte sich auch hier, dass nach Tabakentwöhnung die Anzahl inkorporierter EPC gegenüber dem Ausgangswert signifikant reduziert war (4,76 $\pm 1,12$ vs. 3,99 $\pm 0,62$ Zellen pro mm Netzwerk; $p=0,035 ; n=15)$ (vgl. Abb. 8A und B).

Abbildung 8A) Einfluss von Tabakentwöhnung auf die Inkorporation von EPC im MatrigelTM-Assay $^{\mathrm{TM}}$
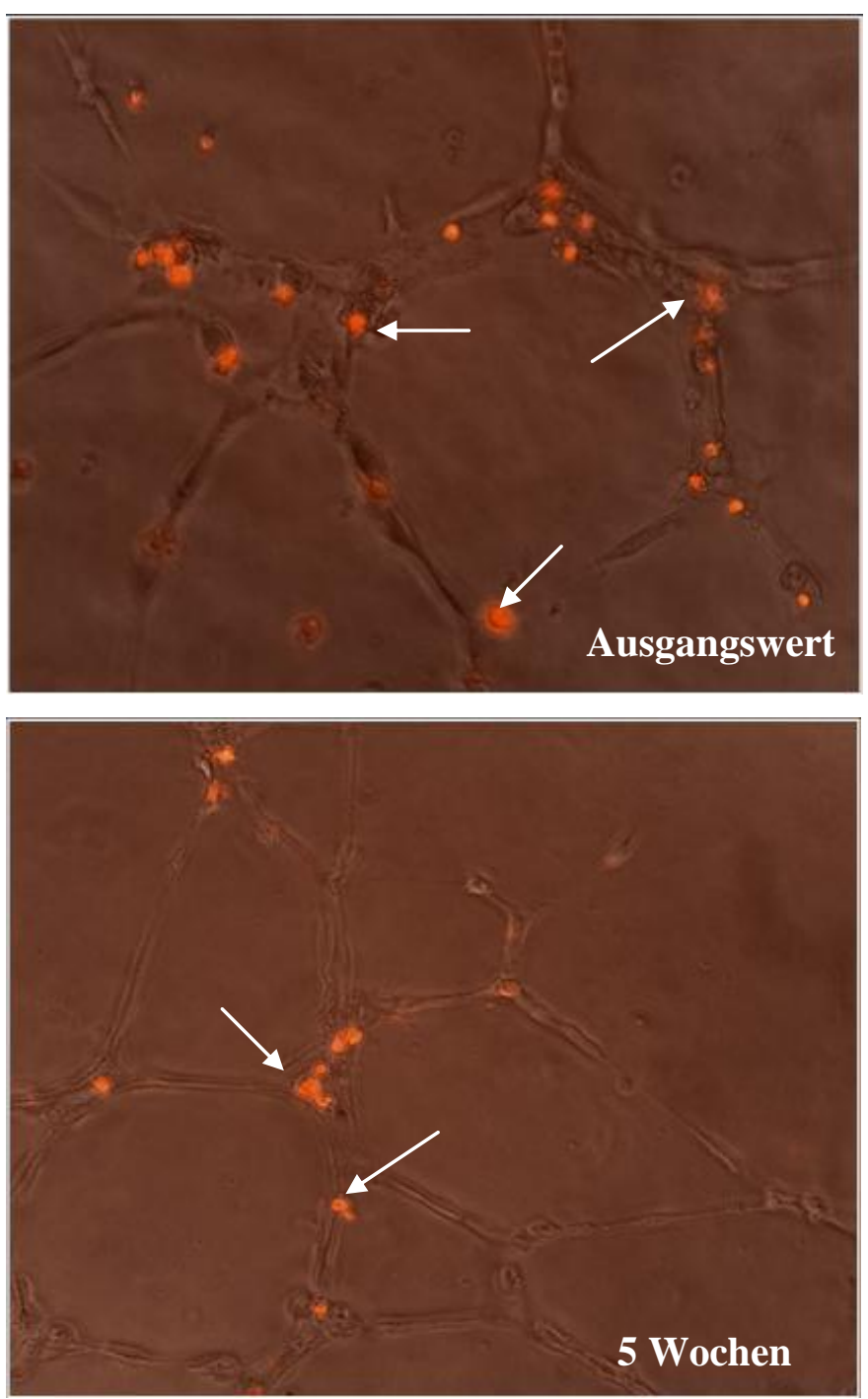

Repräsentative Fotos zeigen den Einfluss von Tabakentwöhnung auf die Inkorporation fluoreszenz-markierter EPC (rot) in ein Netzwerk aus HUVEC im Matrigel ${ }^{\mathrm{TM}}$-Assay. Vergrößerung $100 \mathrm{x}$. 
8B) Quantitative Analyse der EPC-Inkorporation in kapilläre Netzwerke im MatrigelTM-Assay

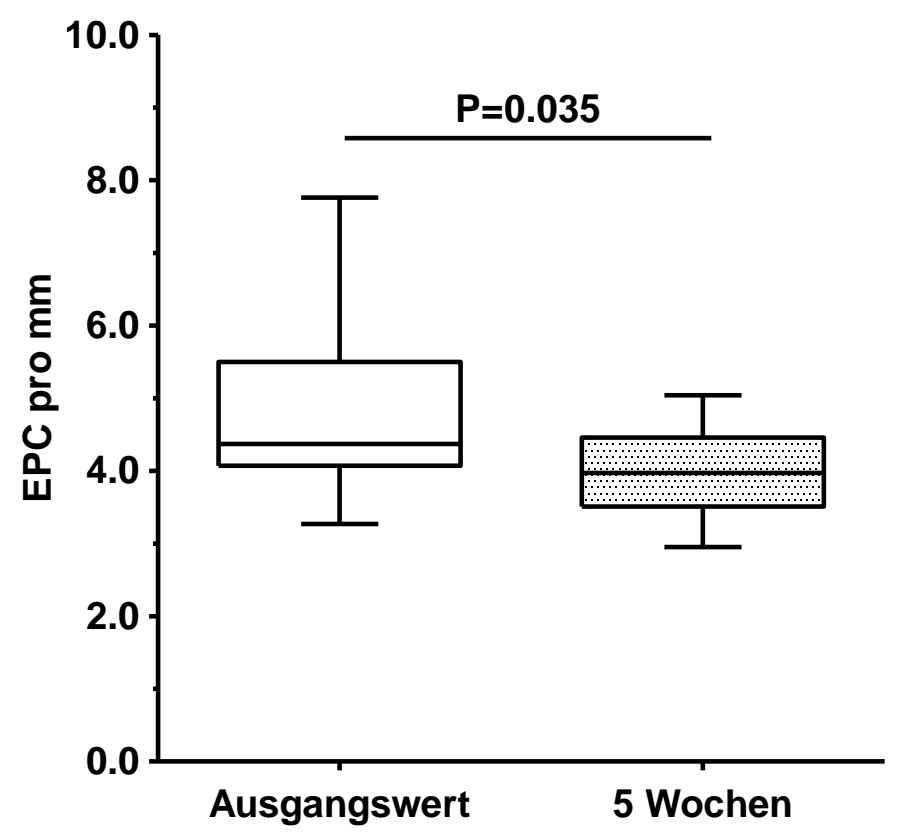

\subsubsection{Tabakentwöhnung reduziert die Expression von $\beta 1$ - und $\beta 2-$ Integrinuntereinheiten auf EPC}

Zur Klärung der Ursache der reduzierten EPC-Adhäsionskapazität nach Tabakentwöhnung untersuchten wir die Expression von Integrinen. Diese sind wichtige Rezeptoren zur Bindung von Zellen an extrazellulärer Matrix und spielen zudem eine Rolle bei Zell-ZellVerbindungen. Eine weitere Aufgabe besteht in der Signaltransduktion zwischen Zellen und extrazellulärer Matrix. Integrine bestehen aus zwei nicht kovalent verbundenen Transmembran-Glykoproteinen, die als $\alpha$ - und $\beta$ - Untereinheit bezeichnet werden. Derzeit sind etwa 24 verschiedene Integrin-Heterodimere identifiziert, welche sich aus $18 \alpha$ - und $8 \beta$ Untereinheiten zusammensetzen. Manche Integrine binden offenbar an mehr als einem Makromolekül. Andererseits können viele Matrixproteine wie z.B. Fibronektin auch von mehr als einem Integrin erkannt werden. 
Es wurden die Integrinuntereinheiten $\beta 1(\mathrm{CD} 29)$ und $\beta 2$ (CD18) zur Untersuchung ausgewählt, da deren Expression auf EPC bekannt ist (DEB et al. 2004; CHAVAKIS et al. 2005) und sie bekanntermaßen die Adhäsion von Zellen an Fibronektin (v.a. über $\alpha 5 \beta 1$ und $\alpha 4 \beta 1$ ) und Endothelzellen (mittels Interaktion mit ICAMs, v.a. über $\alpha \mathrm{L} \beta 2$ und $\alpha M \beta 2$ ) vermitteln (SCHROETER et al. 2008; PLOW et al. 2000).

Nach Tabakentwöhnung war die Expression der Integrinuntereinheiten $\beta 1$ und $\beta 2$ auf EPC von 27 Probanden zwar gering, aber signifikant reduziert. Die Anzahl der $\beta 1$-positiven Zellen sank im Mittel von 90\% auf $84 \%(p<0,001)$, die der $\beta 2$-positiven Zellen von 93\% auf $89 \%$ $(\mathrm{p}=0,007)(\mathrm{vgl}$. Abb. 9).

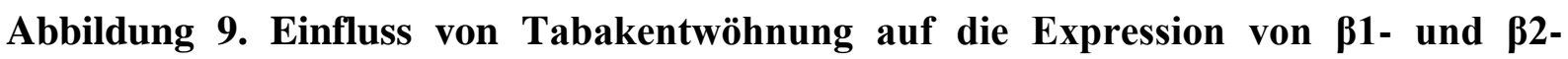
Integrinen auf EPC

9A) Quantitative Analyse von $\beta 1$

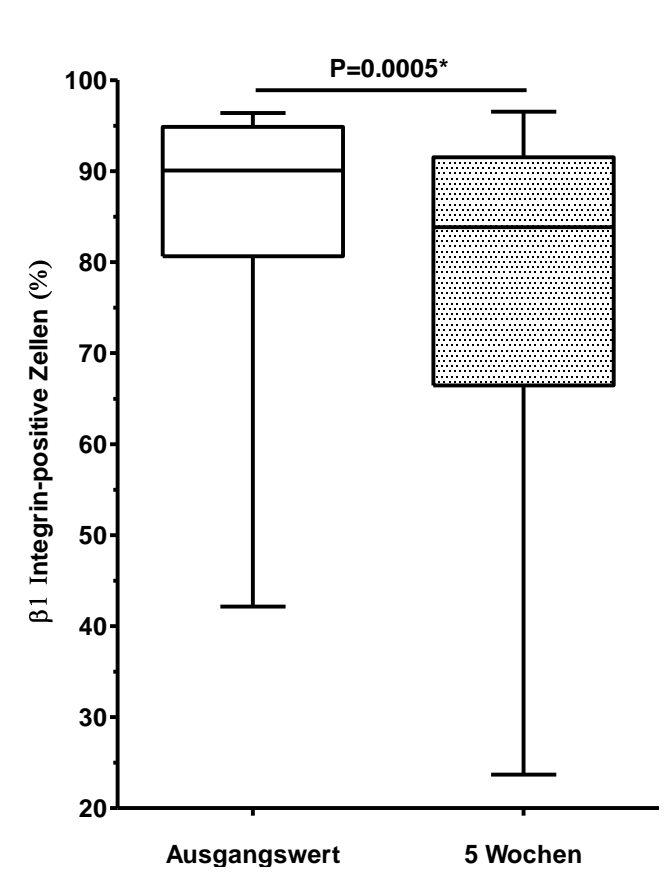

9B) Quantitative Analyse von $\beta 2$

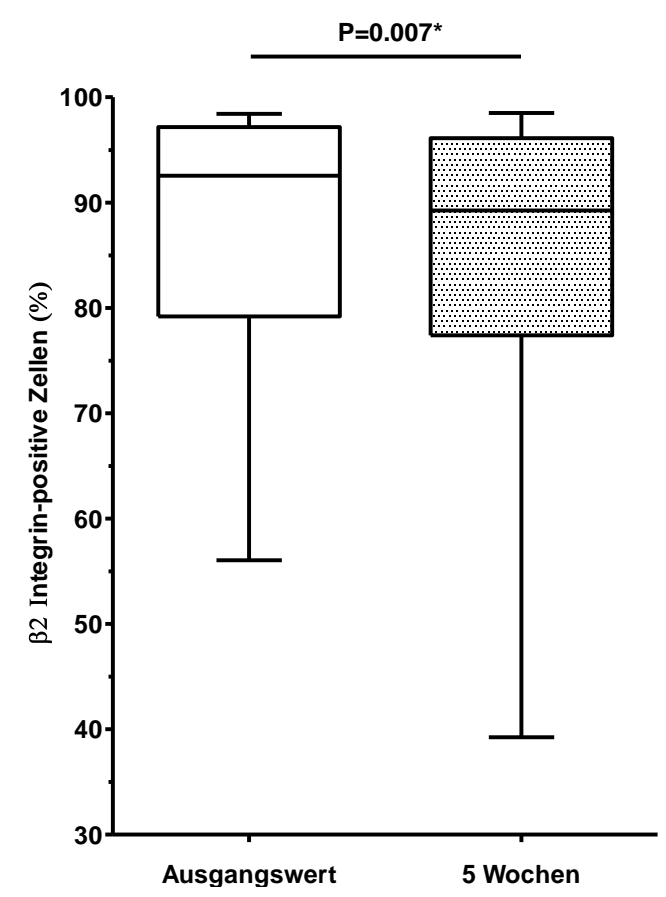




\subsection{Tabakentwöhnung reduziert reaktive Sauerstoffspezies (ROS) in EPC}

Zur Klärung der Hypothese, dass der Wegfall tabakrauchbedingten oxidativen Stresses möglicherweise $\mathrm{zu}$ einer verminderten Integrin-Expression führt, untersuchten wie das Vorkommen reaktiver Sauerstoffspezies (ROS) vor und nach Tabakentwöhnung in EPC.

Diese Untersuchungen ergaben, dass die Anzahl der EPC, in denen ROS nachgewiesen werden konnten, nach 5 Wochen gegenüber dem Ausgangswert signifikant geringer war $(\mathrm{n}=12 ; \mathrm{p}=0,007)(\mathrm{vgl}$. Abb. 10A und B $)$.

Abbildung 10. Einfluss von Tabakentwöhnung auf die Produktion von intrazellulärem ROS

10A) Repräsentative Dot Plots zeigen die Produktion von intrazellulärem ROS (Kopplung an den Fluoreszenzfarbstoff DCF)
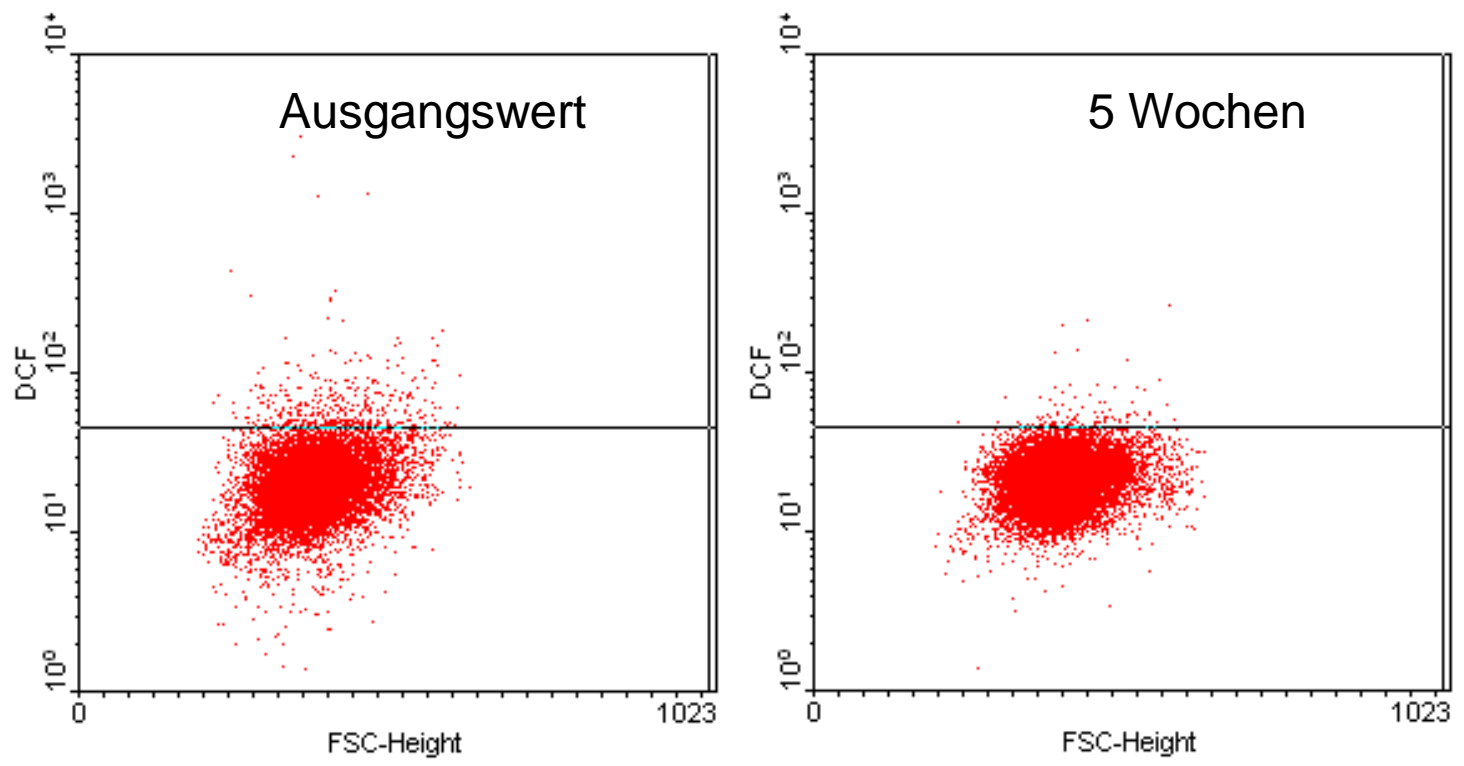


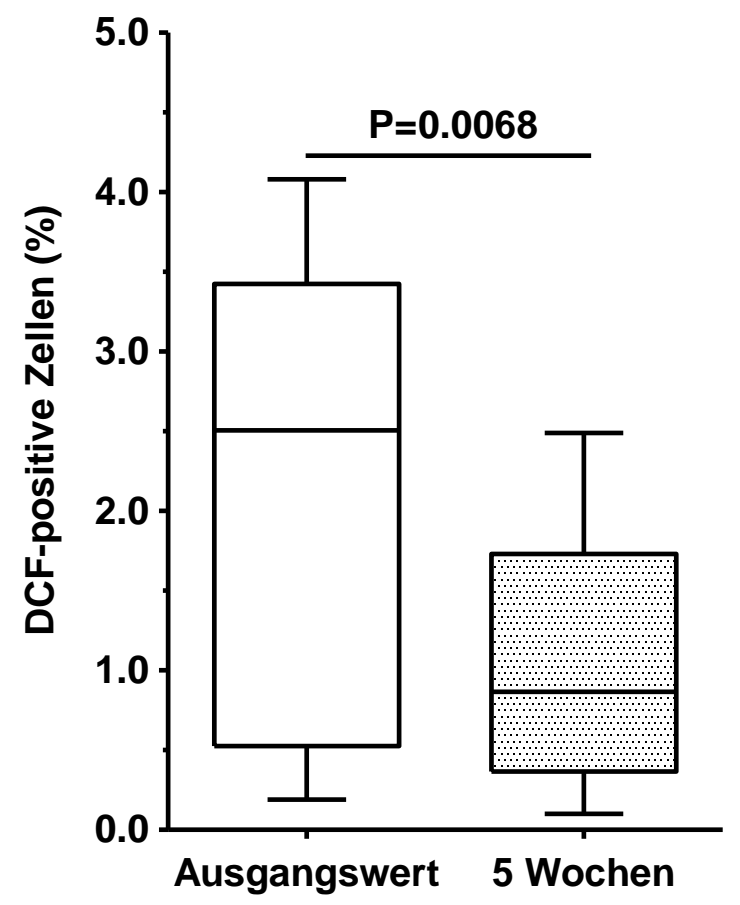

\subsection{Einfluss von Tabakentwöhnung auf verschiedene Plasmaparameter}

Wir bestimmten weiterhin verschiedene Plasmaparameter, die durch Unterhaltung einer inflammatorischen Reaktion zum oxidativen Stress beitragen und infolge Tabakentwöhnung verändert werden könnten.

Eine Untersuchung der Lipoproteine zeigte nach Tabakentwöhnung im Vergleich zum Kursbeginn signifikant niedrigere LDL-Cholesterin-Spiegel $(\mathrm{p}=0,0002)$, während sich das HDL-Cholesterin und die Triglyzeride nicht signifikant änderten (siehe Tab. 4). Die Konzentrationen des Akut-Phase-Proteins Fibrinogen lagen sowohl bei Kursende $(\mathrm{p}<0,0001)$ als auch 6 Monate später $(\mathrm{p}=0,004)$ signifikant unter den Ausgangswerten. Das als Risikofaktor bzw. Prädiktor für Atherosklerose bekannte hsCRP zeigte keine signifikante Veränderung. Die Anzahl der im peripheren Blut zirkulierenden Leukozyten sank dagegen infolge Tabakentwöhnung signifikant $(\mathrm{p}=0,004)$ (siehe Tab. 4). 
Tabelle 4. Einfluss von Tabakentwöhnung auf verschiedene Plasmaparameter

\begin{tabular}{|c|c|c|c|c|c|}
\hline & $\begin{array}{c}\text { Ausgangswert } \\
(\mathrm{n}=144)\end{array}$ & $\begin{array}{c}5 \text { Wochen } \\
(\mathrm{n}=144)\end{array}$ & $p_{1}$ & $\begin{array}{c}6 \text { Monate } \\
(\mathrm{n}=33)\end{array}$ & $p_{2}$ \\
\hline $\begin{array}{l}\text { LDL-Cholesterin, } \\
m g / d l\end{array}$ & $\begin{array}{c}133 \\
(113 \text { bis } 161)\end{array}$ & $\begin{array}{c}125 \\
(106 \text { bis } 151)\end{array}$ & 0,0002 & $\begin{array}{c}118 \\
(101 \text { bis } 155)\end{array}$ & 0,22 \\
\hline $\begin{array}{l}\text { HDL-Cholesterin, } \\
m g / d l\end{array}$ & $\begin{array}{c}57 \\
\text { (47 bis } 66)\end{array}$ & $\begin{array}{c}57 \\
(47 \text { bis } 70)\end{array}$ & 0,05 & $\begin{array}{c}49 \\
\text { (41 bis } 68)\end{array}$ & 0,13 \\
\hline Fibrinogen, $m g / l$ & $\begin{array}{c}359 \\
(295 \text { bis } 431)\end{array}$ & $\begin{array}{c}317 \\
(254 \text { bis } 411)\end{array}$ & $<0,0001$ & $\begin{array}{c}294 \\
(249 \text { bis } 479)\end{array}$ & 0,0082 \\
\hline hs-CRP, $m g / l$ & $\begin{array}{c}1,46 \\
(0,83 \text { bis } 3,91)\end{array}$ & $\begin{array}{c}1,52 \\
(0,89 \text { bis } 3,17)\end{array}$ & 0,163 & $\begin{array}{c}1,23 \\
(0,73 \text { bis } 2,42)\end{array}$ & 0,076 \\
\hline $\begin{array}{l}\text { Leukozyten, } \mathrm{x} \\
10^{6} / \mathrm{ml}\end{array}$ & $\begin{array}{c}8,4 \\
(7,1 \text { bis } 9,5)\end{array}$ & $\begin{array}{c}7,9 \\
(6,8 \text { bis } 8,9)\end{array}$ & 0,004 & $\begin{array}{c}6,9 \\
(6,1 \text { bis } 8,2)\end{array}$ & 0,08 \\
\hline
\end{tabular}

$P_{1}$, Vergleich zwischen Ausgangswert und Zeitpunkt 5 Wochen; $P_{2}$, Vergleich zwischen Ausgangswert und Zeitpunkt 6 Monate; Werte angegeben als Median, in Klammen die entsprechenden 25. und 75. Perzentilen. Statistische Analyse mittels Mann-Whitney-Test.

\subsubsection{Einfluss von Tabakentwöhnung auf ADMA-Konzentrationen}

Zusätzlich untersuchten wir das asymmetrische Dimethylarginin als frühen Biomarker der Atherosklerose. ADMA ist ein im Plasma zirkulierender kompetitiver Inhibitor der NOSynthase und somit letztlich ein Hemmer der endothelabhängigen Vasodilatation. Die im Plasma der Probanden gemessenen ADMA-Spiegel waren nach Tabakentwöhnung gegenüber dem Ausgangswert signifikant erniedrigt $(0,64(0,58$ bis 0,75$)$ vs. $0,62(0,55$ bis 0,71$)$; $\mathrm{p}=0,003)($ vgl. Abb. 11). 
Abbildung 11. Einfluss von Tabakentwöhnung auf ADMA-Spiegel im Plasma

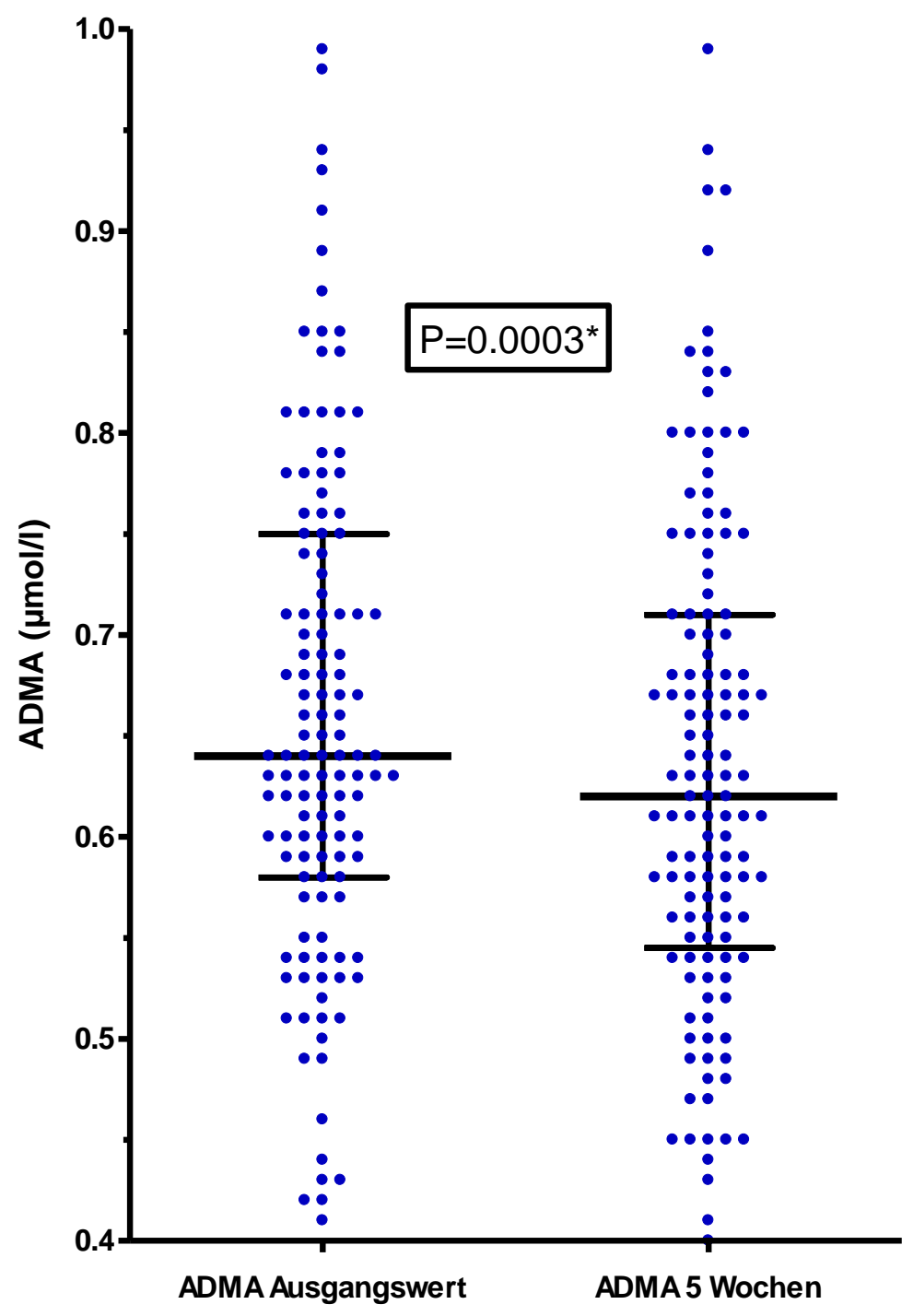




\section{Diskussion}

Tabakkonsum gehört zu den führenden Ursachen vermeidbarer Todesfälle, und der negative Einfluss insbesondere auf das Herzkreislaufsystem ist bekannt. Tabakentwöhnung hingegen führt zu einer deutlichen Reduktion der kardiovaskulär bedingten Mortalität (VAN BERKEL et al. 1999; CRITCHLEY und CAPEWELL 2003).

Ein Zusammenhang zwischen dem Vorhandensein kardiovaskulärer Risikofaktoren, einschließlich Rauchen, und einer reduzierten Anzahl zirkulierender EPC wurde bereits aufgezeigt (VASA et al. 2001 a; HILL et al. 2003). Auch wurden die EPC gesunder Raucher mit denen von gesunden Nichtrauchern verglichen (MICHAUD et al.2006). Bislang wurde jedoch erst eine Studie zum Einfluss von Tabakentwöhnung auf zirkulierende EPC veröffentlicht, wobei allerdings keine funktionellen Eigenschaften untersucht wurden (KONDO et al. 2004).

\subsection{Der Einfluss von Tabakentwöhnung auf die Anzahl zirkulierender EPC}

In der der vorliegenden Arbeit vorausgegangenen Untersuchung unserer Arbeitsgruppe (PULS et al. 2011) wurde wie in der Publikation von KONDO et al. (2004) der Einfluss einer Tabakentwöhnung auf die Anzahl zirkulierender EPC (in unserer Arbeit definiert als CD34 ${ }^{+}$ VEGFR2 ${ }^{+}$- oder CD $34^{+}$-CD $133^{+}$-Zellen) mittels FACS-Analyse untersucht. Es kam hier nicht zu einer signifikanten Änderung der so charakterisierten Zellen, während Kondo et al. eine signifikante Zunahme zirkulierender $\mathrm{CD} 45^{\text {low }}-\mathrm{CD} 34^{+}-\mathrm{CD} 133^{+}-$Zellen fanden. Zum einen muss betont werden, dass auch Kondo et al. keinen signifikanten Effekt mehr sahen, wenn sie VEGFR2 als zusätzlichen endothelzellspezifischen Marker hinzunahmen. Zum anderen wurden die beiden Studien an durchaus unterschiedlichen Kollektiven durchgeführt. In der hier vorliegenden Studie handelte es sich um reale Teilnehmer eines Tabakentwöhnungsprogramms unserer Klinik und damit nicht nur um gesunde Probanden, sondern auch um Patienten mit bereits bestehenden kardiovaskulären Risikofaktoren oder Erkrankungen. Zudem nahm ein Viertel unserer untersuchten Personen antidiabetische, antihypertensive oder cholesterinsenkende Medikamente ein. Von allen genannten Faktoren ist bekannt, dass sie isoliert betrachtet einen Einfluss auf Anzahl und Funktion der EPC haben. Die Tatsache, dass die Werte eines Individuums vor und nach Tabakentwöhnung miteinander verglichen und 
keine weiteren Parameter verändert wurden, gibt die größtmögliche Sicherheit, dass die gefundenen Unterschiede tatsächlich auf die Tabakentwöhnung zurückzuführen sind.

Weitere Untersuchungen zur Anzahl zirkulierender EPC vor und nach Tabakentwöhnung finden sich in der Literatur nicht. Dagegen liegen mehrere Untersuchungen vor, die diese Zellen bei Rauchern und Nichtrauchern vergleichen und $\mathrm{zu}$ durchaus unterschiedlichen Ergebnissen kommen.

Während VASA et al. (2001 a) eine signifikant geringere Anzahl CD34 ${ }^{+}$-VEGFR2 ${ }^{+}$-Zellen bei Rauchern im Vergleich zu Nichtrauchern fanden, konnten HILL et al. (2003) diesbezüglich keine signifikanten Unterschiede finden, während WERNER et al. (2005) sogar höhere EPC-Zahlen bei Rauchern fanden. Insgesamt muss jedoch betont werden, dass die Zielsetzung der vorliegenden Arbeit in der Untersuchung derselben Individuen vor und nach Tabakentwöhnung bestand und die Ergebnisse daher nicht direkt mit denen der oben genannten Arbeiten verglichen werden können.

\subsection{Ist die endotheliale Physiologie eines Rauchers direkt nach Tabakentwöhnung derjenigen eines Nichtrauchers gleichzusetzen?}

Verschiedene bereits veröffentlichte Untersuchungen legen nahe, dass dies nicht der Fall ist. CELERMAJER et al. (1993) verglichen beispielsweise die Endothelfunktion von Nichtrauchern, aktuellen Rauchern und ehemaligen Rauchern. Dabei kamen sie zu dem Ergebnis, dass die endothel-abhängige Vasodilatation ehemaliger Raucher sogar 6 Jahre nach Tabakentwöhnung noch nicht wieder das Niveau von Nichtrauchern erreicht hatte. Dieses legt den Schluss nahe, dass auch Zellen endothelialen Charakters von Nichtrauchern und ehemaligen Rauchern nicht direkt vergleichbar sind.

Weiterhin zeigten WANNAMETHEE et al. (2005), dass sich erst nach über 20 Jahren die Plasmaspiegel inflammatorischer Marker sowie hämatologischer Parameter von Exrauchern denen von Nichtrauchern angeglichen hatten. 


\subsection{Der Einfluss von Tabakentwöhnung auf die Anzahl kultivierbarer acLDL ${ }^{+}$-lectin ${ }^{+}$ Zellen (,early outgrowth EPC“) und deren Adhäsionseigenschaften}

Als weitere Vorarbeit zur hier vorliegenden Untersuchung konnte in unserer Arbeitsgruppe eine Reduktion der Anzahl kultivierbarer acLDL ${ }^{+}$-lectin ${ }^{+}$-Zellen nach Tabakentwöhnung gezeigt werden (PULS et al., 2011). Da dieser Befund wie bereits dargelegt nicht auf eine reduzierte Proliferation der Zellen nach Entwöhnung zurückzuführen war, folgten wir der Hypothese, dass die reduzierte Kultivierbarkeit möglicherweise in einem veränderten Adhäsionsverhalten der EPC begründet ist. Die vorliegende Studie untersuchte somit erstmalig den Einfluss von Tabakentwöhnung auf das Adhäsionsverhalten kultivierbarer EPC, wobei dieselben Individuen vor und nach Tabakentwöhnung verglichen wurden. Dabei konnte eine reduzierte Adhäsion acLDL ${ }^{+}$-lectin ${ }^{+}$-Zellen an Fibronektin und an TNF- $\alpha$-aktivierten HUVEC sowie eine reduzierte Inkorporation in kapillarähnliche Netzwerke nach Tabakentwöhnung gezeigt werden.

Alle Untersuchungen, die sich bisher mit den funktionellen Eigenschaften von EPC in Abhängigkeit vom Tabakkonsum beschäftigten, konzentrierten sich auf den Vergleich von Rauchern mit Nichtrauchern. So verglichen MICHAUD et al. (2006) neben der Anzahl auch die funktionellen Eigenschaften der EPC von 15 gesunden Rauchern mit denen von 11 Nichtrauchern. In diesen Untersuchungen zeigten die EPC der Raucher eine geringere Adhäsion an HUVEC sowie eine geringere Inkorporation in kapillare Netzwerke im Matrigel ${ }^{\mathrm{TM}}$-Assay, was im Widerspruch zu unserer Untersuchung zu stehen scheint. Es muss jedoch erneut betont werden, dass ein Vergleich zwischen Rauchern und Nichtrauchern nicht demjenigen zwischen Rauchern vor und nach Tabakentwöhnung gleichzusetzen ist. Außerdem untersuchten Michaud et al. gesunde Probanden ohne weitere Risikofaktoren oder Medikamenteneinnahme, die in den 10 Stunden vor der Blutentnahme nicht mehr rauchen, essen oder trinken durften, während unser Kollektiv - wie bereits ausgeführt - deutlich heterogener war. Weiterhin führten Michaud et al. ihre Versuche an Zellen nach viertägiger Kultivierung durch, die sich somit in Antigenexpression und funktionellen Eigenschaften wie z.B. der Proliferationsfähigkeit von den in der vorliegenden Studie untersuchten sieben Tage alten Zellen unterscheiden. 


\subsection{Untersuchungen zum Verhalten von Monozyten bei Rauchern}

Im Einklang mit der von uns gefundenen vor Tabakentwöhnung größeren Adhäsionsfähigkeit von EPC, die wie beschrieben von Monozyten abstammen und daher sowohl monozytäre als auch endothelzellartige Eigenschaften besitzen, beschreiben verschiedene Studien einen Zusammenhang von Zigarettenrauch und erhöhter Adhäsion von Monozyten. So zeigten Monozyten von Rauchern in Abhängigkeit von der Menge des Tabakkonsums eine größere Adhärenz an HUVEC als die Zellen nicht-rauchender Kontrollen (DOVGAN et al. 1994). Ebenso adhärierten Monozyten, die zuvor mit cigarette smoke condensate behandelt worden waren, stärker an einem Endothelzellmonolayer als nicht vorbehandelte Zellen (KALRA et al. 1994). Ergänzend dazu zeigten SHEN et al. (1996) eine durch cigarette smoke condensate hochregulierte Expression der Zelladhäsionsmoleküle ICAM-1 (intracellular adhesion molecule 1), ELAM-1 (endothelial cell adhesion molecule 1) und VCAM-1 (vascular cell adhesion molecule 1) in HUVEC.

Eine erhöhte Konzentration des löslichen Adhäsionsrezeptores sICAM-1 beschrieben BERGMANN et al. (1998) selbst bei moderatem Zigarettenkonsum. Der exprimierte Adhäsionsrezeptor ICAM-1 wird infolge inflammatorischer Stimuli ,abgeworfen“, wobei er jedoch aktiv bleibt, und kann so im Plasma das Ausmaß der Aktivierung anzeigen. Im Zusammenhang mit der vorliegenden Studie zu Adhäsion und Tabakentwöhnung besonders interessant sind die Untersuchungen von SCOTT et al. (2000). Sie zeigten nicht nur eine dosisabhängige Erhöhung von sICAM-1 bei Rauchern, sondern fanden zudem auch einen signifikanten Abfall von sICAM-1 nach einjähriger Tabakabstinenz.

\subsection{Adhäsion an das Endothel wird über Integrine vermittelt}

Um eine Erklärung für das veränderte Adhäsionsverhalten kultivierbarer EPC nach Raucherentwöhnung zu finden, untersuchten wir die Expression von Integrinen vor und nach Tabakentwöhnung.

Integrine gehören zur Gruppe der Zelladhäsionsmoleküle und sind maßgeblich für die Bindung zirkulierender Zellen am Endothel und ihre anschließende Migration ins Subendothelium. Dabei kommt der Regulierung ihrer Aktivität eine entscheidende Rolle zu, da viele Integrine zwar auf der Zelloberfläche exprimiert werden, dabei allerdings in einer Art „OFF-Modus“ verharren, in dem sie weder binden noch Signale weiterleiten. So werden 
beispielsweise $\beta 2$-Integrine auf Leukozyten erst durch bestimmte Stimuli wie Zytokine aktiviert und dazu befähigt, an der Gefäßwand zu adhärieren (HYNES 2002). Den Untersuchungen von CHAVAKIS et al. (2005) zufolge spielen $\beta 2$-Integrine zudem eine entscheidende Rolle bei Neovaskularisationsprozessen, da sie neben der Zell-Zell- und ZellMatrix-Bindung auch an der Rekrutierung von EPC in ischämisches Gewebe beteiligt sind. Auch WU Y et al. (2006) zeigten, dass $\beta 2$-Integrine durch Rekrutierung von EPC und nachfolgende Angiogenese an der Revaskularisation in der ischämischen Randzone von Myokardinfarkten maßgeblich beteiligt sind.

In der vorliegenden Studie konnte mittels FACS-Analyse gezeigt werden, dass die Expression von $\beta 1$ - und $\beta 2$ - Integrinen nach Tabakentwöhnung signifikant geringer war als vor Studienbeginn. Dieser Befund könnte eine mögliche Erklärung der reduzierten Adhäsion der EPC an Fibronektin und Endothelzellen nach Tabakentwöhnung darstellen. Allerdings scheint die Änderung der Integrinexpression zu gering, um als alleinige Erklärung angenommen zu werden. Integrinabhängige Adhäsion ist jedoch nicht nur von der Anzahl exprimierter Rezeptoren, sondern auch von deren Affinität für spezifische Liganden abhängig.

\subsection{Einfluss von tabakbedingtem oxidativen Stress auf die Adhäsionsfähigkeit von EPC sowie auf Expression und Funktion der Integrine}

Durch Tabakkonsum ausgelöster fortgesetzter oxidativer Stress verursacht eine leichte chronische Entzündungsreaktion, wie bereits anhand erhöhter Leukozytenzahlen sowie CRPKonzentrationen bei Rauchern belegt werden konnte (YANBAEVA et al. 2007; WANNAMETHEE et al. 2005, PULS et al. 2011).

Kürzlich wurde die Rolle von EPC in einer Entzündungssituation näher untersucht. Es zeigte sich zum einen, dass eine Stimulierung mit TNF- $\alpha$ zu einer Hochregulierung verschiedener Adhäsionsmoleküle auf den EPC führte, und zum anderen EPC selbst verschiedene proinflammatorische Zytokine parakrin sezernierten, welche am atherosklerotischen Geschehen beteiligt sind (ZHANG Y et al. 2009). Diese Ergebnisse zeigen, dass EPC neben ihrem Potential zur Reparation endothelialer Läsionen und Revaskularisation ischämischer Gewebe außerdem durch die Sekretion proinflammatorischer Substanzen zu einer Entzündungssituation weiter beitragen können und so z.B. negativen Einfluss auf die Progression eines atherosklerotischen Plaques haben können. 
Des Weiteren liefern die Untersuchungen von WEBER et al. (1996) Hinweise auf die Beteiligung von ROS. Sie fanden signifikant geringere Vitamin C-Spiegel bei Rauchern im Vergleich zu Nichtrauchern, welche durch die orale Einnahme von 2 g Vitamin C für zehn Tage auf die Werte von Nichtrauchern angehoben werden konnten. Ferner war die erhöhte Monozyten-Adhäsion bei Rauchern durch die Vitamin C-Einnahme reversibel und sank auf Werte vergleichbar mit denen von Nichtrauchern, wohingegen das Adhäsionsverhalten der Monozyten von Nichtrauchern durch die Vitamineinnahme nicht beeinflusst wurde. Demzufolge könnte der Radikalfänger Vitamin C die schädlichen ROS bei Rauchern neutralisieren.

In Bezug auf die hier vorliegende Studie könnte vermutet werden, dass die verminderte Adhäsionsfähigkeit der EPC nach Tabakentwöhnung auf einer Reduktion des oxidativen Stresses mit der Folge einer verminderten Expression und Ligandenaffinität der Integrine beruhen könnte.

\subsection{Oxidativer Stress und EPC}

Endotheliale Progenitorzellen gehören zur Gruppe der adulten Stammzellen und besitzen große regenerative Kapazität. $\mathrm{Zu}$ ihrem Antigenmuster gehört eine Reihe sogenannter „stemness"-Gene, die ihnen z.B. durch Hochregulation von DNA-Reparaturmechanismen und detoxifizierenden Systemen zu einer besonders hohen Resistenz gegenüber oxidativem Stress verhelfen (DERNBACH et al. 2004). So liegt die basale Konzentration von ROS in EPC bereits niedriger als in HUVEC und CD14+-Monozyten, und es zeigte sich bei EPC eine geringere Sensitivität gegenüber einer ROS-induzierten Apoptose. Des Weiteren ist die Expression der intrazellulären antioxidativen Enzyme Katalase, Glutationperoxidase und Manganase-Superoxid-Dismutase bei EPC im Vergleich zu HUVEC signifikant höher. Diese besondere „Stress-Resistenz“ der EPC scheint zum Überleben und zur Beteiligung an Reparaturprozessen in atherosklerotischen oder inflammatorischen Gebieten wichtig zu sein. Besonders interessant sind die von DERNBACH et al. (2004) gelieferten Hinweise, dass erhöhte ROS-Spiegel auch Einfluss auf die funktionellen Eigenschaften von EPC haben: Die Blockade der antioxidativen Enzyme in den EPC führte zu einem signifikant eingeschränkten Migrationsvermögen in Richtung VEGF.

Zahlreiche weitere in-vitro-Untersuchungen und auch klinische Studien liefern Hinweise, dass die Mobilisation und Biologie von EPC durch oxidativen Stress und Entzündungsmediatoren 
beeinflusst wird. TOUSOULIS et al. (2008) geben in ihrem Review einen Überblick über die publizierten Untersuchungen und gelangen zu der Bewertung, dass eine vorübergehende und begrenzte (als „low-grade“ bezeichnete) Entzündung und eine dauerhafte, exzessive (als „high-grade“ bezeichnete) Entzündung möglicherweise unterschiedlichen Einfluss auf EPC haben. Sie sehen Hinweise, dass eine inflammatorische Situation zu einer Einschränkung der funktionellen Kapazität von EPC führt, während sie eine Art „dual-role“ in der Mobilisierung spielt. Demnach stimuliert eine „low-grade“ Entzündung (wie z.B. eine Koronarsklerose) die Freisetzung von EPC aus dem Knochenmark, während eine „high-grade“ Entzündung (wie z.B. eine Herzinsuffizienz) einen gegenteiligen Effekt hat und somit zu einer erniedrigten Anzahl zirkulierender EPC führt. Wenngleich die zugrundeliegenden Mechanismen der Regulation noch nicht bekannt sind, stellen Tousoulis et al. die Hypothese einer „Erschöpfungssituation“ auf. Demnach mündet die anhaltende inflammatorische Stimulation des Knochenmarks in einer Erschöpfung des EPC-Pools und führt letztlich zu der Ausschüttung einer geringeren Anzahl von unreiferen, funktionell eingeschränkten EPC.

Des Weiteren sehen TOUSOULIS et al. (2008) eine Einschränkung der Mobilisation und Funktion als Folge von oxidativem Stress. Neben dem direkten zytotoxischen Effekt von ROS auf EPC (hohe $\mathrm{H}_{2} \mathrm{O}_{2}$-Spiegel induzieren Apoptose) stellen Tousoulis et al. eine Reihe von Mechanismen zusammen, wie oxidativer Stress indirekt zu einer Beeinflussung der Biologie von EPC führt. Dazu gehören die Reaktion von Superoxid und NO zu dem starken Oxidant Peroxynitrit Anion $\left(\mathrm{ONOO}^{-}\right)$und die infolge von oxidativem Stress veränderte Enzymatik von eNOS. Letztendlich ziehen Tousoulis et al. die Schlussfolgerung, dass Entzündung und oxidativer Stress, welche in der Pathophysiologie der Atherosklerose eng miteinander verknüpft sind, zum Teil gegensätzliche Einflüsse auf Anzahl und funktionelle Kapazität von EPC haben können.

Insgesamt ist aus der Literatur ersichtlich, dass oxidativer Stress offensichtlich funktionelle Eigenschaften von EPC beeinflusst, dass die Vorgänge jedoch komplex sind und sich der Effekt möglicherweise „dosisabhängig“ umkehrt. 


\subsection{Tabakentwöhnung reduziert oxidativen Stress}

Die enge Beziehung zwischen Entzündungsreaktion und oxidativem Stress wurde von GUZIK et al. (2003) ausführlich beschrieben. Demzufolge sind inflammatorische Marker und Marker von oxidativem Stress eng miteinander verknüpft und gemeinsam zu interpretieren.

Wir konnten zeigen, dass es infolge der Tabakentwöhnung zu einer signifikanten Reduktion inflammatorischer Marker wie z.B. der Leukozytenzahlen, des Fibrinogen und des ADMA im Plasma der Studienteilnehmer kam.

Erhöhte ADMA-Spiegel gelten als unabhängige Prädiktoren verschiedener kardiovaskulärer Erkrankungen. Darüber hinaus wurde eine positive Korrelation zwischen dem ADMASpiegel im Plasma und dem Vorliegen kardiovaskulärer Risikofaktoren gezeigt (MIYANZAKI et al. 1999). Dazu gehört auch der Konsum von Tabak: ZHANG WZ et al. (2006) fanden $80 \%$ höhere Plasmakonzentrationen von ADMA bei Rauchern im Vergleich zu Nichtrauchern.

Die Aktivitäten der ADMA regulierenden Enzyme PRMT (proteine arginine Nmethyltransferase, type I) und DDAH (dimethylarginine dimethylaminohydrolase) sind redoxsensitiv und führen unter dem Einfluss von ROS zu erhöhten ADMA-Konzentrationen. Demnach sind erhöhte ADMA-Spiegel im Blut eine Folge von oxidativem Stress. Ferner könnte ADMA über einen als „uncoupling“ bezeichneten Prozess der eNOS selbst zur Generierung von ROS beitragen. Dabei wird die Enzymatik von eNOS so verändert, dass diese letztlich selbst Radikale in Form von Superoxiden bildet und eine Art Negativspirale in Gang gesetzt wird (FÖRSTERMANN und MÜNZEL 2006).

Die Messung von intrazellulär gebildetem ROS stellt eine direkte Analyse von oxidativem Stress dar. In unserer Studie sank die Generierung von intrazellulärem ROS in den kultivierbaren EPC infolge der Tabakentwöhnung signifikant. Auch MICHAUD et al. (2006) fanden höhere ROS-Spiegel bei Rauchern im Vergleich zu Nichtrauchern, wodurch insgesamt nahegelegt wird, dass das Zigarettenrauchen eine wichtige Ursache der Generierung von intrazellulärem ROS ist.

Die nachgewiesene Reduktion des oxidativen Stresses bei unseren Studienteilnehmern könnte maßgeblich zur verminderten Adhäsionsfähigkeit der EPC infolge veränderter Integrinexpression sowie möglicherweise verminderter Ligandenaffinität beigetragen haben. 


\section{Ausblick}

\subsection{Erhöhter „EPC-Bedarf“ in der Peripherie als möglicher Erklärungsansatz der höheren EPC-Zahlen vor Tabakentwöhnung?}

Zigarettenrauch ist ein komplexes Aerosol, das neben den relativ gut untersuchten Stoffen Kohlenstoffmonoxid und Nikotin wohl mehrere tausend, zum Teil noch nicht identifizierte und somit noch nicht untersuchte, Substanzen enthält. Das inhalierte Kohlenstoffmonoxid reagiert im Blut mit Hämoglobin zu Carboxyhämoglobin und behindert so den Sauerstofftransport im Blut. Die bei Rauchern gemessenen Level von Carboxyhämoglobin liegen bei etwa 5-10\%, schwanken jedoch stark, abhängig davon, wann und wie viel zuletzt geraucht wurde. Auch wenn das CO des Zigarettenrauchs selbst offenbar auf die Entstehung bzw. Progression von atherosklerotischen Läsionen keinen Einfluss hat (SMITH und FISCHER 2001), führt das Carboxyhämoglobin zu einer Hypoxie, welche ein potenter Stimulus zur Mobilisierung und Rekrutierung von EPC ist. Nach Tabakentwöhnung könnte es somit über eine Reduktion des Carboxyhämoglobins und damit der Gewebehypoxie zu einer reduzierten EPC-Mobilisation kommen. Diese Hypothese könnte Grundlage weiterführender Untersuchungen sein.

Auch das Nikotin selbst, das für die psychoaktivierende Wirkung und das Suchtpotential des Tabaks verantwortlich ist, könnte einen Einfluss auf die EPC-Mobilisation ausüben. HEESCHEN et al. (2001) konnten mit in-vivo-Studien zeigen, dass systemisch verabreichtes Nikotin im Rahmen eines entzündlichen, ischämischen, tumorösen oder atherosklerotischen Geschehens die Angiogenese fördert. Demnach kann Nikotin über eine verstärkte Neovaskularisation eines atherosklerotischen Plaques auch zu dessen Progression und späterer Ruptur beitragen. Spätere Arbeiten belegten, dass die Mobilisation von EPC Teil des proangiogenetischen Effektes des Nikotins ist (HEESCHEN et al. 2006).

In in-vitro-Versuchen mit EPC bewirkte Nikotin eine dosisabhängige Verstärkung der Mobilisation (WANG et al. 2004). Dabei zeigten Nikotinspiegel, die mit denen im Blut von Rauchern vergleichbar waren, die größte Wirkung, während sehr hohe Spiegel zytotoxisch wirkten.

In unserer Studie nutzten allerdings etwa $70 \%$ der Probanden nach Tabakentwöhnung Nikotinersatzprodukte, was jedoch keinen Einfluss auf die Anzahl kultivierbarer acLDL ${ }^{+}$ 
lectin ${ }^{+}$-Zellen hatte, so dass wir das Nikotin selbst nicht als das auslösende Agens der gefundenen Veränderungen betrachten.

\subsection{Limitationen der Studie}

Wenngleich die hier vorliegende Untersuchung interessante Ergebnisse aufzeigen kann, sind doch einige Limitationen der Studie zu benennen.

Mit insgesamt 144 Personen konnte eine relativ große Probandenzahl in die Studie eingeschlossen werden. Allerdings konnten die funktionellen Experimente nicht mit den Zellen aller 144 Teilnehmer durchgeführt werden, sondern nur jeweils mit denen eines Teils des Gesamtkollektivs. Der Hauptgrund dafür liegt in der begrenzten Anzahl von EPC, die aus den entnommenen $27 \mathrm{ml}$ Venenblut gewonnen werden konnten, und der Anzahl der für die entsprechenden Versuche benötigten Zellen. Darüber hinaus war es technisch nicht möglich, mehrere Versuche zeitgleich durchzuführen. Daher wurden die Probanden randomisiert und ohne vorherige Selektion auf die verschiedenen Versuche aufgeteilt. Wie bereits gezeigt, bestanden jedoch zwischen den Subgruppen keine Unterschiede bezüglich der klinischen Charakteristika.

Ein weiterer möglicher Kritikpunkt ist die relativ kurze Zeitspanne von nur 5 Wochen zwischen den Untersuchungen. Welcher Zeitraum zur Detektion funktioneller EPCVeränderungen infolge Tabakentwöhnung ideal ist, lässt sich aus der Literatur nicht erschließen. Andere Studien, die den Einfluss von Präventionsstrategien zur kardiovaskulären Risikoreduktion auf die Anzahl und Funktion von EPC untersuchten, zeigten messbare Unterschiede zu sehr unterschiedlichen Zeitpunkten im Anschluss an die Intervention (von wenigen Minuten bis hin zu mehreren Monaten oder Jahren). Dazu gehörten beispielsweise der Einfluss von körperlicher Aktivität (REHMAN et al. 2004), die Einnahme von HMGCoA-Reduktase-Hemmern (VASA et al. 2001b) sowie die Gewichtsabnahme bei Übergewicht (MULLER-EHMSEN et al. 2008).

Die Zeitpunkte der Untersuchungen ergaben sich in der vorliegenden Studie aus der Dauer des Tabakentwöhnungskurses, im Rahmen dessen die Teilnehmer am ersten und am letzten Kurstag aufgesucht wurden. Auf diese Weise wurde versucht, die ohnehin relativ große Ausfallquote möglichst gering $\mathrm{zu}$ halten. Der Versuch, einen Langzeiteffekt der 
Tabakentwöhnung nach sechs Monaten zu untersuchen, stellte sich aufgrund geringer Compliance als äußerst schwierig heraus. Von den 144 erneut kontaktierten Probanden waren lediglich $56 \mathrm{zu}$ einer erneuten Teilnahme an dem Projekt bereit. Allerdings rauchten mittlerweile $23(41 \%)$ dieser Probanden wieder und wurden so von weiteren Analysen ausgeschlossen. Mit den Zellen der 33 verbliebenen weiterhin tabakabstinenten Probanden wurden dann exakt die gleichen Versuche wie zu Kursbeginn und nach fünf Wochen durchgeführt. Letztlich war die Anzahl der in den einzelnen Experimenten untersuchten Probanden jedoch zu gering, um zu aussagekräftigen Ergebnissen zu gelangen. Lediglich die Untersuchungen zum Adhäsionsvermögen an Fibronektin konnten nach 6-monatiger Tabakabstinenz bei 10 Probanden wiederholt werden, wobei sich der nach 5 Wochen gezeigte Effekt bestätigte.

Des Weiteren wäre eine Kontrollgruppe bestehend aus Rauchern, die ihr Rauchverhalten nicht änderten, zur Unterstützung der Ergebnisse wünschenswert gewesen. Die Gruppe der Probanden, die am Ende des fünfwöchigen Kurses entsprechend der zuvor festgelegten Definition weiterhin Raucher waren, erfüllte allerdings nicht die Anforderungen einer geeigneten Kontrollgruppe. $\mathrm{Zu}$ viele Probanden hatten nicht konstant weiter geraucht, sondern nach anfänglicher Tabakabstinenz wieder mit dem Rauchen begonnen oder in verschiedenen Zeiträumen unterschiedlich viel Tabak konsumiert.

Zum Ausschluss methodischer Fehler war zuvor das Adhäsionsverhalten von EPC an Fibronektin bei 10 gesunden Nichtrauchern und 10 gesunden Rauchern (Probanden, die nicht am Entwöhnungsprogramm teilnahmen) jeweils mit einem Zeitabstand von 5 Wochen untersucht worden, wobei sich keine Veränderungen gezeigt hatten.

Letztlich handelt es sich bei der vorliegenden Studie um eine Analyse der funktionellen Eigenschaften von EPC vor und nach Tabakentwöhnung ex vivo. Dabei bleibt offen, ob sich die ex vivo gezeigten Veränderungen in einem veränderten Mitwirken von EPC an Gefäßreparaturprozessen in vivo widerspiegeln würden. Die Untersuchung des Einflusses von Tabakentwöhnung auf klinische Aspekte, wie beispielsweise die Reduktion des kardiovaskulären Risikos, war jedoch nicht Ziel dieser Studie.

In diesem Sinne ist es auch wichtig zu unterstreichen, dass unsere Ergebnisse keinesfalls so interpretiert werden sollten, dass der anerkannte Nutzen von Tabakentwöhnung in Frage 
gestellt wird. Tabakentwöhnung ist zur primären und sekundären Prävention von Herzkreislauferkrankungen von außerordentlicher Bedeutung.

Vielmehr zeigen unsere Ergebnisse, dass der Einfluss von Tabakkonsum und Tabakentwöhnung auf das Zusammenspiel zwischen Mobilisierung von EPC aus dem Knochenmark, Adhäsion an Matrixproteinen und Reendothelialisierungsprozessen viel zu komplex ist, als dass sie auf veränderte Zahlen zirkulierender oder adhärierender Zellen reduziert werden könnten. Es besteht daher weiterer Forschungsbedarf hinsichtlich eines möglichen Anteils der EPC am positiven Einfluss von Tabakentwöhnung auf kardiovaskuläre Erkrankungen. Zukünftige Untersuchungen könnten beispielsweise klären, wie systemische Entzündungsreaktionen und lokale Gefäßverletzungen die Rekrutierung und Funktion von EPC beeinflussen und welche Rolle der Wegfall „aktivierender“ Stimuli wie z.B. Tabakkonsum dabei spielt. 


\section{Zusammenfassung}

Tabakkonsum ist die führende Ursache vermeidbarer Todesfälle in der westlichen Welt und der positive Einfluss von Tabakentwöhnung auf Morbidität und Mortalität ist bekannt.

Endotheliale Progenitorzellen sind an Reparatur- und Angiogeneseprozessen in den Gefäßen beteiligt und können durch kardiovaskuläre Risikofaktoren in Anzahl und Funktion beeinflusst werden.

Die vorliegende Arbeit untersucht nun erstmalig den Einfluss von Tabakentwöhnung auf die funktionellen Eigenschaften von EPC und baut damit auf vorangegangenen Untersuchungen auf, die bei gleicher Anzahl zirkulierender CD34+-VEGF-R2 ${ }^{+}$- doppelt positiver Zellen eine reduzierte Anzahl kultivierbarer acLDL ${ }^{+}-$lectin $^{+}$-Zellen nach erfolgreicher Tabakentwöhnung zeigten. Es wurde der Hypothese nachgegangen, dass ein verändertes Adhäsionsverhalten der EPC zugrunde liegen könnte. Dazu wurden Versuche zum Adhäsionsverhalten der Zellen durchgeführt und die Expression von Integrinen sowie das Vorliegen von oxidativem Stress analysiert.

Die Untersuchungen wurden an EPC einer heterogenen Probandengruppe, die erfolgreich an einem fünfwöchigen Tabakentwöhnungsprogramm teilnahm, durchgeführt. Dafür wurden die Zellen zunächst aus dem peripheren Blut isoliert und für sieben Tage auf Fibronektin kultiviert.

Diese Arbeit zeigt, dass Tabakentwöhnung mit einem signifikant verminderten Adhäsionsvermögen von kultivierten EPC an Fibronektin und TNF- $\alpha$-stimulierten HUVEC einhergeht. Zudem war die Anzahl inkorporierender EPC in kapillarähnlichen Strukturen reduziert. Des Weiteren führte Tabakentwöhnung zu einer signifikant verminderten Expression von $\beta 1$ - und $\beta 2$-Integrinuntereinheiten auf den EPC, zu erniedrigten Level von intrazellulärem ROS in den EPC sowie zu geringeren ADMA-Spiegeln im Plasma der Probanden. 
Es ist zu betonen, dass in der vorliegenden Arbeit die Zellen eines Individuums vor und nach Tabakentwöhnung miteinander verglichen wurden und nicht die von Rauchern und Nichtrauchern. Offenbar unterscheiden sich die endotheliale Physiologie bzw. die Eigenschaften von EPC von ehemaligen Rauchern und lebenslangen Nichtrauchern. Eine wichtige Rolle könnten dabei die durch Tabakentwöhnung reduzierte low-grade- Entzündung bzw. oxidativer Stress und deren Einfluss auf das Adhäsionsverhalten der EPC spielen.

Diese Arbeit verdeutlicht, dass der Einfluss von Tabakkonsum und Tabakentwöhnung auf das Zusammenspiel zwischen Mobilisierung von EPC aus dem Knochenmark, Adhäsion an Matrixproteinen und Reendothelialisierungsprozessen sehr komplex ist und nicht auf veränderte Zahlen zirkulierender oder adhärierender Zellen reduziert werden kann. Es besteht daher weiterer Forschungsbedarf hinsichtlich eines möglichen Anteils der EPC am positiven Einfluss von Tabakentwöhnung auf kardiovaskuläre Erkrankungen. 


\section{Literaturverzeichnis}

Asahara T, Murohara T, Sullivan A, Silver M, Zee R, Li T, Witzenbichler B, Schatteman $\mathrm{G}$, Isner JM (1997): Isolation of putative progenitor endothelial cells for angiogenesis. Science $\underline{275}, 964-967$

Bartecchi CE, MacKenzie TD, Schrier RW (1994): The Human Costs of Tobacco Use - First of Two Parts. N Engl J Med $\underline{330}$, 907-912

Barua RS, Ambrose JA, Eales-Reynolds L-J, DeVoe MC, Zervas JG, Saha DC (2001): Dysfunctional Endothelial Nitric Oxide Biosynthesis in Healthy Smokers With Impaired Endothelium-Dependent Vasodilatation. Circulation 104, 1905-1910

Barua RS, Ambrose JA, Srivastava S, DeVoe MC, Eales-Reynolds L-J (2003): Reactive Oxygen Species Are Involved in Smoking-Induced Dysfunktion of Nitric Oxide Biosynthesis and Upregulation of Endothelial Nitric Oxide Synthase: An In Vitro Demonstration in Human Coronary Artery Endothelial Cells. Circulation 107, 2342-2347

Bergmann S, Siekmeier R, Mix C, Jaross W (1998): Even moderate cigarette smoking influences the pattern of circulating monocytes and the concentration of sICAM-1. Respir Physiol 114, 269-275

Bollerot K, Pouget C, Jaffredo T (2005): The embryonic origins of hematopoietic stem cells: a tale of hemangioblast and hemogenic endothelium. APMIS $\underline{113}, 790-803$

Böger RH (2003): The emerging role of asymmetric dimethylarginine as a novel cardiovascular risk factor. Cardiovasc Res $\underline{59}, 824-833$

Celermajer DS, Sorensen KE, Georgakopoulos D, Bull C, Thomas O, Robinson J, Deanfield JE (1993): Cigarette smoking is associated with dose-related and potentially reversible impairment of endothelium-dependent dilation in healthy young adults. Circulation $\underline{88}, 2149$ 2155

Chavakis E, Aicher A, Heeschen C, Sasaki K, Kaiser R, El Makhfi N, Urbich C, Peters T, Scharffetter-Kochanek K, Zeiher AM, Chavakis T, Dimmeler S(2005): Role of beta2integrins for homing and neovascularization capacity of endothelial progenitor cells. J Exp Med 201, 63-72

Critchley JA, Capewell S (2003): Mortality Risk Reduction Associated With Smoking Cessation in Patients With Coronary Heart Disease. JAMA 290, 86-97

Deb A, Skelding KA, Wang S, Reeder M, Simper D, Caplice NM (2004): Integrin Profile and In Vivo Homing of Human Smooth Muscle Progenitor Cells. Circulation 110, 2673-2677

Dernbach E, Urbich C, Brandes RP, Hofmann WK, Zeiher AM, Dimmeler S (2004):

Antioxidative stress-associated genes in circulating progenitor cells: evidence for enhanced resistance against oxidative stress. Blood $\underline{104}, 3591-3597$ 
Doll R, Peto R, Boreham J, Sutherland I (2004): Mortality in relation to smoking: 50 years' observations on male British doctors. BMJ $\underline{328}$

Dovgan PS, Edwards JD, Zhan X, Agrawal DK (1994): Cigarette smoke increases monocyte adherence to cultured endothelial cell monolayer. Biochem Biophys Res Commun 203, 929934

Durand C, Dzierzak E (2005): Embryonic beginnings of adult hematopoietic stem cells. Haematologica 90, 100-108

Ezzati M, Lopez AD (2003): Estimates of global mortality attributable to smoking in 2000. Lancet $\underline{362}, 847-852$

Felten D, Raupach T, Sessler C, Lüthje L. Hasenfuß G, Andreas S (2006): Effektivität eines kognitiv-verhaltenstherapeutischen Raucherentwöhnungsprogramms mit pharmakologischer Unterstützung. Dtsch Med Wochenschr 131, 197-202

Flamme I, Risau W (1992): Induction of vasculogenesis and hematopoiesis in vitro. Development $\underline{119}$, 435- 439

Folkman J, Shing Y (1992): Angiogenesis. J Biol Chem 267, 10931-10934

Förstermann U, Münzel T (2006): Endothelial Nitric Oxide Synthase in Vascular Disese: From Marvel to Menace. Circulation $\underline{113}$, 1708-1714

Furchgott RF, Zawadzki JV (1980): The obligatory role of endothelial cells in the relaxation of arterial smooth muscle by acetylcholine. Nature 288, 373-376

Gordon T, Kannel WB, McGee D, Dawber TR (1974): Death and coronary attacks in men after giving up cigarette smoking. A report from the Framingham study. Lancet 1974, 2 , $1345-1348$.

Greisler HP, Dennis JW, Endean ED, Ellinger J, Buttle KF, Kim DU (1988): Derivation of neointima in vascular grafts. Circulation $\underline{78}$, I6-12

Guzik TJ, Korbut R, Adamek-Guzik T (2003): Nitric oxide and superoxide in inflammation and immune regulation. J Physiol Pharmacol 54, 469-487

Hansson GK (2005): Inflammation, Atherosclerosis, and Coronary Artery Disease. N Engl J Med $\underline{352}, 1685-1695$

Heeschen C, Jang JJ, Weis M, Pathak A, Kaji S, Hu RS, Tsao PS, Johnson FL, Cooke JP (2001): Nicotine stimulates angiogenesis and promotes tumor growth and atherosclerosis. Nat Med 7, 833-839

Heeschen C, Lehmann R, Honold J, Assmus B, Aicher A, Walter DH, Martin H, Zeiher AM, Dimmeler S (2004): Profoundly Reduced Neovascularization Capacity of Bone Marrow Mononuclear Cells Derived From Patients With Chronic Ischemic Heart Disease. Circulation $\underline{109}, 1615-1622$ 
Heeschen C, Chang E, Aicher A, Cooke JP (2006): Endothelial Progenitor Cells Participate in Nicotine-Mediated Angiogenesis. J Am Coll Cardiol 4요, 2553-2560

Hill JM, Zalos G, Halcox JPJ, Schenke WH, Waclawiw MA, Quyyumi AA, Finkel T (2003): Circulating Endothelial Progenitor Cells, Vascular Function, and Cardiovascular Risk. N Engl J Med 348, 593-600

Hirschi KK, Ingram DA, Yoder MC (2008): Assessing identity, phenotype, and fate of endothelial progenitor cells. Arterioscler Thromb Vasc Biol 28, 1584-1595

Howard G, Wagenknecht LE, Burke GL, Diez-Roux A, Evans GW, McGovern P, Nieto FJ, Tell GS (1998) Cigarette Smoking and Progression of Atherosclerosis. JAMA $\underline{279}, 119-124$

Hynes RO (2002): Integrins: Bidirectional, Allosteric Signaling Machines. Cell 110, 673-687

Kalra VK, Ying Y, Deemer K, Natarajan R, Nadler JL, Coates TD (1994): Mechanism of cigarette smoke condensate induced adhesion of human monocytes to cultured endothelial cells. J Cell Physiol 160, 154-162

Kinlay S, Ganz P (1997): Role of endothelial dysfunction in coronary artery disease and implications for therapy. Am J Cardiol $\underline{80}, 11-16$

Kondo T, Hayashi M, Takeshita K, Numaguchi Y, Kobayashi K, Iino S, Inden Y, Murohara T (2004): Smoking Cessation Rapidly Increases Circulating Progenitor Cells in Peripheral Blood in Chronic Smokers. Arterioscler Thromb Vasc Biol 24, 1442-1447

Laufs U, Werner N, Link A, Böhm M, Nickening G (2004): Physical Training Increases Endothelial Progenitor Cells, Inhibits Neointima Formation, and Enhances Angiogenesis. Circulation 109, 220-226

Mathers CD, Loncar D (2006): Projections of Global Mortality and Burden of Disease from 2002 to 2030. PLoS Med $\underline{3}, 2011-2030$

McCusker K, Hoidal J (1990): Selective increase of antioxidant enzyme activity in the alveolar macrophages from cigarette smokers and smoke-exposed hamsters. Am Respir Dis $\underline{141}, 678-682$

Michaud SE, Dussault S, Haddad P, Groleau J, Rivard A (2006): Circulating endothelial progenitor cells from healthy smokers exhibit impaired functional activities. Atherosclerosis $\underline{187}, 423-432$

Middleton ET, Morice AH (2000): Breath Carbon Monoxide as an Indication of Smoking Habit. Chest $117,758-763$

Miyazaki H, Matsuoka H, Cooke JP, Usui M, Ueda S, Okuda S, Imaizumi T (1999): Endogenous Nitric Oxide Synthase Inhibitor A Novel Marker of Atherosclerosis. Circulation $\underline{99}, 1141-1146$

Moncada S, Higgs A (1993): The L-Arginine-Nitric Oxide Pathway. N Engl J Med $\underline{329}$, 2002-2012 
Müller-Ehmsen J, Braun D, Schneider T, Pfister R, Worm N, Wielckens K, Scheid C, Frommolt P, Flesch M (2008): Decreased number of circulating progenitor cells in obesity: beneficial effects of weight reduction. Eur Heart J $\underline{29}, 1560-1568$

Mullick AE, McDonald JM, Melkonian G, Talbot P, Pinkerton KE, Rutledge JC (2002): Reactive carbonyls from tobacco smoke increase arterial endothelial layer injury. Am $\mathrm{J}$ Physiol Heart Circ Physiol 283, 591-597

Mügge A (1998): The role of reactive oxygen species in atherosclerosis. Z Kardiol $\underline{87}$, 851864

Ockene IS, Miller NH (1997): Cigarette Smoking, Cardiovascular Disease, and Stroke. Circulation 무, 3243-3247

Palmer RM, Ashton DS, Moncada S (1988): Vascular endothelial cells synthesize nitric oxide from L-arginine. Nature 333, 664-666

Plow EF, Haas TA, Zhang L, Loftus J, Smith JW (2000): Ligand binding to integrins. J Biol Chem $\underline{275}, 21785-21788$

Pryor WA, Stone K (1993): Oxidants in Cigarette Smoke. Radicals, Hydrogen Peroxide, Peroxynitrate and Peroxynitrite. Ann N Y Acad Sci $\underline{686}, 12-27$

Pryor WA, Stone K, Zang L.Y, Bermudez E (1998): Fractionation of Aqueous Cigarette Tar Extracts: Fractions That Contain the Tar Radical Cause DNA Damage. Chem Res Toxicol 11 , 441-448

Puls M, Schroeter MR, Steier J, Stijohann L, Hasenfuss G, Konstantinides S, Schäfer K (2011): Effect of smoking cessation on the number and adhesive properties of early outgrowth endothelial progenitor cells. Int J Cardiol 152, 61-69

Raij L, DeMaster EG, Jaimes EA (2001): Cigarette smoke-induced endothelium dysfunction: role of superoxide anion. J Hypertens $\underline{19}$, 891-897

Raupach T, Schäfer K, Konstantinides S, Andreas S (2006): Secondhand smoke as an acute threat for the cardiovascular system: a change in paradigm. Eur Heart J 27, 386-392

Raupach T, Shahab L, Neubert K, Felten D, Hasenfuß G, Andreas S (2008): Implementing a hospital-based smoking cessation programme: Evidence for a learning effect. Patient Educ Couns $\underline{70}$, 199-204

Rea T, Heckbert S, Kaplan RC, Smith NL, Lemaitre RN, Psyta BM (2002): Smoking Status and Risk for Recurrent Coronary Events after Myocardial Infarction. Ann Intern Med. 137, 494-500

Rehman J, Li J, Parvathaneni L, Karlsson G, Panchal VR, Temm CJ, Mahenthiran J, March KL (2004): Exercise acutely increases circulating endothelial progenitor cells and monocyte/macrophage-derived angiogenic cells. J Am Coll Cardiol 43 , 2314-2318. 
Ross R (1999): Atherosclerosis-an inflammatory disease. N Engl J Med 340, 115-126

Ross R, Glomset J, Harker L (1977): Response to Injury and Atherogenesis. Am J Pathol $\underline{86}$, 675-684

Ruff LK, Volmer T, Nowak D. Meyer A (2000): The economic impact of smoking in Germany. Eur Respir J 16, 385-390

Schatteman GC, Dunnwald M, Jiao C (2007): Biology of Bone Marrow-Derived Endothelial Cell Precursors. Am J Physiol Heart Circ Physiol 292, 1-18

Schmidt-Lucke C, Rössing L, Fichtlscherer S, Vasa M, Britten M, Kämper U, Dimmeler S, Zeiher AM (2005): Reduced Number of Circulating Endothelial Progenitor Cells Predicts Future Cardiovascular Events Proof of Concept for the Clinical Importance of Endogenous Vascular Repair. Circulation 111, 2981-2987

Schroeter MR, Leifheit M, Sudholt P, Heida NM, Dellas C, Rohm I, Alves F, Zientkowska M, Rafail S, Puls M, Hasenfuss G, Konstantinides S, Schäfer K(2008): Leptin enhances the recruitment of endothelial progenitor cells into neointimal lesions after vascular injury by promoting integrin-mediated adhesion. Circ Res $\underline{103}$, 536-544

Scott DA, Stapleton JA, Wilson RF, Sutherland G, Palmer RM, Coward PY, Gustavsson G (2000): Dramatic Decline in Circulating Intercellular Adhesion Molecule-1 Concentration on Quitting Tobacco Smoking. Blood Cells Mol Dis 26, 255-258

Shen Y, Rattan V, Sultana C, Kalra VK (1996): Cigarette smoke condensate-induced adhesion molecule expression and transendothelial migration of monocytes. Am J Physiol $\underline{270}, \mathrm{H} 1624-\mathrm{H} 1633$

Shinton R, Beevers G (1989): Meta-analysis of relation between cigarette smoking and stroke. Br Med J 298, 789-794

Smith CJ, Fischer TH (2001): Particulate and vapor phase constituents of cigarette mainstream smoke and risk of myocardial infarction. Atherosclerosis $\underline{158}, 257-267$

Strehlow K, Werner N, Berweiler J, Link A, Dirnagel U, Priller J, Laufs K, Ghaeni L, Milosevic M, Böhm M, Nickening G (2003): Estrogen Increases Bone Marrow-Derived Endothelial Progenitor Cell Production and Diminishes Neointima Formation. Circulation $\underline{107}, 3059-3065$

Takahashi T, Kalka C, Masuda H, Chen D, Silver M, Kearney M, Magner M, Isner JM, Ashara T (1999): Ischemia- and cytokine-induced mobilization of bone marrow-derived endothelial progenitor cells for neovascularization. Nat Med $\underline{5}, 434-438$

Tepper OM, Galiana RD, Capla JM, Kalka C, Gagne PJ, Jacobowitz GR, Levine JP, Gurtner GC (2002): Human Endothelial Progenitor Cells From Type II Diabetics Exhibit Impaired Proliferation, Adhesion, and Incorporation Into Vascular Structures. Circulation 106, 27812786 
Third Report on the National Cholesterol Education Progam (NCEP): Education Panel on Detection, Evaluation and Treatment of High Blood Cholesterol in Adults (ATPIII). Circulation 106, 536-544

Tousoulis D, Andreou I, Antoniades C, Tentolouris C, Stefanadis C (2008) : Role of inflammation and ocidative stress in endothelial progenitor cell function and mobilization: Therapeutic implications for cardiovascular diseases. Atherosclerosis $\underline{201}, 236-247$

Vallance P, Leone A, Calver A, Collier J, Moncada S (1992): Endogenous dimethylarginine as an inhibitor of nitric oxide synthesis. J Cardiovasc Pharmacol. 20, 60-62

van Berkel TFM, Boersma H, Roos-Hesselink JW, Erdman RAM, Simoons ML (1999): Impact of smoking cessation and smoking interventions in patients with coronary heart disease. Eur Heart J $\underline{20}$, 1773-1782

Vasa M, Fichtlscherer S, Aicher A, Adler K, Urbrich C, Martin H, Zeiher AM, Dimmeler S (2001 a): Number and Migratory Activity of Circulating Endothelial Progenitor Cells Inversely Correlate With Risk Factors for Coronary Artery Disease. Circ Res $\underline{89}$, 1-7

Vasa M, Fichtlscherer S, Adler K, Aicher A, Martin H, Zieher AM, Dimmeler S (2001 b): Increase in Circulating Endothelial Progenitor Cells by Statin Therapy in Patients With Stable Coronary Artery Disease. Circulation 103, 2885-2890

Verma S, Anderson TJ (2002): Fundamentals of endothelial function for the clinical cardiologist. Circulation 105, 546-549

Wald NJ, Idle M, Boreham J, Bailey A (1981): Carbon monoxide in breath in relation to smoking and carboxyhaemoglobin levels. Thorax $\underline{36}, 366-369$

Wang XX, Zhu JH, Chen JZ, Shang YS (2004): Effects of Nicotin on the Number and Activity of Circulating Endothelial Progenitor Cells. J Clin Pharmacol 44, 881-889

Wannamethee SG, Lowe GDO, Shaper AG, Rumley A, Lennon L, Whincup PH (2005): Associations between cigarette smoking, pipe/cigar smoking, and smoking cessation, and haemostatic and inflammatory markers for cardiovascular disease. Eur Heart J 26, 1765-1773

Weber C, Erl W, Weber K, Weber PC (1996): Increased Adheasiveness of Isolated Monocytes to Endothelium Is prevented by Vitamin C Intake in Smokers. Circulation 93 , 1488-1492

Werner N, Kosiol S, Schiegl T, Ahlers P, Walenta K, Link A, Böhm M, Nickening W (2005): Circulationg Endothelial Progenitor Cells and Cardiovascular Outcomes. N Engl J Med 353, 999-1007

West R, Hajek P, Stead L, Stapleton J (2005): Outcome criteria in smoking cessation trials: proposal for a common standard. Addiction $\underline{100}, 299-303$

WHO Report on the Global Tobacco Epidemic, 2008: The MPOWER package. World Health Organisation, Geneva 2008 
Wolf PA, D'Agostino RB, Kannel WB, Bonita R, Belanger AJ (1988):Cigarette smoking as a risk factor for stroke. The Framingham Study. JAMA 259, 1025-1029

Wu MH, Shi Q, Wechezak AR, Clowes AW, Gordon IL, Sauvage LR (1995): Deffinitive proof of endothelialization of a Dacron arterial prosthesis in a human being. J Vasc Surg $\underline{21}, 862-867$

Wu Y, Ip JE, Huang J, Zhang L, Matsushita K, Liew CC, Pratt RE, Dzau VJ (2006) : Essential Role of ICAM-1/CD18 in Mediating EPC Recruitment, Angiogenesis, and Repair to the Infarcted Myocardium. Circ Res $\underline{99}$, 315-322

Yanbaeva DG, Dentener MA, Creutzberg EC, Wesseling G, Wouters EF (2007): Systemic effects of smoking. Chest $\underline{131}, 1557-1566$

Yusuf S, Hawken S, Ounpuu S, Dans T, Avezum A, Lanas F, McQueen M, Budaj A, Pais P, Varigos J, Lisheng L (2004): Effect of Potentially modifiable risk factors associated with myocardial infarction in 52 countries (the INTERHEART study): case-control study. Lancet $\underline{364}, 937-952$

Zhang WZ, Venardos K, Chin-Dusting J, Kaye DM (2006): Adverse Effects of Cigarette Smoke an NO Bioavailability: Role of Arginine Metabolism and Oxidative Stress. Hypertension $\underline{48}$, 278-285

Zhang Y, Ingram DA, Murphy MP, Saadatzadeh MR, Mead LE, Prater DN, Rehman J (2009): Release of proinflammatory mediators and expression of proinflammatory adhesion molecules by endothelial progenitor cells. Am J Physiol Heart Circ Physiol 296, H1675H1682 


\section{Danksagung}

In erster Linie danke ich Frau Prof. Dr. med. Katrin Schäfer und Frau Dr. med. Miriam Puls für die Anregung zu diesem interessanten Thema und die Begleitung der wissenschaftlichexperimentellen Arbeiten. Insbesondere Frau Dr. Puls danke ich für die Bereitstellung und umfassende Einführung in die Methodik sowie die nicht nachlassende Unterstützung in jeglicher Hinsicht über die gesamte Zeit hinweg mit großem persönlichen Einsatz.

Zudem danke ich Frau Dorothea Felten für die Etablierung des Raucherentwöhnungsprogramms an dem Universitätsklinikum Göttingen und die Unterstützung bei der Gewinnung der Probanden.

Auch möchte ich mich ausdrücklich bei Frau Stephanie Minne und Frau Sara Barke bedanken. Sie standen mir als medizinisch-technische Assistentinnen im Labor stets für Fragen und bei der Durchführung der Versuche zur Seite.

Der Abteilung Hämatologie und Onkologie der Universitätsklinik Göttingen danke ich für die Bereitstellung verschiedener technischer Geräte und Ressourcen. 


\section{Lebenslauf}

Ich wurde am 25.02.1983 als Zwilling und drittes Kind in Münster geboren. Meine Eltern sind Dr. med. dent. Anna-Luise Stijohann und Franz-Josef Stijohann.

Ich bin mit Daniel Immer verheiratet und Mutter einer 3-jährigen Tochter; im Dezember 2011 erwarten wir unser zweites Kind.

Nach der Grundschulzeit in Lipperode besuchte ich das Gymnasium Marienschule Lipperbruch, Lippstadt, das ich 2002 mit dem Abitur abschloss. Von August 1999 bis Januar 2000 lebte ich bei einer Gastfamilie in Greenville, SC, USA und besuchte dort die Travelers Rest High School.

Im Oktober 2002 begann ich das Studium der Humanmedizin an der Georg-AugustUniversität Göttingen und konnte dieses im Mai 2010 mit der ärztlichen Prüfung abschließen. Die ärztliche Vorprüfung legte ich im September 2004 ab. Die Forschungsarbeiten für meine Doktorarbeit begannen im Dezember 2005 in der Arbeitsgruppe für Vaskuläre Biologie, Abteilung Kardiologie und Pneumologie, unter der Leitung von Frau Prof. Dr. med. Katrin Schäfer und der Betreuung von Frau Dr. med. Miriam Puls. In der Zeit von Mai 2008 bis Februar 2009 war ich nach der Geburt meiner Tochter in Elternzeit, ehe ich das Praktische Jahr am Klinik und Rehabilitationszentrum Lippoldsberg gGmbH (Innere Medizin) und am St. Vincenz Krankenhaus GmbH Paderborn (Gynäkologie / Geburtshilfe und Chirurgie) absolvierte.

Seit Dezember 2010 arbeite ich als Assistenzärztin am Klinikum Stadt Soest gGmbH in der Gynäkologie und Geburtshilfe, Chefärztin Dr. med. Simone Flachsenberg. 